In cooperation with the San Antonio Water System

\title{
Statistical Analysis of Major lon and Trace Element Geochemistry of Water, 1986-2006, at Seven Wells Transecting the Freshwater/Saline-Water Interface of the Edwards Aquifer, San Antonio, Texas
}

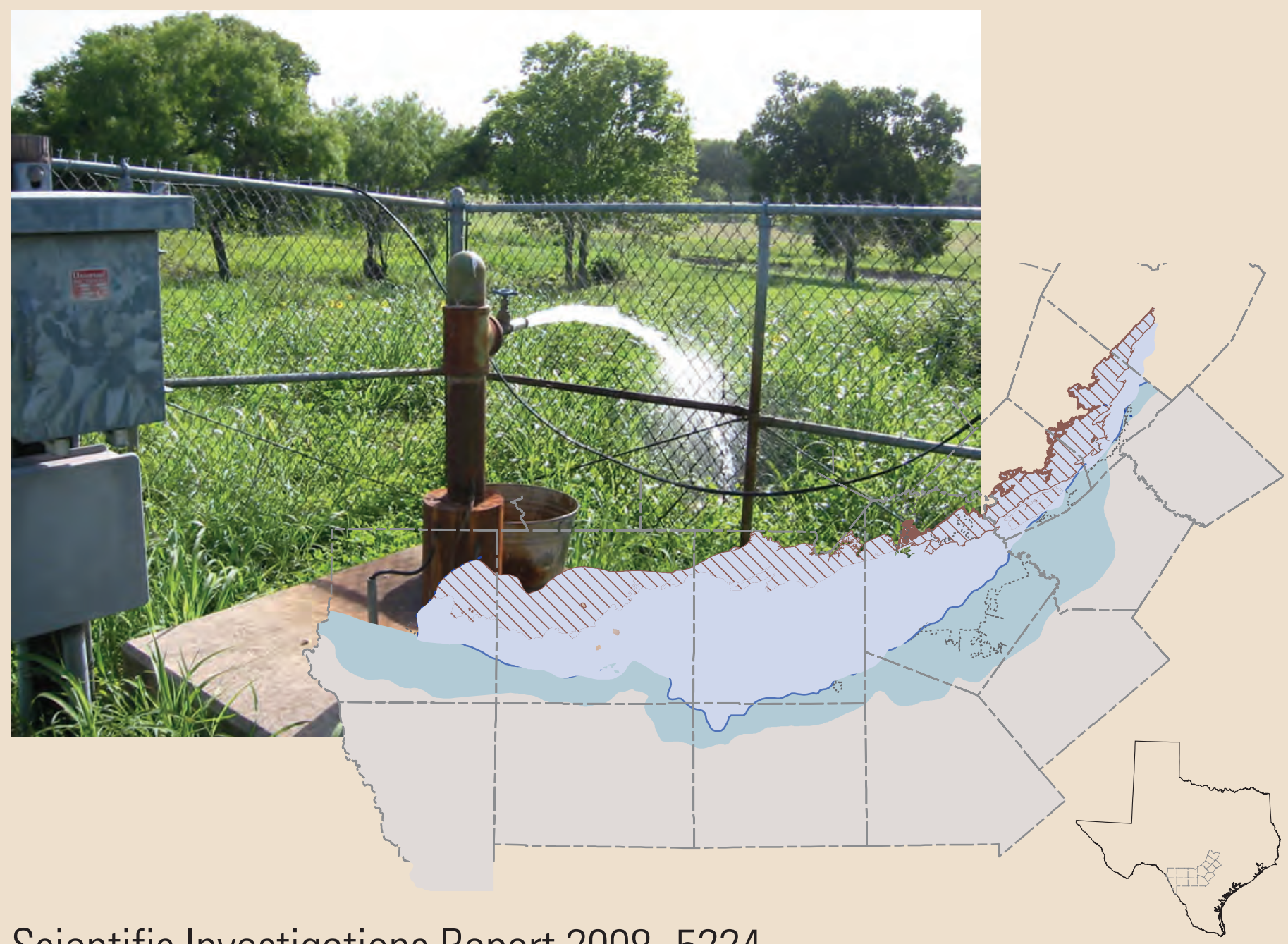

Scientific Investigations Report 2008-5224 
Cover: Monitor well near freshwater/saline-water transition zone in central Bexar County, Texas. Well is being purged prior to sample collection, July 12, 2002. Photograph by R.B. Lambert, U.S. Geological Survey. 


\section{Statistical Analysis of Major Ion and Trace Element Geochemistry of Water, 1986-2006, at Seven Wells Transecting the Freshwater/Saline-Water Interface of the Edwards Aquifer, San Antonio, Texas}

By Barbara J. Mahler

In cooperation with the San Antonio Water System

Scientific Investigations Report 2008-5224 


\section{U.S. Department of the Interior DIRK KEMPTHORNE, Secretary}

\section{U.S. Geological Survey \\ Mark D. Myers, Director}

\section{U.S. Geological Survey, Reston, Virginia: 2008}

For product and ordering information:

World Wide Web: http://www.usgs.gov/pubprod

Telephone: 1-888-ASK-USGS

For more information on the USGS — the Federal source for science about the Earth, its natural and living resources, natural hazards, and the environment:

World Wide Web: http://www.usgs.gov

Telephone: 1-888-ASK-USGS

Any use of trade, product, or firm names is for descriptive purposes only and does not imply endorsement by the U.S. Government.

Although this report is in the public domain, permission must be secured from the individual copyright owners to reproduce any copyrighted materials contained within this report.

Suggested citation:

Mahler, B.J., 2008, Statistical analysis of major ion and trace element geochemistry of water, 1986-2006, at seven wells transecting the freshwater/saline-water interface of the Edwards aquifer, San Antonio, Texas: U.S. Geological Survey Scientific Investigations Report 2008-5224, 46 p. 


\section{Contents}

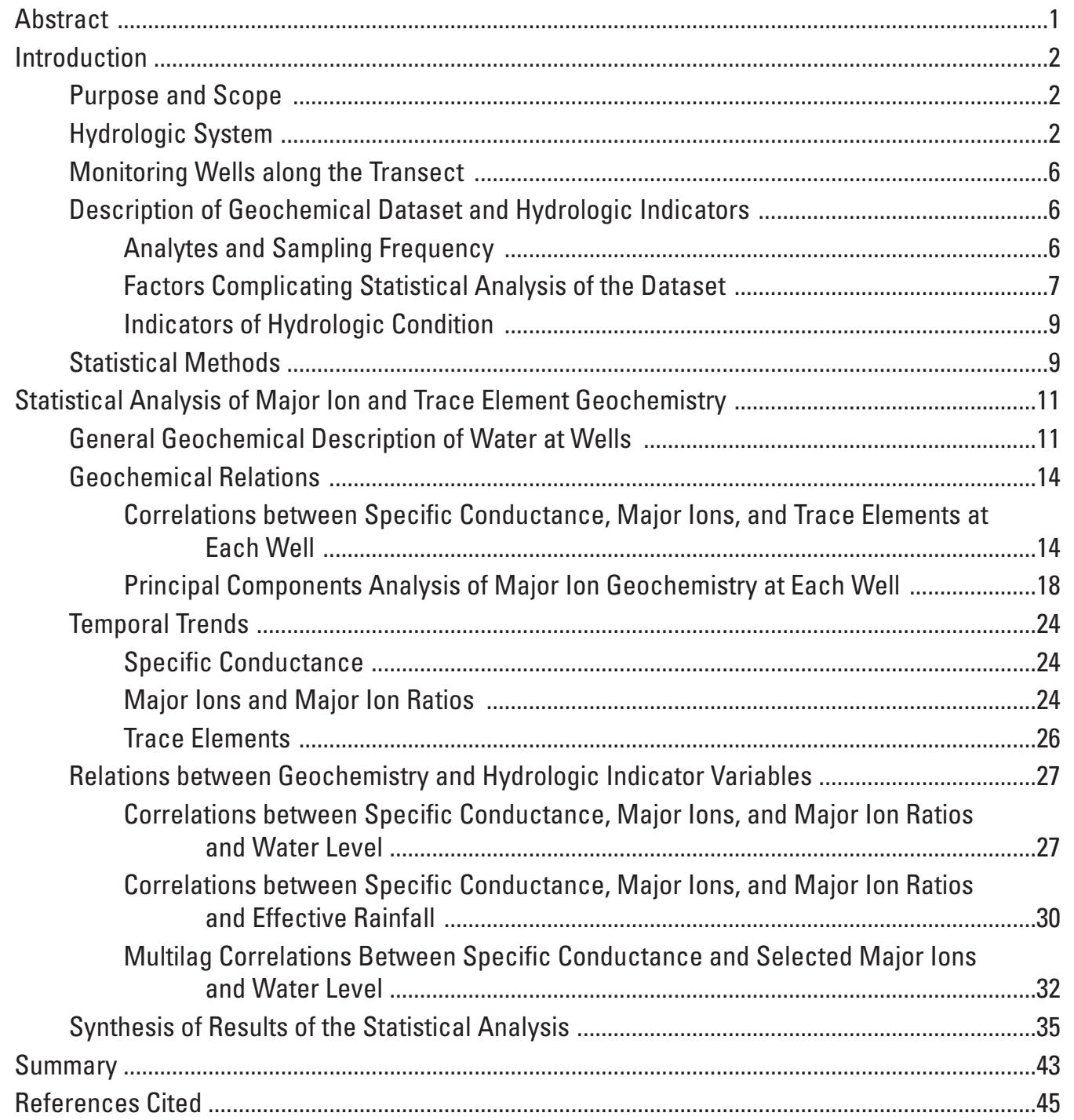

\section{Figures}

1-2. Maps showing:

1. San Antonio segment of the Edwards aquifer and location of seven monitoring wells transecting the freshwater/saline-water interface, San Antonio, Texas 3

2. Location of seven monitoring wells transecting the freshwater/saline-water interface, San Antonio, Texas

3. Hydrogeologic section transecting the freshwater/saline-water interface, San Antonio, Texas 
4-9. Graphs showing:

4. Temporal variability in $(A)$ sulfate concentration at transition-zone well $A 3$ and (B) fluoride concentration at freshwater-zone well D2, San Antonio, Texas, and analytical methods used

5. Examples of $(A)$ non-constant variance demonstrated by residuals for linear regression between sulfate concentration and time, transition-zone well C2, and $(B)$ non-independence of residuals demonstrated by serial correlation of residuals of linear regression between sulfate concentration and time, freshwater-zone well C1, San Antonio, Texas

6. Loadings of geochemical variables on the first two principal components (PC) at (A) transition-zone wells $A 1, A 2, A 3$, and $C 2$, and (B) freshwater-zone wells C1, D1, and D2, San Antonio, Texas

7. Specific conductance datasets, $(A)$ transition zone and (B) freshwater zone, for seven monitoring wells transecting the freshwater/saline-water interface, San Antonio, Texas

8. Daily maximum water level and 1-year moving average of daily maximum water level in the J-17 index well, San Antonio, Texas, 1986-2006, and time intervals (T1-T10) used for piecewise analysis of the relation between geochemical variables at freshwater-zone well $\mathrm{C} 1$ and water level in the $\mathrm{J}-17$ index well

9. Relations between (A) specific conductance and (B) sulfate concentration at freshwater-zone well $\mathrm{C} 1$ and 1 -year moving average of daily maximum water level in the $\mathrm{J}-17$ index well, San Antonio, Texas, for 10 time intervals, March 1986-November 2006

\section{Tables}

1. Monitoring-well completion data for seven wells transecting the freshwater/salinewater interface of the Edwards aquifer, San Antonio, Texas

2. Number of samples collected (1986-2006) from each of seven wells transecting the freshwater/saline-water interface of the Edwards aquifer, San Antonio, Texas, and list of analytes measured

3. Summary of statistical relations investigated, and table containing results from each statistical method, for analysis of data (1986-2006) for seven wells transecting the freshwater/saline-water interface of the Edwards aquifer, San Antonio, Texas .....10

4. Means, standard deviations, and coefficients of variation for specific conductance, major ion concentrations, and major ion molar ratios for water (1986-2006) at seven wells transecting the freshwater/saline-water interface of the Edwards aquifer, San Antonio, Texas

5. Medians, 25th percentiles, and 75th percentiles for trace element concentrations for water (1986-2006) at seven wells transecting the freshwater/saline-water interface of the Edwards aquifer, San Antonio, Texas

6. Correlations between specific conductance and major ion concentrations and between major ion concentrations, as indicated by Pearson's r, for water (19862006) at seven wells transecting the freshwater/saline-water interface of the Edwards aquifer, San Antonio, Texas

7. Correlations between trace element concentrations, as indicated by Kendall's tau, for water (1986-2006) at seven wells transecting the freshwater/saline-water interface of the Edwards aquifer, San Antonio, Texas 
8. Correlations between specific conductance and trace element concentrations and between major ion and trace element concentrations, as indicated by Kendall's tau, for water (1986-2006) at seven wells transecting the freshwater/saline-water interface of the Edwards aquifer, San Antonio, Texas

9. Fraction of variance explained by principal components analysis for water (19862006) at seven wells transecting the freshwater/saline-water interface of the Edwards aquifer, San Antonio, Texas

10. Summary of temporal trends in major ion concentrations and major ion molar ratios for water (1986-2006) at seven wells transecting the freshwater/salinewater interface of the Edwards aquifer, San Antonio, Texas

11. Summary of temporal trends in trace element concentrations for water (19862006) at seven wells transecting the freshwater/saline-water interface of the Edwards aquifer, San Antonio, Texas

12. Correlations, as indicated by Pearson's $r$, between specific conductance, major ion concentrations, and major ion molar ratios in water (1986-2006) and water level in the J-17 index well, Edwards aquifer, San Antonio, Texas

13. Summary of time periods and intervals analyzed for concurrent and multilag correlation between specific conductance and major ion concentrations in water (1986-2006) at well C1 and water level in the J-17 index well, Edwards aquifer, San Antonio area, Texas

14. Correlations, as indicated by Pearson's $r$, between specific conductance and major ion concentrations in water (1986-2006) at well C1, and concurrent and timeaveraged prior water levels in the J-17 index well, Edwards aquifer, San Antonio, Texas

15. Correlations, as indicated by Pearson's $r$, between specific conductance, major ion concentrations, and major ion molar ratios in water (1986-2006) and effective rainfall, Edwards aquifer, San Antonio, Texas

16. Cross-correlation coefficients (multilag model) for selected major ion concentrations and major ion molar ratios in water (1986-2006) and water levels in the J-17 index well for 0 to 15 lags, Edwards aquifer, San Antonio, Texas

\section{Datum}

Horizontal coordinate information is referenced to the North American Datum of 1927 (NAD 27) or the North American Datum of 1983 (NAD 83).

Vertical coordinate information is referenced to the National Geodetic Vertical Datum of 1929 (NGVD 29). 
Blank Page 


\title{
Statistical Analysis of Major Ion and Trace Element Geochemistry of Water, 1986-2006, at Seven Wells Transecting the Freshwater/Saline-Water Interface of the Edwards Aquifer, San Antonio Area, Texas
}

\author{
By Barbara J. Mahler
}

\section{Abstract}

This report by the U.S. Geological Survey, in cooperation with the San Antonio Water System, describes the results of a statistical analysis of major ion and trace element geochemistry of water at seven wells transecting the freshwater/ saline-water interface of the Edwards aquifer in San Antonio, Texas, either over time or in response to variations in hydrologic conditions. The data used in this report were collected during 1986-2006. The seven monitoring wells are screened at different depths in the aquifer at three sites that form a generally north-to-south transect. The three wells of the southern site and the deeper of the two middle-site wells are open to the freshwater/saline-water transition zone, which contains saline water. The shallower well of the middle site and the two wells of the northern site are open to the freshwater zone.

Mean specific conductance (SC) values were greater at transition-zone wells than at freshwater-zone wells, but SC did not vary systematically with depth. Concentrations of all major ions except bicarbonate were greater at transition-zone wells than at freshwater-zone wells, but concentrations tended to be more variable at freshwater-zone wells. Mean molar ratios of magnesium:calcium, sulfate:chloride, and sodium:chloride were similar at transition-zone wells and freshwater-zone wells. Concentrations of trace elements for many water samples at the seven transect wells were below the laboratory analytical reporting level. Detections of trace elements were more frequent at transition-zone wells, and mean concentrations of cadmium, chromium, copper, lead, and silver were elevated at transition-zone wells relative to freshwater-zone wells.

All strong correlations between SC and major ions were positive, and in general there were more and stronger correlations between SC and major ions in the water from the freshwater-zone wells than from the transition-zone wells. Except for the shallowest transition-zone well, the transition-zone wells had relatively few strong correlations overall. The lack of a strong correlation indicates that much of the variability in the major ion concentrations at these wells might be a result of analytical variability caused by the multiple laboratory analytical methods used. In most cases, strong correlations between concentrations of trace elements were positive, and transitionzone wells and freshwater-zone wells had water with a similar number of significant correlations.

Principal components analysis indicates dilution of ground water by low-ionic-strength meteoric water at the three freshwater-zone wells and at the shallowest transition-zone well. At the two deeper transition-zone wells at the southern site, principal components analysis indicates that there is no systematic variation in major ion concentrations. At three transition-zone wells, there was a general trend toward less salinity over the 21-year period of sampling. Trends in SC at the freshwater-zone wells were less consistent. There is no systematic change in the direction of trend in SC by water type (saline or fresh), between sites, or with depth. In general, trends in major ion concentrations corresponded to those in SC. For each trace element over the 21-year sampling period, there was either no trend or a downward trend.

Relations between SC, major ions, and major ion molar ratios and hydrologic indicators (concurrent or prior timeaveraged measures of water level and effective rainfall) were investigated. Correlations between geochemical variables and measures of water level in the freshwater-zone wells were much more frequent than correlations between geochemical variables and measures of water level in the transition-zone wells. There were correlations between SC and all measures of water level at the two freshwater-zone wells at the northern site, but there were no correlations between SC and any measures of water level at any transition-zone wells. SC was correlated with effective rainfall at all freshwater-zone wells and at one transition-zone well.

The statistical analyses taken together indicate that the geochemistry at the freshwater-zone wells is more variable than that at the transition-zone wells. The geochemical variability at the freshwater-zone wells might result from dilution of ground water by meteoric water. This is indicated by relatively constant major ion molar ratios; a preponderance of positive correlations between SC, major ions, and trace elements; 
and a principal components analysis in which the major ions are strongly loaded on the first principal component. Much of the variability at three of the four transition-zone wells might result from the use of different laboratory analytical methods or reporting procedures during the period of sampling. This is reflected by a lack of correlation between SC and major ion concentrations at the transition-zone wells and by a principal components analysis in which the variability is fairly evenly distributed across several principal components. The statistical analyses further indicate that, although the transition-zone wells are less well connected to surficial hydrologic conditions than the freshwater-zone wells, there is some connection but the response time is longer.

\section{Introduction}

The San Antonio segment of the Edwards aquifer (hereinafter, Edwards aquifer) (fig. 1) is the principal source of water in the San Antonio area of Texas. The aquifer dips and becomes more deeply buried with distance toward the Texas Gulf Coast; and downdip at depth, salinity (dissolved solids concentration) in the aquifer increases. The freshwater zone of the aquifer thus is adjacent on the south and east to a freshwater/saline-water transition zone that commonly is defined as the zone in which dissolved solids concentration varies between 1,000 and 10,000 milligrams per liter (mg/L); thus the transition zone contains saline water. Downdip of the transition zone is the saline zone in which dissolved solids concentration is greater than $10,000 \mathrm{mg} / \mathrm{L}$. The interface between the freshwater and transition zones (the freshwater/saline-water interface) is the $1,000-\mathrm{mg} / \mathrm{L}$ dissolved solids concentration threshold. The interface thus is a surface in the aquifer and a line on a map. Historically, the freshwater/saline-water interface has been referred to as the "bad-water line."

Water-resource managers have been concerned that intrusion of saline water into the freshwater zone might occur, particularly when water levels in the aquifer are low (Harden, 1968). The "Edwards aquifer bad-water-line experiment" (William F. Guyton Associates, Inc., 1986) began in the 1980s. As part of this experiment, seven monitoring wells were constructed in 1986 at three sites to form a transect of the freshwater/saline-water interface in Bexar County (fig. 2). The objective for installing the wells was to establish a long-term monitoring system and to develop detailed, site-specific information regarding the geochemistry of water at one location along the downdip limit of freshwater (William F. Guyton Associates, Inc., 1986). The local well numbers and State well numbers for the seven monitoring wells at transect sites $\mathrm{A}, \mathrm{C}$, and D depicted in figure 2 are A2 (AY-68-37-522), A3 (AY-68-37-523), A1 (AY-68-37-521), C2 (AY-68-37-525), C1 (AY-68-37-524), D2 (AY-68-37-527), and D1 (AY-68-37-526). Since 1986, samples have been collected from the seven wells as often as monthly for analysis of major ions and yearly for analysis of trace elements.
To learn what 21 years of geochemical data might indicate about water at the freshwater/saline-water interface, the U.S. Geological Survey (USGS), in cooperation with the San Antonio Water System, did a study involving statistical analysis of the data collected from the seven monitoring wells during 1986-2006. The specific objectives of the study were to

1. Summarize statistically the existing major ion and trace element data and correlations between major ions and trace elements;

2. Identify temporal trends in major ion and trace element geochemistry;

3. Evaluate correlations between major ion and trace element geochemistry and hydrologic conditions, as represented by two hydrologic indicators-water levels in an index well and effective rainfall.

\section{Purpose and Scope}

This report describes the results of a statistical analysis of major ion and trace element geochemistry of water at the seven wells transecting the freshwater/saline-water interface of the Edwards aquifer over time or in response to variations in hydrologic conditions. The data used in this report were collected during 1986-2006 (U.S. Geological Survey, 2007) and analyzed by the U.S. Geological Survey National Water Quality Laboratory using a variety of analytical methods (U.S. Geological Survey, 2008). The seven monitoring wells are screened at different depths in the aquifer at three sites. Standard statistical methods were used to compute descriptive statistics. Principal components analysis was used to gain insight into the relations between the major ions in water at each of the seven wells. Temporal trends were evaluated by linear regression or by the Kendall's tau test. Relations between the aqueous geochemistry at each well and the two hydrologic indicators, water levels in an index well and effective rainfall, were investigated using simple correlation (Pearson's r) and a multilag model.

\section{Hydrologic System}

The Edwards aquifer consists of regionally extensive, faulted and fractured carbonate rocks that crop out within the Edwards Plateau and the Balcones fault zone and underlie the Gulf Coastal Plain (fig. 1). The aquifer (freshwater zone) is bounded to the north by the updip limit of contiguous, outcropping rocks of the Edwards Group and the Georgetown Formation (the rocks that compose the Edwards aquifer), and their stratigraphic equivalents, and to the south and east by the transition zone.

Recharge to the aquifer results from direct infiltration on and streamflow losses in the recharge zone. After entering the aquifer, water moves generally south before being deflected generally northeastward by northeast-trending "barrier" faults 


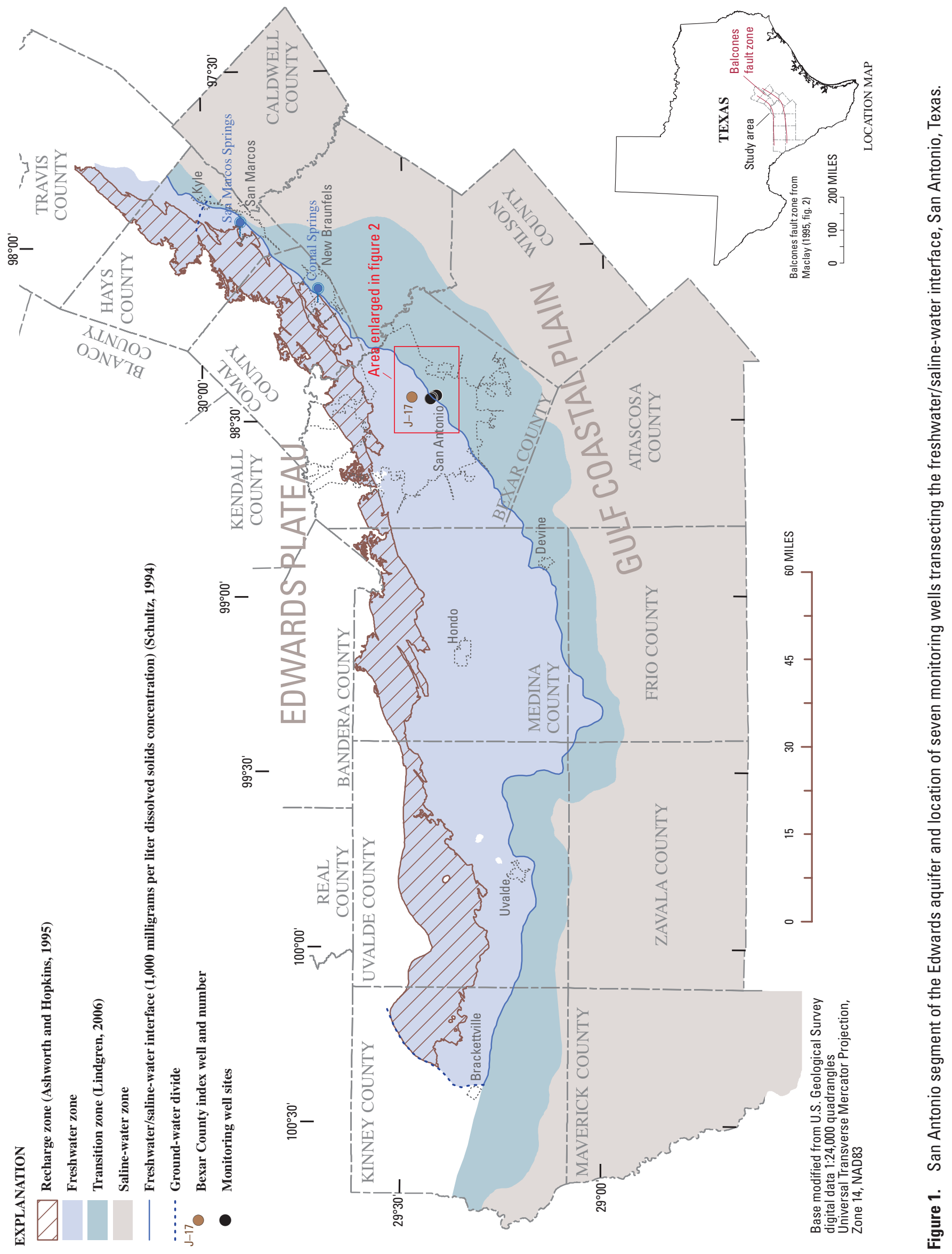




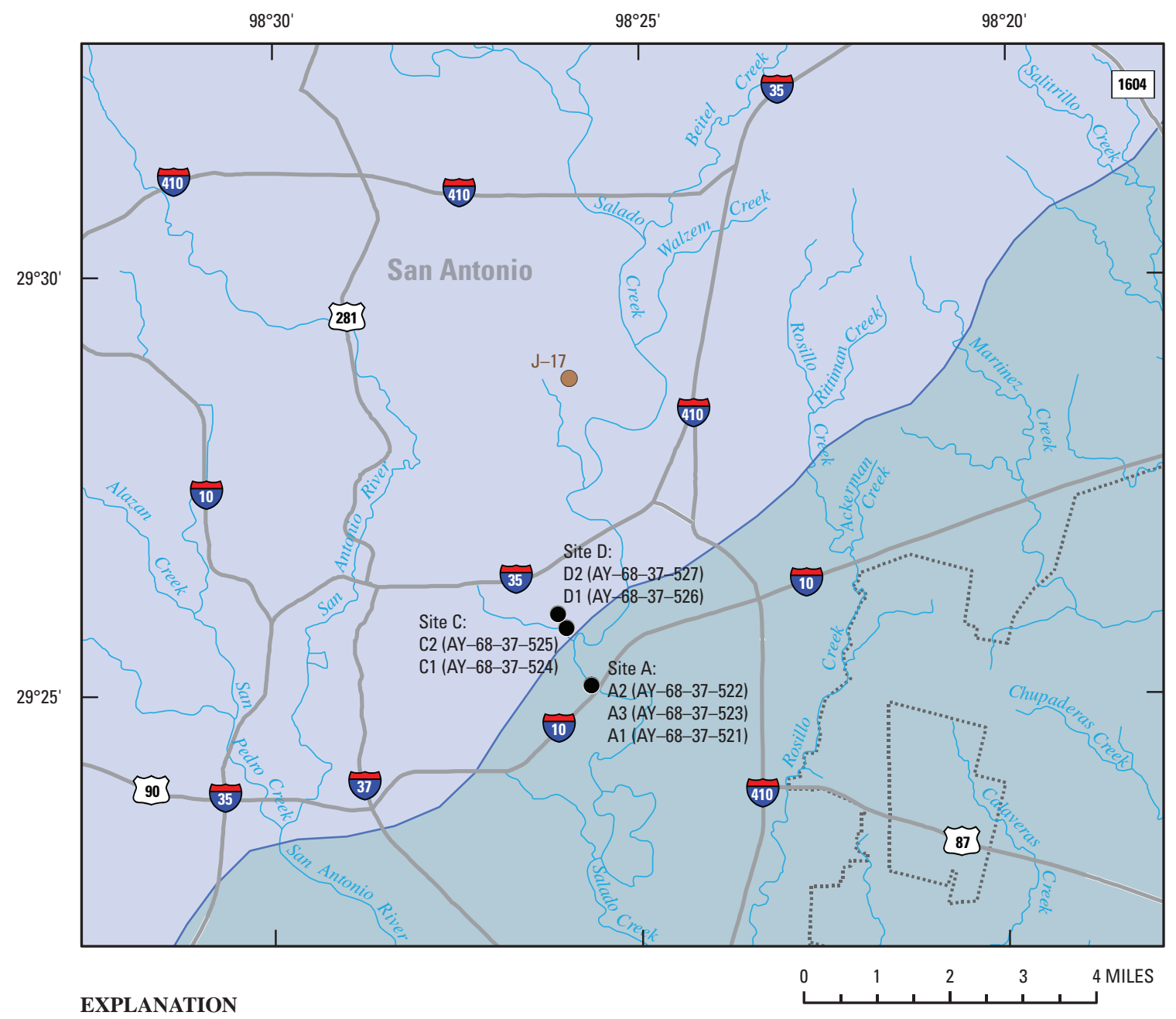

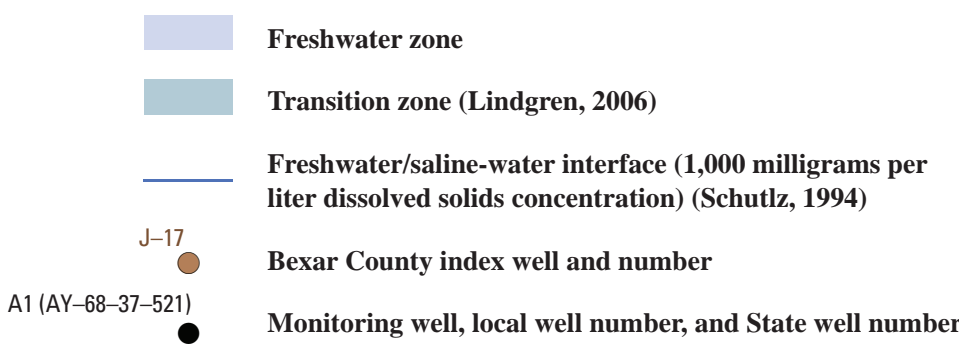

Figure 2. Location of seven monitoring wells transecting the freshwater/saline-water interface, San Antonio, Texas.

that juxtapose down-dropped, less-permeable rocks against the more-permeable rocks of the aquifer. Hydraulic gradients drive freshwater flow near the downdip limit of freshwater northeastward through structurally controlled "flow units" (Maclay and Land, 1988) and parallel to the freshwater/salinewater interface toward major springs, Comal Springs in Comal County and San Marcos Springs in Hays County.

The freshwater/saline-water interface is three-dimensionally complex. The interface is an irregularly shaped surface, roughly concave upward and tilted toward the freshwater zone (fig. 3) (Groschen, 1994). As a result, freshwater overlies saline water along the transect. In some sections of the aquifer the overlying freshwater is separated from the underlying saline water by the regional dense member (RDM), the lowermost member of the Person Formation (fig. 3).

According to Lindgren and others (2004, p. 31) and based on work of Schultz (1992), the freshwater zone and the transition zone are hydraulically connected, but the freshwater zone transmits water at a much greater rate than does the transition zone. The absence of major known saline-water discharge points or areas is evidence that flow in the transition zone is relatively slow. 

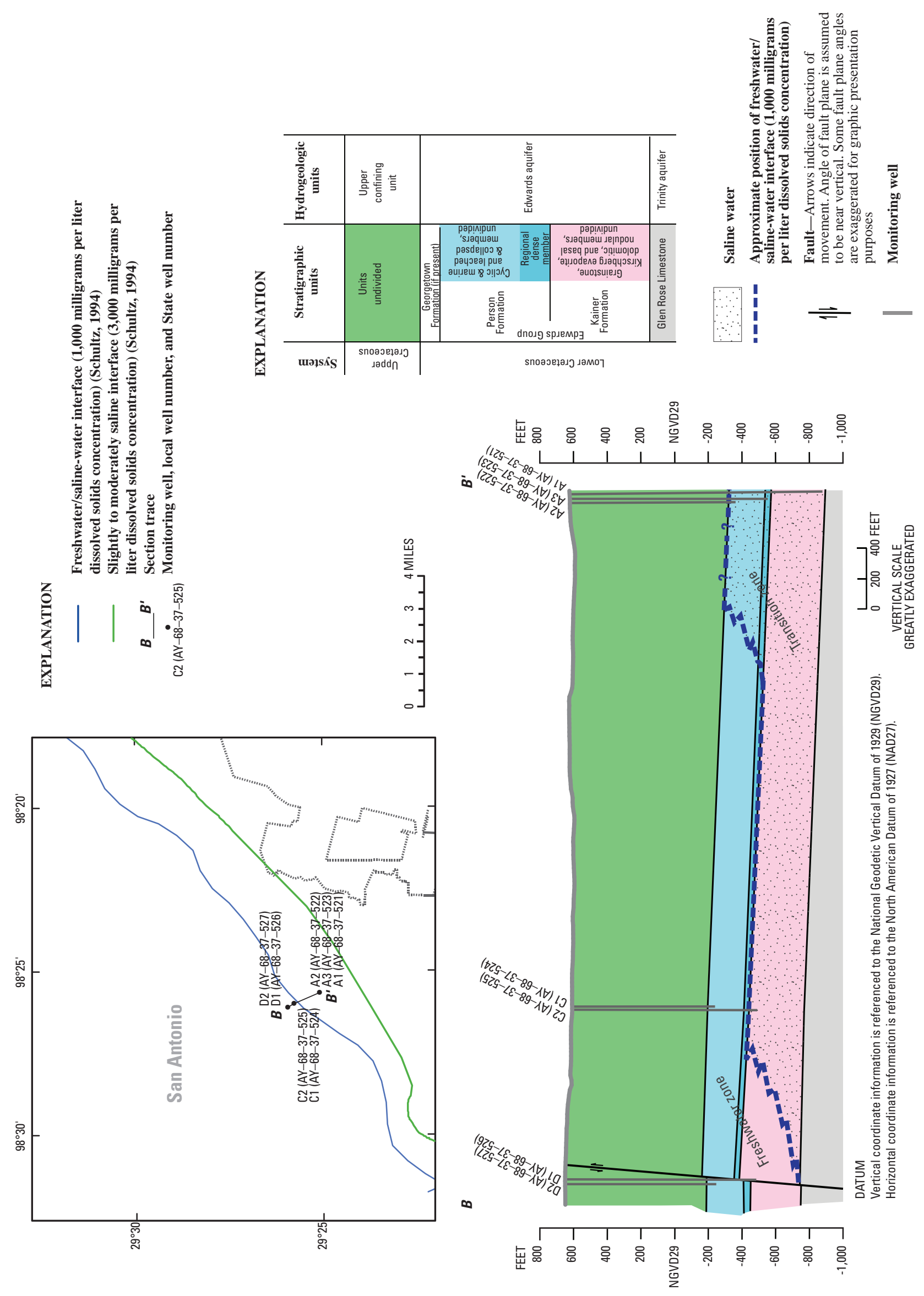


\section{Monitoring Wells along the Transect}

Multiple wells at each of three sites that compose the transect are completed at different depths in the Edwards aquifer (fig. 3). The wells of the southern site (shallowest to deepest, A2, A3, and A1) and the deeper well of the middle site (C2) are open to the transition zone. The shallower well of the middle site $(\mathrm{C} 1)$ and the wells of the northern site (shallowest to deepest, D2 and D1) are open to the freshwater zone. At each site, the deepest well is screened below the RDM (wells A1, C2, and D1), and the other wells, with one exception, are screened above the RDM; well A3 is completed in the RDM.

The drilling and construction of the monitoring wells is described in William F. Guyton Associates, Inc. (1986). In brief, two methods were used to drill each of the holes. The mud-rotary method was used to drill and ream to a depth just above the top of the aquifer, and the wells were cased to this depth. The air-assist reverse circulation method was used to drill the remainder of the hole into the aquifer. The wells were plugged below the depth selected for well completion, and about 50 feet of stainless steel screen was placed above the plug. Pipe was installed from the top of the screen to just below land surface. Gravel pack and cement were used to fill and seal the annulus back to the surface. Monitoring-well completion data are shown in table 1.

Geologic, geophysical, and hydrologic data collected during the drilling of the wells are described and interpreted in Groschen (1994). From that report, well C1 penetrates a cavern about 8 feet in the vertical dimension at a depth of 840 feet, and well D1 is drilled in a fault zone. The shallowest wells usually had the highest hydraulic heads and the deepest wells had the lowest heads. At site A, the differences in head were influenced by increases in salinity with depth. Water levels in all wells fluctuated in response to rainfall and to regional and local pumping.

\section{Description of Geochemical Dataset and Hydrologic Indicators}

\section{Analytes and Sampling Frequency}

Samples for geochemical analysis were collected from the seven wells from March or July 1986 through December 2006, except for a 22-month hiatus in the early 1990s. From March or July 1986 through September 1993 and from August 1995 through September 2001 samples for analysis of major ions were collected monthly, except for well A1 in October 1992; wells A2 and A3 in November 1992; all wells in December 1995; well D1 in January 1998; and wells D1 and D2 in December 1998, October 2000, and November 2000. After September 2001, samples were collected less frequently. Samples for analysis of trace elements were collected annually.

Major ions measured were calcium $(\mathrm{Ca})$, chloride $(\mathrm{Cl})$, fluoride $(\mathrm{F})$, magnesium $(\mathrm{Mg})$, potassium $(\mathrm{K})$, silica $(\mathrm{Si})$, sodium ( $\mathrm{Na}$ ), and sulfate $\left(\mathrm{SO}_{4}\right)$, however, $\mathrm{F}, \mathrm{K}, \mathrm{Si}$, and $\mathrm{Na}$ were measured less frequently than the other major ions until 1989, at which time they were measured with the same frequency. Bicarbonate ion $\left(\mathrm{HCO}_{3}\right)$ was computed from alkalinity, which is predominantly $\mathrm{HCO}_{3}$ at the sites (Groschen, 1994). Trace elements measured were arsenic (As), barium (Ba), cadmium $(\mathrm{Cd})$, chromium $(\mathrm{Cr})$, copper $(\mathrm{Cu})$, iron $(\mathrm{Fe})$, lead $(\mathrm{Pb})$, manganese $(\mathrm{Mn})$, mercury $(\mathrm{Hg})$, selenium $(\mathrm{Se})$, silver ( $\mathrm{Ag})$, and zinc ( $\mathrm{Zn})$. Specific conductance (SC) was measured for each sample. The number of samples analyzed for any major ion at a site was from 148 to 177 , and the number of samples analyzed for any trace element was from 13 to 18 . The number of samples collected from each monitoring well and list of analytes measured is shown in table 2. Samples collected frequently (1- to 3-day intervals) during well

Table 1. Monitoring-well completion data for seven wells transecting the freshwater/saline-water interface of the Edwards aquifer, San Antonio, Texas.

[Well completion data from William F. Guyton Associates, Inc. (1986); USGS, U.S. Geological Survey; NGVD 29, National Geodetic Vertical Datum of 1929]

\begin{tabular}{|c|c|c|c|c|c|c|}
\hline $\begin{array}{l}\text { Local well } \\
\text { name } \\
\text { (fig. 2) }\end{array}$ & State well number & $\begin{array}{c}\text { USGS site } \\
\text { identification } \\
\text { number }\end{array}$ & $\begin{array}{c}\text { Elevation of } \\
\text { land surface } \\
\text { (feet above } \\
\text { NGVD 29) }\end{array}$ & $\begin{array}{c}\text { Total depth } \\
\text { of well } \\
\text { (feet) }\end{array}$ & $\begin{array}{c}\text { Completion } \\
\text { interval } \\
\text { (feet) }\end{array}$ & $\begin{array}{l}\text { Completion } \\
\text { zone }\end{array}$ \\
\hline A1 & AY-68-37-521 & 292505098254001 & 620 & 1,489 & $1,193-1,303$ & Transition \\
\hline A2 & AY-68-37-522 & 292505098254002 & 620 & 1,075 & $1,001-1,075$ & Transition \\
\hline A3 & AY-68-37-523 & 292505098254003 & 620 & 1,175 & $1,087-1,175$ & Transition \\
\hline $\mathrm{C} 2$ & AY-68-37-525 & 292546098260002 & 624 & 1,150 & $1,068-1,150$ & Transition \\
\hline D1 & AY-68-37-526 & 292556098260701 & 642 & 1,384 & $1,150-1,223$ & Freshwater \\
\hline D2 & AY-68-37-527 & 292556098260702 & 641 & 926 & $874-926$ & Freshwater \\
\hline
\end{tabular}


Table 2. Number of samples collected (1986-2006) from each of seven wells transecting the freshwater/saline-water interface of the Edwards aquifer, San Antonio, Texas, and list of analytes measured.

\begin{tabular}{ccccccccccc}
\hline \multirow{2}{*}{$\begin{array}{c}\text { Well } \\
\text { (fig. 2) }\end{array}$} & $\begin{array}{c}\text { Specific } \\
\text { conductance }\end{array}$ & \multicolumn{7}{c}{ Major ions } \\
\cline { 3 - 11 } & Bicarbonate & Calcium & Chloride & Fluoride & Magnesium & Potassium & Silica & Sodium & Sulfate \\
\hline A1 & 177 & 176 & 177 & 177 & 153 & 177 & 153 & 153 & 153 & 177 \\
A2 & 171 & 172 & 173 & 171 & 148 & 173 & 150 & 148 & 149 & 172 \\
A3 & 174 & 174 & 175 & 174 & 150 & 175 & 151 & 151 & 151 & 175 \\
C1 & 175 & 174 & 174 & 176 & 150 & 174 & 150 & 152 & 150 & 176 \\
C2 & 176 & 175 & 177 & 175 & 153 & 177 & 152 & 152 & 153 & 177 \\
D1 & 171 & 171 & 171 & 171 & 171 & 171 & 171 & 171 & 171 & 171 \\
D2 & 169 & 170 & 170 & 170 & 148 & 170 & 149 & 148 & 148 & 170
\end{tabular}

\begin{tabular}{|c|c|c|c|c|c|c|c|c|c|c|c|c|}
\hline \multirow{2}{*}{$\begin{array}{c}\text { Well } \\
\text { (fig. 2) }\end{array}$} & \multicolumn{12}{|c|}{ Trace elements } \\
\hline & Arsenic & Barium & Cadmium & Chromium & Copper & Iron & Lead & Manganese & Mercury & Selenium & Silver & Zinc \\
\hline $\mathrm{A} 1$ & 17 & 18 & 18 & 18 & 18 & 18 & 18 & 18 & 13 & 17 & 17 & 18 \\
\hline A2 & 17 & 18 & 18 & 18 & 18 & 18 & 18 & 18 & 14 & 17 & 17 & 18 \\
\hline A3 & 17 & 18 & 18 & 18 & 18 & 18 & 18 & 18 & 13 & 17 & 17 & 18 \\
\hline $\mathrm{C} 1$ & 17 & 18 & 18 & 18 & 18 & 18 & 18 & 18 & 14 & 17 & 18 & 18 \\
\hline $\mathrm{C} 2$ & 17 & 18 & 18 & 18 & 18 & 18 & 18 & 18 & 14 & 17 & 17 & 18 \\
\hline D1 & 17 & 18 & 18 & 18 & 18 & 18 & 18 & 18 & 14 & 17 & 18 & 18 \\
\hline D2 & 16 & 17 & 17 & 17 & 17 & 17 & 17 & 17 & 13 & 16 & 17 & 17 \\
\hline
\end{tabular}

development (wells A1, C1, and D1) were not used for the statistical analyses in this report.

\section{Factors Complicating Statistical Analysis of the Dataset}

Changes in analytical reporting (for example, laboratory precision and reporting level) and methods over the course of the 21-year sampling period have resulted in some artifacts in the dataset. For example, three different methods were used to analyze F (fig. 4). In well D2, analytical results for one of the methods (IC021; U.S. Geological Survey, 2008) are much more variable than for the method most frequently used (ISE05; U.S. Geological Survey, 2008) (standard deviation of 0.10 and 0.05 , respectively). Further, the variability of the ISE05 method is much less from 1986 through 1990 (standard deviation of 0.01) than from 1995 through 2006 (standard deviation of 0.05 ), probably as a result of a change in precision (number of decimal places reported). This greatly complicates evaluation of trends: for example, it is difficult to determine whether the increase in mean from 0.30 (1986-90) to 0.35
(1995-2006) is meaningful. Also, the analytical methods used for samples collected on any given date were not always consistent between wells. Therefore, except where noted, results for a given well were evaluated statistically without regard to the analytical method used.

A second complicating factor in the analysis of the dataset for this report is the hiatus in sampling during October 1993-July 1995, resulting in 22 contiguous months with no data. In some cases the resumption of sampling coincided with a change in analytical method. In others, resumption coincided with a change in variability or trend. For this report, results from samples collected before and after the break in sampling are considered separately in some cases, as noted.

A charge balance within \pm 5 percent commonly is used as an indicator that analytical measurements were of high quality. Charge balances exceeding the \pm 5 -percent range might indicate unresolved problems with some of the analyses. Groschen (1994) reported that for data collected from the transitionzone (saline-water) wells (A1, A2, A3, and C2) during July 1986-April 1987, major anion equivalents of the analytical data usually were greater than the major cation equivalents. A charge balance was computed for those data in the dataset 
A. Sulfate (transition-zone well A3)

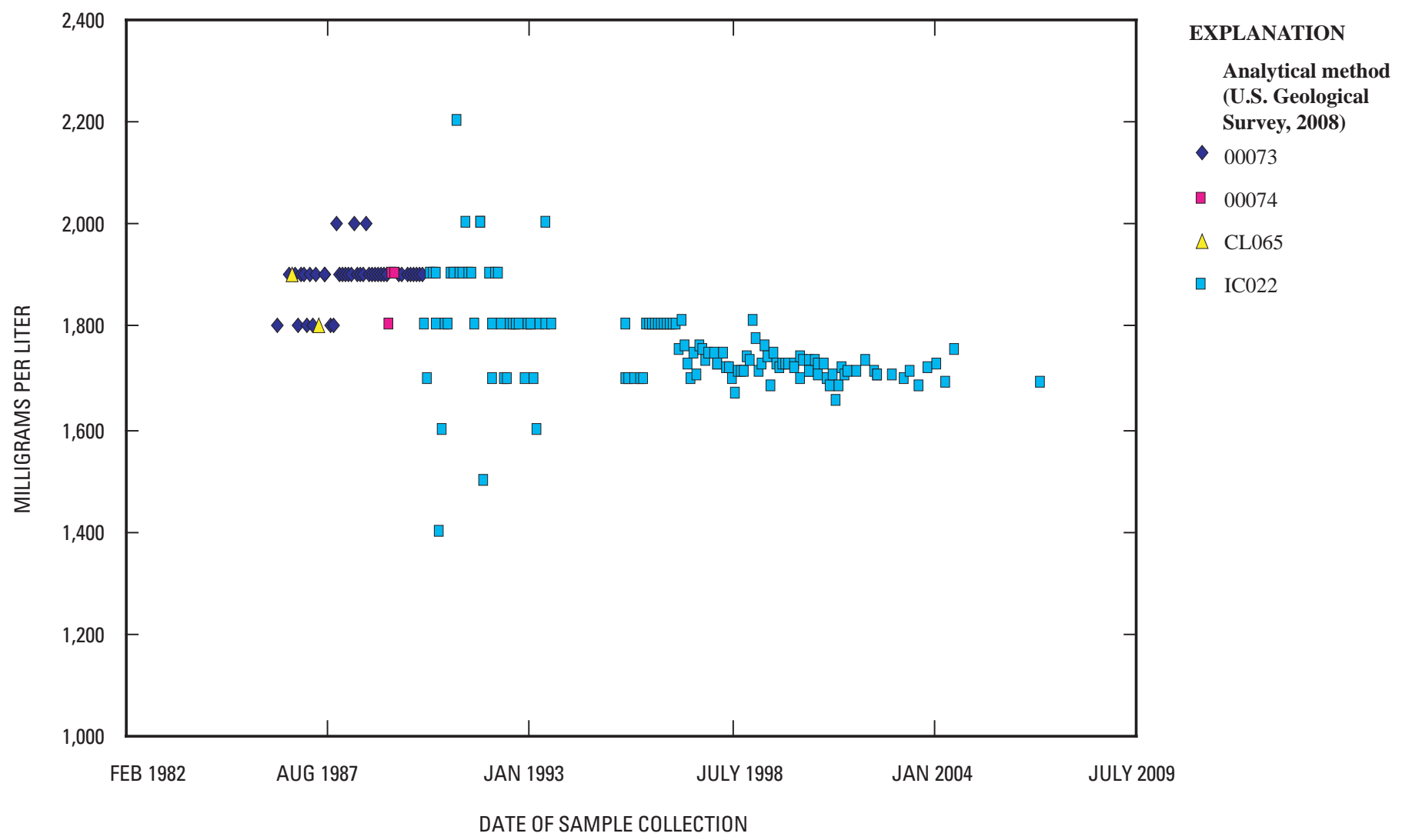

B. Fluoride (freshwater-zonewell D2)

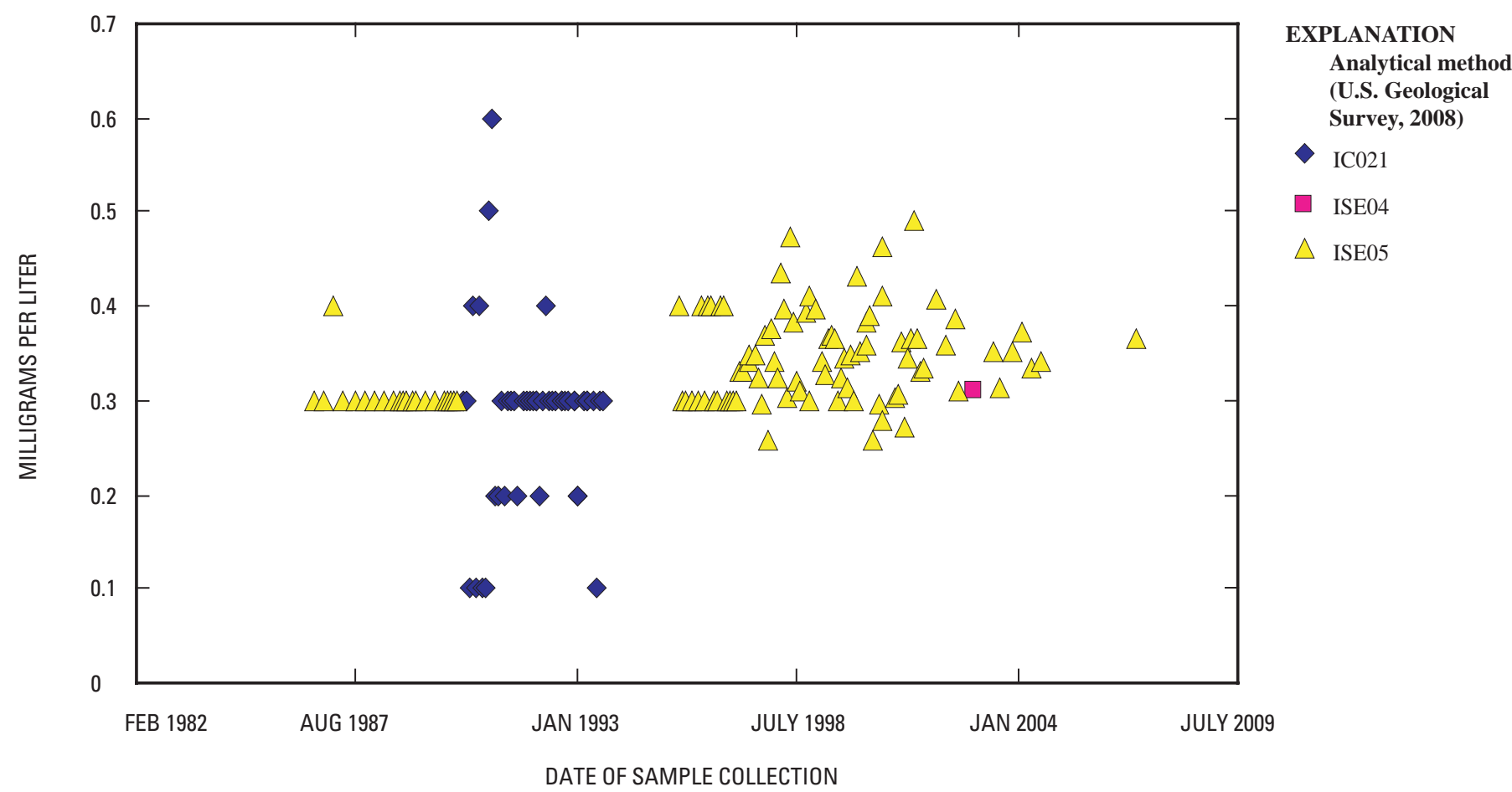

Figure 4. Temporal variability in (A) sulfate concentration at transition-zone well $A 3$ and (B) fluoride concentration at freshwater-zone well D2, San Antonio, Texas, and analytical methods used. 
presented here for which all major ions and Fe were analyzed (1,039 samples). The charge balance indicates that throughout the period of sampling and for all wells, the sum of anion equivalents exceeded those of cation equivalents, with a mean difference of 2.0 percent. If Fe was included in the charge balance, and a charge balance for just those samples with Fe data was computed (118 samples), the mean difference decreased to 1.5 percent. Nevertheless, charge balances were within \pm 5 percent for 92 percent of the samples, and all data were used in the statistical analyses presented in this report.

\section{Indicators of Hydrologic Condition}

One of the principal objectives of this report is to investigate relations between variations in aqueous geochemistry in the transition-zone wells and variations in hydrologic conditions. For that purpose, two sets of time-series data are used here as indicators of hydrologic condition: water level and effective rainfall.

Water-level data used are for the J-17 index well, which is near the transect (figs. 1, 2). Water level in the J-17 well has been recorded since 1956. The Edwards Aquifer Authority uses the highest level recorded for each day as its official reading and for enforcing limits on ground-water withdrawals during periods of high water demand or drought, or both. Accordingly, the highest level recorded for each day was used in this report. J-17 water-level data for 1986-2002 were obtained from Miller and Long (2006) and for 2002-06 from U.S. Geological Survey (2007).

Daily effective rainfall $\left(\mathrm{P}_{\text {eff }}\right)$ data for the flow unit presumed to be one to which the J-17 well is open (Maclay and Land, 1988) were obtained from Miller and Long (2006). The term "effective rainfall" refers to the amount of total rainfall that recharges an aquifer by direct infiltration. Miller and Long (2006) used an antecedent-rainfall and transfer-function model to determine the $\mathrm{P}_{\text {eff }}$ recharging the aquifer and subsequently moving in three different flow units.

Although water level in the aquifer and $\mathrm{P}_{\text {eff }}$ are related, the relation is nonlinear and relatively complex. Miller and Long (2006) used $\mathrm{P}_{\text {eff }}$ to simulate water level in several wells in the Edwards aquifer, including the J-17 index well. Simulating water level in the $\mathrm{J}-17$ well required three separate transfer-function models that reflect three different components of flow in the aquifer: conduit flow, diffuse flow, and delayed flow.

\section{Statistical Methods}

Parametric and nonparametric statistical methods were used to analyze the geochemical data. Nonparametric methods commonly are used when the dataset is non-normally distributed or contains censored data (nondetections), or both. Nondetections are ranked equally and lower than all detections. Normality of data for SC and major ion concentrations at each site was evaluated as three datasets: data collected during period 1 (March or July 1986 through September 1993), data collected during period 2 (January 1996 through December 2006), and all data combined (period T, March or July 1986 through December 2006). Each dataset was graphed as a normal-probability plot and evaluated visually for gross deviations from linearity. A standard test for normality, such as the Kolmogorov-Smirnov test, was not used because for large datasets, one or two outliers can have a large effect on the test statistic and might result in a rejection of the null hypothesis for a dataset that is otherwise normally distributed; such tests are discouraged when testing hydrologic frequency distributions (Haan, 1977).

A variety of statistical methods were used in this report (table 3). Standard statistical methods were used to compute descriptive statistics, including means, standard deviations, medians, and percentiles. Parametric and nonparametric correlative tests were used for more complex relations. For all correlative tests, the criterion used for statistical significance was a p-value less than .05 ( $\mathrm{p}<.05)$.

The strength of correlation between major ions and between SC and major ions was measured using Pearson's r (linear correlation), which ranges from -1 to +1 and reflects the degree of the linear relation between two variables (Helsel and Hirsch, 2002). Use of Pearson's $r$ is recommended for relations for which there is no curvature, few outliers, constant variance, and independence of residuals. These conditions were evaluated by inspecting graphs of all relations between major ions and between SC and major ions at each well. There was no curvature, nonconstant variance, or dependence of residuals observed for any relation. In the few cases that an outlier might skew the correlation, the outlier was removed for analysis of Pearson's $r$. The maximum number of outliers for any major ion that was removed was three, and in most cases zero or one outlier was removed.

The strength of correlations between trace elements, the concentrations of which included many nondetections, and between trace elements and major ions was assessed using the Kendall's tau test. The Kendall's tau test can be used with datasets containing censored data and is resistant to skewness and outliers (Helsel and Hirsch, 2002). The test measures the degree of correspondence between the rankings of two sets of data. If the agreement between rankings of the two sets is perfect, the Kendall's tau coefficient equals 1, and if the disagreement is perfect, tau equals - 1 . If the rankings are independent, tau equals 0 . The closer the absolute value of tau is to 1 , the greater the degree of correspondence, either positive or negative. Tau values generally are smaller than Pearson's $r$ for linear correlations of the same strength: for example, a Pearson's $r$ of .9 or greater corresponds to a tau of about .7 or greater (Helsel and Hirsch, 2002). The only assumption that must be met for Kendall's tau test is that the relation is monotonic (Helsel and Hirsch, 2002). Those datasets for which the Kendall's tau test was used to investigate correlations between concentrations were examined visually for this criterion; no non-monotonic relations were observed. 
Table 3. Summary of statistical relations investigated, and table containing results from each statistical method, for analysis of data (1986-2006) for seven wells transecting the freshwater/saline-water interface of the Edwards aquifer, San Antonio, Texas.

[SC, specific conductance; --, not applicable]

Statistical relation investigated Statistical method $\quad$ Statistical coefficient

Linear correlation

Relations between SC and major ion concentrations and

between major ion concentrations

Relations between trace element concentrations

Kendall's tau

Pearson's $r$

tau

7

\begin{tabular}{|c|c|c|c|}
\hline $\begin{array}{l}\text { Relations between SC and trace element concentrations and } \\
\text { between major ion and trace element concentrations }\end{array}$ & Kendall's tau & tau & 8 \\
\hline Interdependence of SC and major ions & $\begin{array}{l}\text { Principal components } \\
\text { analysis }\end{array}$ & -- & 9 \\
\hline \multirow{2}{*}{$\begin{array}{l}\text { Temporal trends in SC, major ion concentrations, and major } \\
\text { ion ratios }\end{array}$} & Linear regression & Coefficient of determination & 10 \\
\hline & Kendall's tau & tau & 10 \\
\hline Temporal trends in trace element concentrations & Kendall's tau & tau & 11 \\
\hline $\begin{array}{l}\text { Relations between SC, major ion concentrations, and major } \\
\text { ion ratios and water level }\end{array}$ & Linear correlation & Pearson's $r$ & 12,14 \\
\hline $\begin{array}{l}\text { Relations between SC, major ion concentrations, and major } \\
\text { ion ratios and effective rainfall }\end{array}$ & Linear correlation & Pearson's $r$ & 15 \\
\hline $\begin{array}{l}\text { Relations between SC, major ion concentrations, and major } \\
\text { ion ratios and water level with a time lag }\end{array}$ & Cross correlation & Cross-correlation coefficient & 16 \\
\hline
\end{tabular}

Principal components analysis (PCA) was used to gain insight into the relations between the major ions in water at each of the seven wells. PCA is a statistical technique that is used to reduce the number of variables and to detect structure in relations between variables. In PCA, a linear transformation is done that results in a new coordinate system for the dataset such that the greatest variance by any projection of the dataset lies along the first axis or principal component (PC), the second greatest variance along the second axis or PC, and so on (Davis, 1986). The PCs thus are new variables that are linear combinations of the original variables and are linearly independent. The strength of a variable in the linear combination defining the PC is called the loading. If two variables are both heavily and positively loaded or heavily and negatively loaded on a PC, they are strongly positively correlated in that PC space; a variable that is heavily and positively loaded on a PC and a variable that is heavily and negatively loaded on a PC are strongly negatively correlated in that PC space. The sign of the loading has no intrinsic meaning. Each case (here, a sample) also can be graphed in the PC space and its position interpreted in the context of the variable loadings. The utility of PCA for interpreting geochemical data is that a large number of variables often can be reduced to two or three while still explaining most of the variability in the data. For this report, the PCA for data from each well was run independently of the other wells. Data for each major ion for each well was standardized by subtracting the mean and dividing by the standard deviation before entering it into the PCA. SC was entered into the analysis as a supplemental variable, meaning that it does not affect the results, but its loadings on the PCs are determined. The analysis was based on correlation, and variances were computed as SS/(N-1), where SS is the sum of squares of differences between each data point and the mean of the samples, and $\mathrm{N}$ is the number of data points. Samples with missing data were deleted from the analysis.

Temporal trends in SC, major ion concentrations and ratios, and trace element concentrations were determined either by linear regression, if the dataset was normally distributed, or by the Kendall's tau test, if the dataset was not normally distributed or contained censored data. The Kendall's tau test was used for the trace element datasets because of the large number of nondetections. In linear regression, the strength of a relation between a dependent and independent variable is expressed by the coefficient of determination $r^{2}$, which is the square of Pearson's r, ranges from 0 to +1 , and reflects the fraction of the variance explained by the regression. The same conditions required for correlation hold for linear regression. Therefore the relation between time (sampling 
date) and concentration or ratio was evaluated for the presence of curvature, outliers, constant variance, and independence of residuals. Strategies for resolution of these problems include use of a piecewise linear fit, data transformation, or sampling from the dataset. In numerous instances within the major ion dataset, the variance over time was not constant between period 1 and period 2; this was most often true for $\mathrm{Cl}, \mathrm{F}$, and $\mathrm{SO}_{4}$ ( example shown in fig. 5A). Nonconstant variance was resolved by analyzing temporal trends for period 1 and period 2 separately for all major ions; for those major ions that had constant variance throughout the entire sampling period, temporal trends also were evaluated for period T. For data from all wells except $\mathrm{C} 1$, residuals were independent.

SC and major ion data for well C1 vary cyclically, resulting in strong autocorrelation of the data and serial correlation of the residuals (example shown in fig. 5B). For this reason, linear regression cannot be used on the raw data to investigate long-term temporal trends. Further, the Kendall's tau test cannot be used because the relations with time are not monotonic. To resolve this problem, grouping of data by time periods was used (Helsel and Hirsch, 2002). The data were grouped into periods of 1 year, the mean computed for each year, and those summary statistics used in a linear regression with time. This resulted in 8 data points for period 1 and 10 for period 2 .

Those datasets for which the Kendall's tau test was used were examined visually to determine if there were any nonmonotonic temporal relations; no non-monotonic relations were observed.

Relations between the aqueous geochemistry at each well and two hydrologic indicator variables (water level in the index well and rainfall) were investigated using linear correlation (Pearson's r). Plots of all relations were inspected to evaluate conditions of curvature, outliers, variance, and independence of residuals. Between water level and SC, water level and major ions, and water level and major ion molar ratios, the assumptions required for the application of linear correlation were met for data from all wells except $\mathrm{C} 1$ and $\mathrm{C} 2$. At well $\mathrm{C} 1$, the residuals from the relations between water level and SC and water level and major ions were serially correlated (residuals from the relations between water level and major ion ratios were not); this problem was resolved by use of a piecewise linear analysis (that is, dividing the relation into subsets that were not serially correlated). At well C2, the relations between water level and SC and between water level and $\mathrm{Ca}$ had residuals that trended upward with time. This trend resulted from an upward temporal trend in $\mathrm{SC}$ and $\mathrm{Ca}$. To resolve this problem, the temporal trend in $\mathrm{SC}$ and $\mathrm{Ca}$ was removed using linear regression and the residuals tested for correlation with water level. For the relations between SC and $\mathrm{P}_{\text {eff }}$ and major ions and $\mathrm{P}_{\text {eff }}$, there was no curvature, few outliers, constant variance, and independent residuals at all of the wells; the relations therefore were suitable for analysis with linear correlation.

Potential relations that might exist between aqueous geochemistry at the wells and water level at the J-17 index well but which might be lagged in time were investigated using a multilag linear model (Haan, 1977). The multilag model (cross-correlation) allows investigation of the linear relation between two variables for which the response of one variable to the other is lagged in time; for example, rainfall might result in an increase in water level, but the peak response of water level to rainfall might lag by days or weeks. The strength of the correlation between the two datasets for each lag interval is expressed by the cross-correlation coefficient, analogous to Pearson's r. One requirement for a multilag model is that the data are collected at a consistent frequency (for example, hourly, weekly, monthly). For this reason, the data used in the multilag model were for those periods when samples were collected every month with only a few exceptions: March or July 1986 through September 1993 and August 1995 through September 2001. For the few months during these two periods when a sample was not collected, the data point was estimated by linear interpolation.

\section{Statistical Analysis of Major lon and Trace Element Geochemistry}

\section{General Geochemical Description of Water at Wells}

Mean, standard deviation, and coefficient of variation (a measure of variability, computed as the ratio of the standard deviation to the mean) for SC and major ions were computed for each of the seven wells (table 4). The transition-zone wells (A1, A2, A3, C2) have water with a mean SC of about 4,060 (A2) to 6,220 (C2) microsiemens per centimeter at 25 degrees Celsius $(\mu \mathrm{S} / \mathrm{cm})$. The freshwater-zone (freshwater) wells (C1, D1, D2) have water with a mean SC of 515 (D2) to 871 (C1) $\mu \mathrm{S} / \mathrm{cm}$. For a given set of wells at a single site, SC does not increase systematically with depth; and variability in $\mathrm{SC}$, as measured by the coefficient of variation, varies systematically neither with depth at a given location nor laterally across the transect. However, for some major ions with the highest concentrations, those concentrations varied less in the transition-zone wells than in the freshwater-zone wells. For example, concentrations of $\mathrm{SO}_{4}$ were less variable in water from the four transition-zone wells than in water from the three freshwater-zone wells, and concentrations of $\mathrm{Mg}, \mathrm{Cl}$, and $\mathrm{Na}$ were less variable in the transition-zone wells than freshwater-zone wells C1 and D1. Water from the transitionzone wells is elevated for all major ions except $\mathrm{HCO}_{3}$ relative to water from the freshwater-zone wells. Mean molar ratios of $\mathrm{Mg}: \mathrm{Ca}, \mathrm{SO}_{4}: \mathrm{Cl}$, and $\mathrm{Na}: \mathrm{Cl}$ were similar at the transition-zone wells and freshwater-zone wells, but $\mathrm{Mg}: \mathrm{Na}$ was elevated at the freshwater-zone wells relative to the transition-zone wells.

Concentrations of trace elements for many water samples from the seven wells were less than the laboratory reporting level. For that reason, median, 25th, and 75th percentiles were 
A. Transition-zone well C2

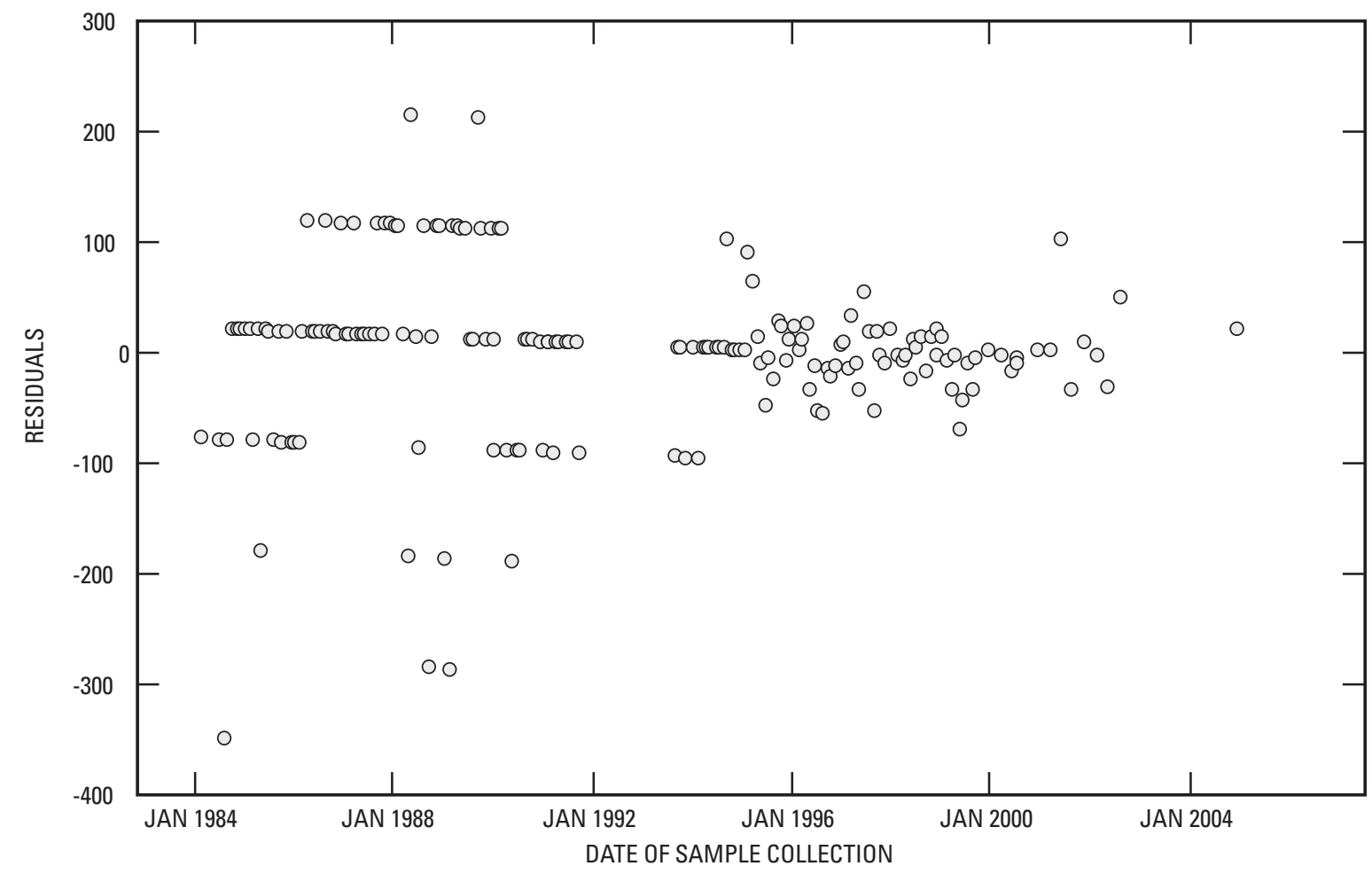

B. Freshwater-zone well C1

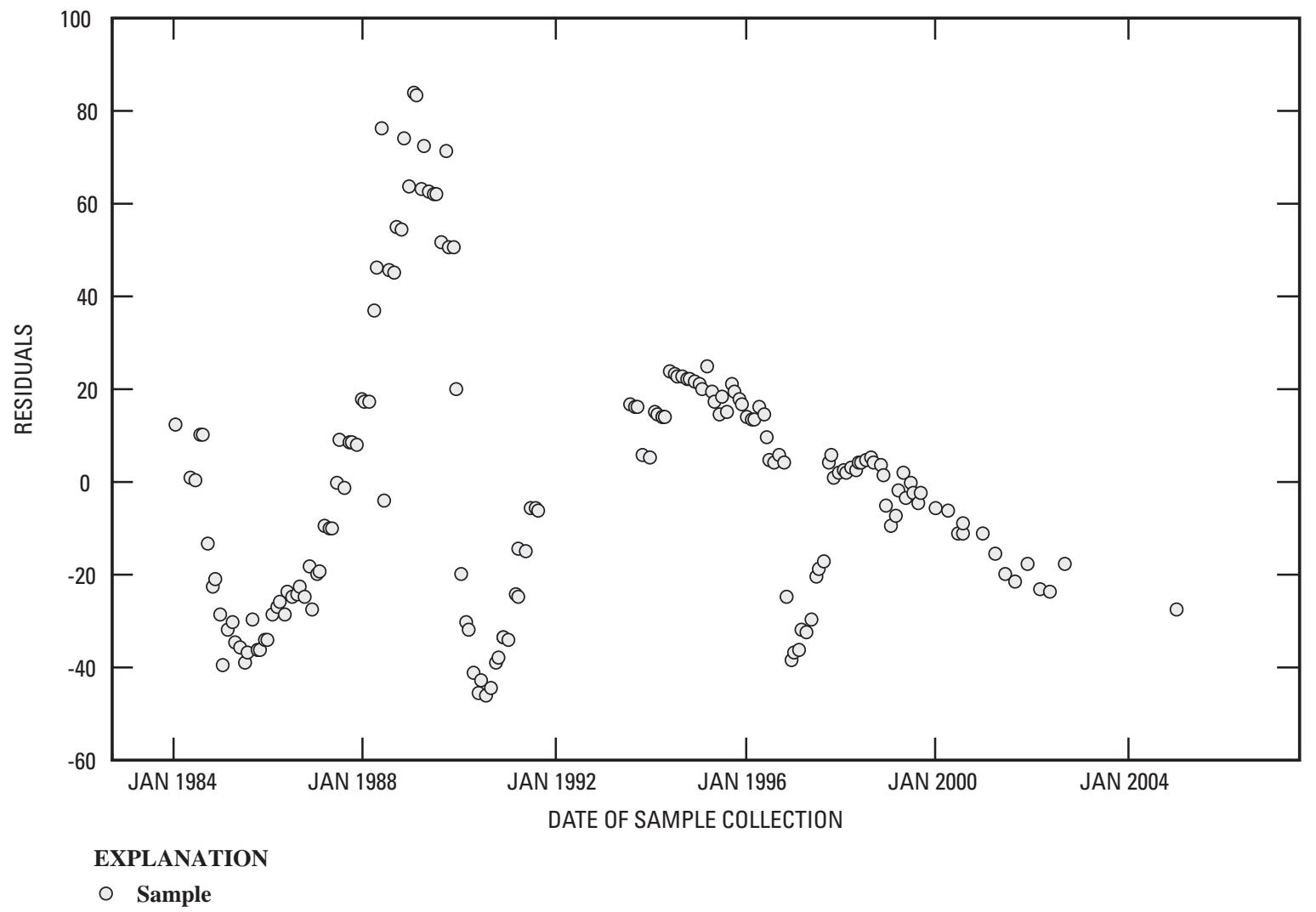

Figure 5. Examples of (A) non-constant variance demonstrated by residuals for linear regression between sulfate concentration and time, transition-zone well C2, and (B) non-independence of residuals demonstrated by serial correlation of residuals of linear regression between sulfate concentration and time, freshwater-zone well C1, San Antonio, Texas. 


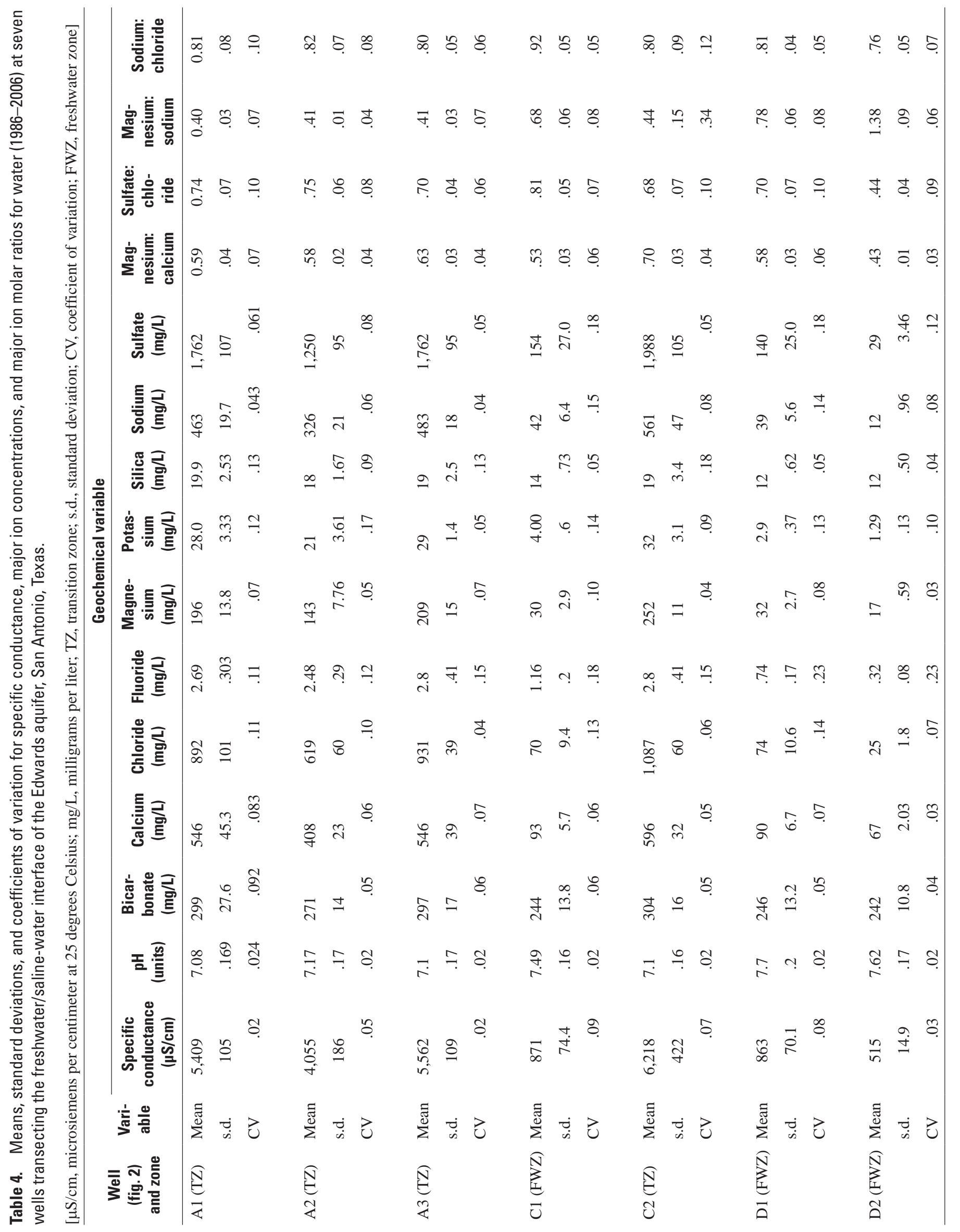


computed for trace elements, with all nondetections ranked equally and less than all detections (table 5). $\mathrm{Cu}, \mathrm{Pb}, \mathrm{Se}$, and $\mathrm{Ag}$ were the trace elements detected least frequently (less than 50 detections each). $\mathrm{Ba}, \mathrm{Fe}$, and $\mathrm{Zn}$ were detected in every sample (125 detections). $\mathrm{Cr}, \mathrm{Pb}$, and $\mathrm{Ag}$ were detected more frequently in water from the transition-zone wells than in water from the freshwater-zone wells, and $\mathrm{Cd}$ was more frequently detected in water from wells A1, A2, and A3 than in water from the other wells. Samples from the transitionzone wells had mean concentrations of $\mathrm{Cd}, \mathrm{Cr}, \mathrm{Cu}, \mathrm{Pb}$, and $\mathrm{Ag}$ that were elevated relative to concentrations in samples from the freshwater-zone wells. Samples from the freshwaterzone wells had mean concentrations of Ba that were elevated relative to the transition-zone wells. Concentrations of $\mathrm{Fe}$ in wells $\mathrm{C} 1$ and $\mathrm{D} 1$, both freshwater-zone wells, were 10 to 40 times higher than concentrations of $\mathrm{Fe}$ in transition-zone wells.

\section{Geochemical Relations}

\section{Correlations between Specific Conductance, Major Ions, and Trace Elements at Each Well}

Correlation matrixes were computed for SC and major ion concentrations (table 6), for major ion concentrations (table 6), for trace element concentrations (table 7), for SC and trace element concentrations (table 8), and for major ion and trace element concentrations (table 8) in water samples from each of the seven wells. Those samples without complete data were excluded from the analysis. For comparison in this report, a relation with a Pearson's r or Kendall's tau greater than or equal to .50 or less than or equal to -.50 is described as strong, and a relation with a Pearson's $r$ or Kendall's tau between -.50 and .50 is described as weak.

Table 5. Medians, 25th percentiles, and 75th percentiles for trace element concentrations for water (1986-2006) at seven wells transecting the freshwater/saline-water interface of the Edwards aquifer, San Antonio, Texas.

[In micrograms per liter; TZ, transition zone; ND, nondetection; FWZ, freshwater zone]

\begin{tabular}{|c|c|c|c|c|c|c|c|c|c|c|c|c|c|}
\hline $\begin{array}{l}\text { Well } \\
\text { (fig. 2) and } \\
\text { zone }\end{array}$ & Variable & Arsenic & Barium & $\begin{array}{l}\text { Cad- } \\
\text { mium }\end{array}$ & $\begin{array}{l}\text { Chro- } \\
\text { mium }\end{array}$ & Copper & Iron & Lead & $\begin{array}{c}\text { Manga- } \\
\text { nese }\end{array}$ & $\begin{array}{l}\text { Mer- } \\
\text { cury }\end{array}$ & $\begin{array}{l}\text { Sele- } \\
\text { nium }\end{array}$ & Silver & Zinc \\
\hline \multirow[t]{3}{*}{ A1 (TZ) } & Median & 0.50 & 8.9 & 0.17 & 0.80 & 1.2 & 50 & 0.40 & 11 & 0.10 & ND & 0.30 & 10 \\
\hline & 25th percentile & ND & 2.0 & ND & .65 & ND & 30 & ND & 7.8 & .02 & ND & ND & 9.3 \\
\hline & 75th percentile & 1.9 & 10 & .86 & 1.9 & 2.9 & 59 & 2.0 & 20 & .10 & 2.1 & 1.04 & 28 \\
\hline \multirow[t]{3}{*}{ A2 (TZ) } & Median & .18 & 7.0 & .11 & .80 & ND & 94 & ND & 13 & .10 & .24 & ND & 11 \\
\hline & 25th percentile & ND & 6.0 & ND & .09 & ND & 55 & ND & 11 & .02 & $\mathrm{ND}$ & ND & 10 \\
\hline & 75th percentile & 1.9 & 7.6 & .28 & 1.1 & 1.3 & 131 & 1.6 & 28 & .10 & 2.0 & .26 & 42 \\
\hline \multirow[t]{3}{*}{ A3 (TZ) } & Median & 1.0 & 5.8 & .12 & .80 & .65 & 50 & 1.4 & 14 & .10 & ND & .20 & 10 \\
\hline & 25th percentile & ND & 5.1 & ND & .65 & ND & 30 & ND & 8.6 & .02 & ND & ND & 9.0 \\
\hline & 75th percentile & 2.0 & 6.5 & .43 & 1.9 & 2.9 & 50 & 2.0 & 20 & .10 & 2.0 & .52 & 28 \\
\hline \multirow[t]{3}{*}{ C1 (FWZ) } & Median & 3.3 & 54 & .02 & .46 & .20 & 1,021 & ND & 8.7 & .10 & 2.0 & ND & 7.5 \\
\hline & 25th percentile & 2.0 & 52 & ND & ND & ND & 807 & ND & 7.4 & .02 & ND & ND & 3.0 \\
\hline & 75th percentile & 5.0 & 62 & .13 & .80 & 1.2 & 1,401 & .06 & 14 & .10 & 2.4 & .075 & 20 \\
\hline \multirow[t]{3}{*}{ C2 (TZ) } & Median & .45 & 12 & .05 & .80 & .50 & 50 & .14 & 20 & .10 & ND & .30 & 11 \\
\hline & 25th percentile & ND & 10 & ND & .65 & ND & 25 & ND & 16 & .02 & ND & ND & 9.3 \\
\hline & 75th percentile & 2.0 & 12 & .35 & 2.8 & 2.4 & 75 & 2.0 & 29 & .10 & 2.0 & 1.20 & 68 \\
\hline \multirow[t]{3}{*}{ D1 (FWZ) } & Median & 1.0 & 108 & .01 & .27 & ND & 915 & ND & 30 & .10 & ND & ND & 8.0 \\
\hline & 25th percentile & ND & 102 & ND & ND & ND & 557 & ND & 23 & .02 & ND & ND & 3.1 \\
\hline & 75th percentile & 2.0 & 110 & .13 & .80 & 1.02 & 1,295 & .06 & 40 & .10 & 2.0 & .10 & 17 \\
\hline \multirow[t]{3}{*}{ D2 (FWZ) } & Median & .25 & 102 & ND & .09 & ND & 24 & ND & 7.0 & .10 & .28 & ND & 12 \\
\hline & 25th percentile & ND & 100 & ND & ND & ND & 10 & ND & 4.3 & .02 & ND & ND & 5.0 \\
\hline & 75th percentile & 1.9 & 105 & .14 & .80 & 1.0 & 40 & ND & 8.6 & .10 & 2.1 & .10 & 20 \\
\hline
\end{tabular}


Table 6. Correlations between specific conductance and major ion concentrations and between major ion concentrations, as indicated by Pearson's $r$, for water (1986-2006) at seven wells transecting the freshwater/saline-water interface of the Edwards aquifer, San Antonio, Texas.

[Significant (at .05 level) correlation in bold; strong correlation (Pearson's r greater than .5) in blue (positive); SC, specific conductance; TZ, transition zone; FWZ, freshwater zone]

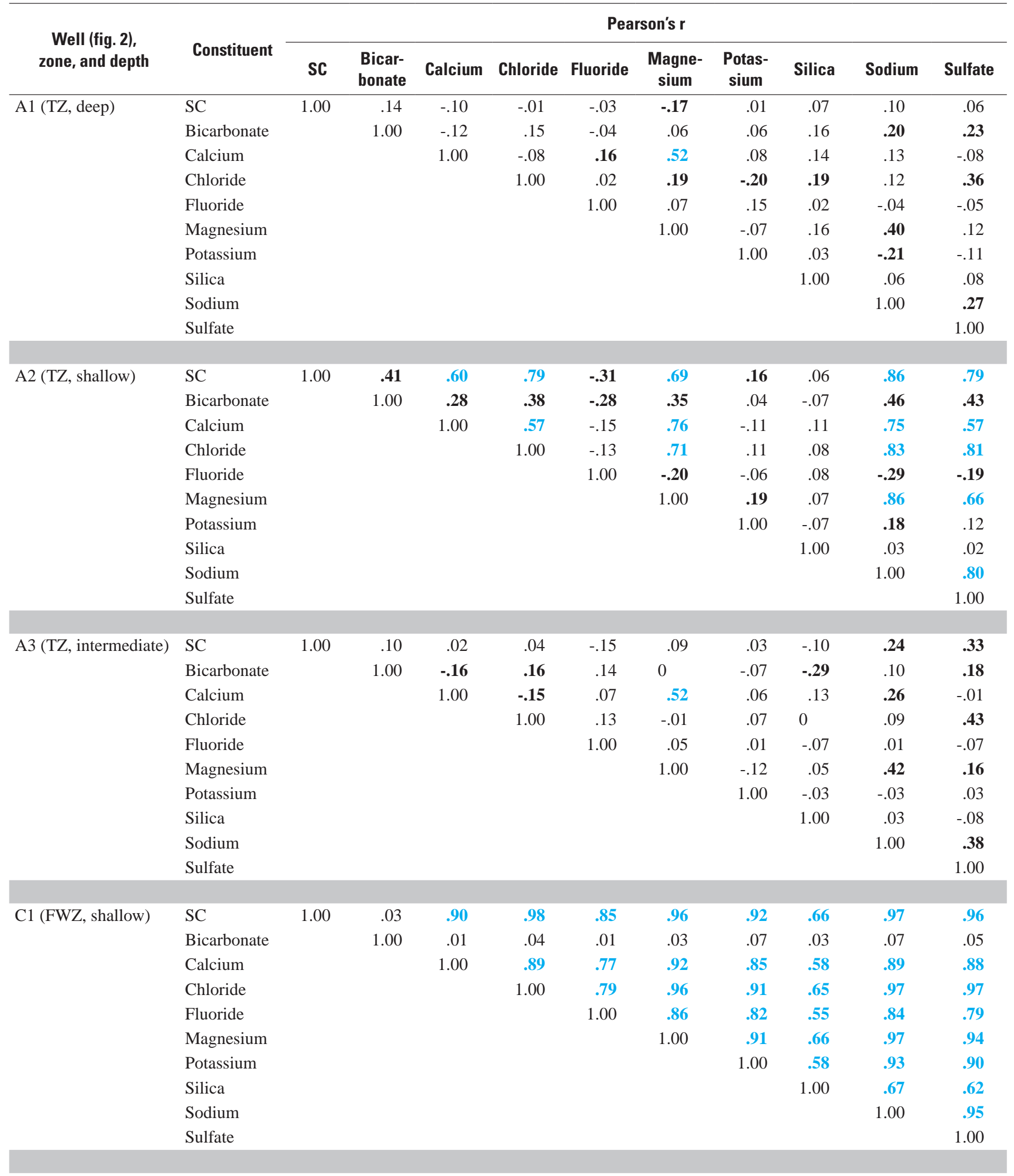


Table 6. Correlations between specific conductance and major ion concentrations and between major ion concentrations, as indicated by Pearson's r, for water (1986-2006) at seven wells transecting the freshwater/saline-water interface of the Edwards aquifer, San Antonio, Texas-Continued.

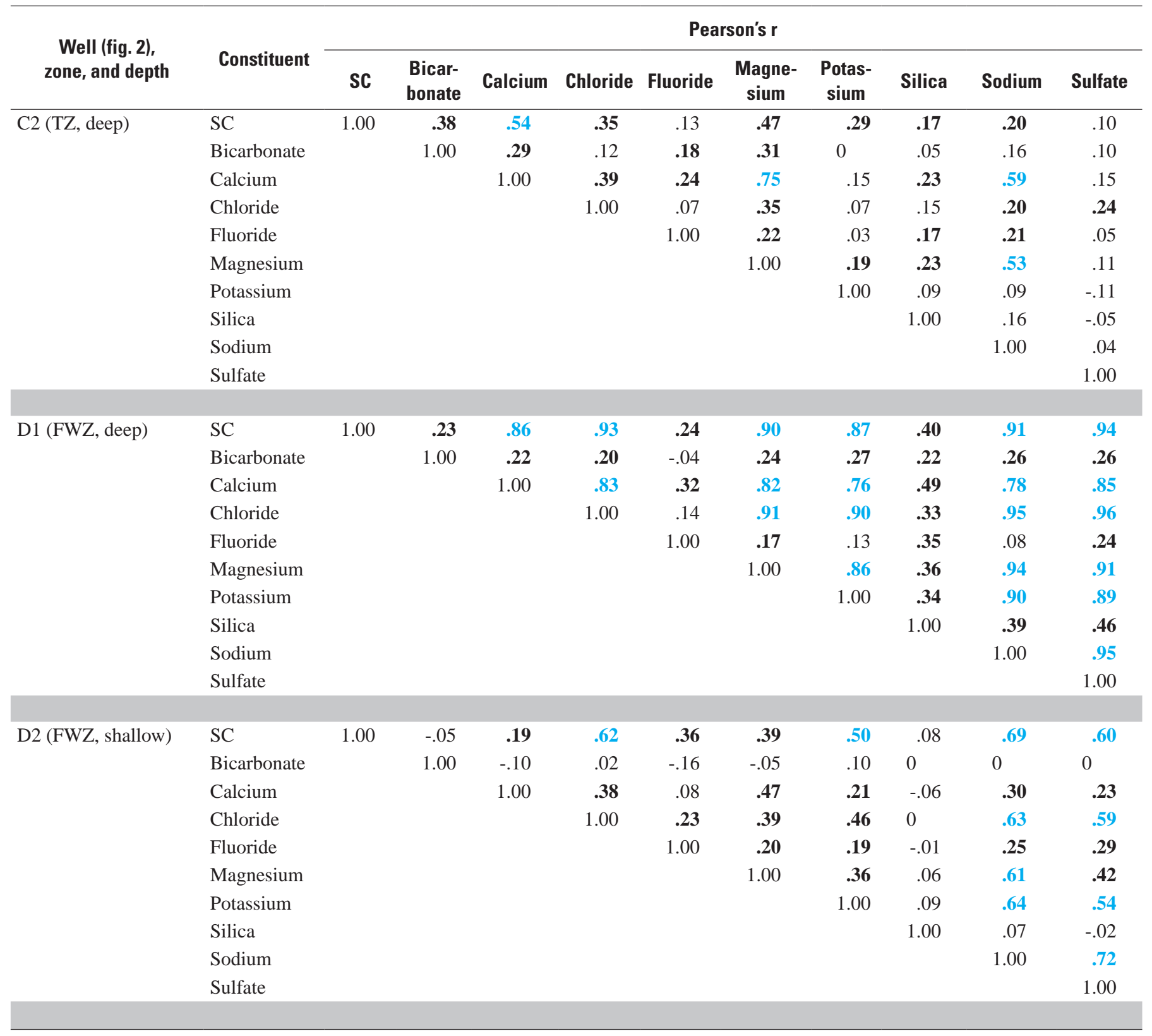

All strong correlations between SC and major ion concentrations and between major ion concentrations (table 6) were positive, meaning that as one variable increased the other also increased. In general, there were more and stronger correlations between SC and major ions in water samples from the freshwater-zone wells than in samples from the transition-zone wells. Except for the shallowest transition-zone well (A2), the transition-zone wells had relatively few strong correlations overall, and in A1 and A3 only the correlation between $\mathrm{Ca}$ and $\mathrm{Mg}$ was strong. At two of the transition-zone wells (A1 and A3), SC was not strongly correlated with any major ion. This was unexpected because SC is a function of the dissolved solids concentration, which in turn is the sum of the major ions in the water. Water from two freshwater-zone wells (C1 and D1) had numerous and strong correlations. Freshwaterzone well D2 had fewer strong correlations than well D1 but still about twice as many as transition-zone wells A1 and A3. The lack of a strong correlation indicates that much of the variability in the major ion concentrations at wells A1 and A3 might be a result of analytical variability caused by the multiple analytical methods used.

In most cases, strong correlations between concentrations of trace elements were positive (table 7). Transition-zone wells and freshwater-zone wells had water with a similar number 
Table 7. Correlations between trace element concentrations, as indicated by Kendall's tau, for water (1986-2006) at seven wells transecting the freshwater/saline-water interface of the Edwards aquifer, San Antonio, Texas.

[Significant (at .05 level) correlation in bold; strong correlation (Kendall's tau greater than .5) in blue (positive) or red (negative); TZ, transition zone; FWZ freshwater zone; NA, not applicable (all lead concentrations below detection limit]

\begin{tabular}{|c|c|c|c|c|c|c|c|c|c|c|c|c|c|}
\hline \multirow{2}{*}{$\begin{array}{c}\text { Well (fig. 2), } \\
\text { zone, and depth }\end{array}$} & \multirow{2}{*}{$\begin{array}{c}\text { Trace } \\
\text { element }\end{array}$} & \multicolumn{12}{|c|}{ Kendall's tau } \\
\hline & & Arsenic & Barium & Cadmium & Chromium & Copper & Iron & Lead & Manganese & Mercury & Selenium & Silver & Zinc \\
\hline \multirow[t]{12}{*}{ A1 (TZ, deep) } & Arsenic & 1.00 & -.31 & .07 & .01 & .72 & -.12 & -.01 & -.56 & -.46 & .72 & .30 & -.02 \\
\hline & Barium & & 1.00 & .05 & .45 & -.17 & .41 & .20 & .57 & .09 & -.51 & -.13 & .11 \\
\hline & Cadmium & & & 1.00 & .29 & .41 & .10 & .63 & -.02 & -.02 & .30 & .48 & 0 \\
\hline & Chromium & & & & 1.00 & .18 & .47 & .63 & .40 & -.11 & -.04 & .14 & -.04 \\
\hline & Copper & & & & & 1.00 & .04 & .37 & -.33 & -.35 & .74 & .44 & -.08 \\
\hline & Iron & & & & & & 1.00 & .19 & .56 & .32 & -.22 & -.12 & .06 \\
\hline & Lead & & & & & & & 1.00 & .20 & -.17 & .15 & .32 & -.12 \\
\hline & Manganese & & & & & & & & 1.00 & .46 & -.58 & -.18 & 0 \\
\hline & Mercury & & & & & & & & & 1.00 & -.31 & .22 & .04 \\
\hline & Selenium & & & & & & & & & & 1.00 & .50 & -.22 \\
\hline & Silver & & & & & & & & & & & 1.00 & -.03 \\
\hline & Zinc & & & & & & & & & & & & 1.00 \\
\hline \multirow[t]{12}{*}{ A2 (TZ, shallow) } & Arsenic & 1.00 & -.40 & .46 & .18 & .53 & -.21 & -.13 & -.37 & -.27 & .66 & .37 & .15 \\
\hline & Barium & & 1.00 & -.03 & .26 & -.33 & .33 & .16 & .47 & .27 & -.47 & -.04 & .03 \\
\hline & Cadmium & & & 1.00 & .61 & .48 & .10 & .53 & .10 & -.24 & .48 & .40 & .16 \\
\hline & Chromium & & & & 1.00 & .22 & .24 & .40 & .28 & -.01 & .21 & .36 & .11 \\
\hline & Copper & & & & & 1.00 & -.02 & .31 & -.22 & .02 & .71 & .56 & -.19 \\
\hline & Iron & & & & & & 1.00 & .13 & .48 & .28 & -.25 & .01 & -.18 \\
\hline & Lead & & & & & & & 1.00 & .25 & .14 & .11 & .24 & -.09 \\
\hline & Manganese & & & & & & & & 1.00 & .51 & -.40 & -.19 & .01 \\
\hline & Mercury & & & & & & & & & 1.00 & -.30 & -.22 & .01 \\
\hline & Selenium & & & & & & & & & & 1.00 & .41 & 0 \\
\hline & Silver & & & & & & & & & & & 1.00 & -.10 \\
\hline & Zinc & & & & & & & & & & & -- & 1.00 \\
\hline \multirow[t]{12}{*}{ A3 (TZ, intermediate) } & Arsenic & 1.00 & -.03 & .49 & .17 & .70 & .15 & .06 & -.42 & -.32 & .64 & .17 & .02 \\
\hline & Barium & & 1.00 & -.07 & .52 & -.09 & .49 & .20 & .42 & .04 & -.31 & .02 & .11 \\
\hline & Cadmium & & & 1.00 & .32 & .64 & .09 & .50 & -.23 & -.25 & .52 & .50 & -.06 \\
\hline & Chromium & & & & 1.00 & .15 & .58 & .52 & .39 & -.02 & -.08 & .16 & .07 \\
\hline & Copper & & & & & 1.00 & .06 & .35 & -.43 & -.48 & .73 & .51 & -.10 \\
\hline & Iron & & & & & & 1.00 & .31 & .43 & .25 & -.09 & -.03 & .24 \\
\hline & Lead & & & & & & & 1.00 & .18 & -.28 & 0 & .30 & .06 \\
\hline & Manganese & & & & & & & & 1.00 & .45 & -.69 & -.23 & .15 \\
\hline & Mercury & & & & & & & & & 1.00 & -.38 & -.09 & .03 \\
\hline & Selenium & & & & & & & & & & 1.00 & .36 & -.15 \\
\hline & Silver & & & & & & & & & & & 1.00 & -.10 \\
\hline & Zinc & & & & & & & & & & & & 1.00 \\
\hline \multirow[t]{12}{*}{ C1 (FWZ, shallow) } & Arsenic & 1.00 & .13 & -.10 & -.40 & -.35 & .62 & -.50 & .37 & .30 & -.42 & -.36 & .15 \\
\hline & Barium & & 1.00 & -.13 & -.29 & .20 & .14 & .26 & .14 & .25 & -.24 & -.33 & .26 \\
\hline & Cadmium & & & 1.00 & .47 & .41 & .14 & .02 & .19 & -.34 & .40 & .51 & -.06 \\
\hline & Chromium & & & & 1.00 & .48 & -.22 & .33 & -.19 & -.38 & .85 & .36 & 0 \\
\hline & Copper & & & & & 1.00 & -.18 & .63 & -.04 & -.13 & .57 & .03 & -.03 \\
\hline & Iron & & & & & & 1.00 & -.30 & .70 & .26 & -.41 & -.24 & .03 \\
\hline & Lead & & & & & & & 1.00 & -.24 & -.32 & .28 & -.18 & -.14 \\
\hline & Manganese & & & & & & & & 1.00 & .11 & -.32 & -.20 & -.08 \\
\hline & Mercury & & & & & & & & & 1.00 & -.21 & -.54 & .03 \\
\hline & Selenium & & & & & & & & & & 1.00 & .45 & 0 \\
\hline & Silver & & & & & & & & & & & 1.00 & -.04 \\
\hline & Zinc & & & & & & & & & & & & 1.00 \\
\hline \multirow[t]{12}{*}{ C2 (TZ, deep) } & Arsenic & 1.00 & -.37 & .42 & .25 & .68 & .13 & .01 & -.23 & -.24 & .58 & .20 & -.06 \\
\hline & Barium & & 1.00 & -.27 & .42 & -.43 & .26 & .13 & .44 & -.10 & -.40 & -.39 & .06 \\
\hline & Cadmium & & & 1.00 & .17 & .55 & -.05 & .56 & -.25 & -.19 & .54 & .29 & -.18 \\
\hline & Chromium & & & & 1.00 & .02 & .45 & .45 & .37 & -.10 & -.01 & -.14 & -.04 \\
\hline & Copper & & & & & 1.00 & -.08 & .21 & -.41 & -.42 & .77 & .26 & -.21 \\
\hline & Iron & & & & & & 1.00 & .08 & .58 & .17 & -.12 & -.22 & .24 \\
\hline & Lead & & & & & & & 1.00 & .04 & -.19 & .13 & .15 & -.26 \\
\hline & Manganese & & & & & & & & 1.00 & .64 & -.46 & -.17 & .11 \\
\hline & Mercury & & & & & & & & & 1.00 & -.34 & .27 & .07 \\
\hline & Selenium & & & & & & & & & & 1.00 & .32 & -.12 \\
\hline & Silver & & & & & & & & & & & 1.00 & -.08 \\
\hline & Zinc & & & & & & & & & & & & 1.00 \\
\hline
\end{tabular}


Table 7. Correlations between trace element concentrations, as indicated by Kendall's tau, for water (1986-2006) at seven wells transecting the freshwater/saline-water interface of the Edwards aquifer, San Antonio, Texas-Continued.

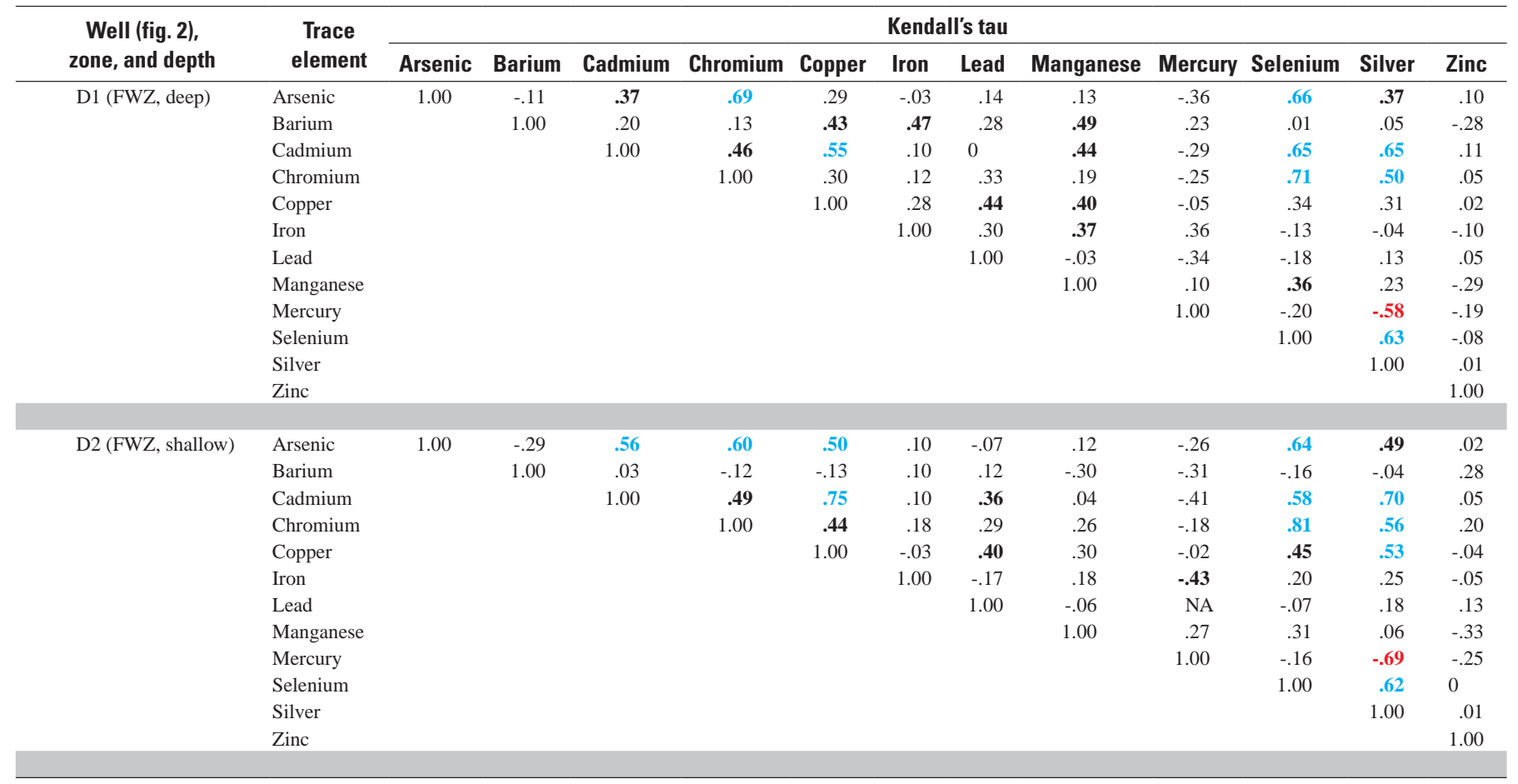

of significant correlations. In water from the transition-zone wells, there were four consistent correlations: As and $\mathrm{Cu}$, $\mathrm{Cd}$ and $\mathrm{Pb}$, As and $\mathrm{Se}$, and $\mathrm{Cu}$ and $\mathrm{Se}$. In the water from the three freshwater-zone wells, concentrations of $\mathrm{Cr}$ and $\mathrm{Se}$ were strongly correlated. Concentrations of all trace elements were correlated with concentrations of one or more other trace element except $\mathrm{Zn}$, which was not correlated with any other trace element at any site.

There were about twice as many correlations that were positive and strong between SC or major ions and trace elements as there were correlations that were negative and strong (table 8), but the correlations that were negative and strong between SC or major ions and trace elements (table 8) were more numerous than between major ions (table 6) or between trace elements (table 7). There were one or more strong negative correlations between $\mathrm{SC}$ or a major ion and $\mathrm{Se}$ in transition-zone wells A1, A2, and A3 (table 8). There were numerous positive correlations between a major ion and $\mathrm{Ba}$ in wells A2 and D1, and numerous negative correlations between a major ion and both $\mathrm{Ba}$ and $\mathrm{Pb}$ in well $\mathrm{C} 1$. There were numerous positive correlations between a major ion and $\mathrm{Mn}$ in wells A2, A3, and D1.

\section{Principal Components Analysis of Major lon Geochemistry at Each Well}

PCA was used to investigate how major ions or groups of major ions covary. For geochemical data, the PCs sometimes are interpreted as indicating individual geochemical processes or sources (Laaksoharju and others, 1999). Of interest was which PCs explain the most variance in the data at each well and which major ions are most heavily loaded on those PCs; for that reason the PCA for each well was run independently of the other wells. This provides information on which major ions vary together and which ones vary inversely at each well, and to what degree those relations explain the total variance in the data at the well.

The number of PCs required to explain most of the variance in the data ranged widely among wells (table 9). On a scale of 0 to 1 , at freshwater-zone wells $\mathrm{C} 1$ and D1, the first PC (PC1) explained more than 0.75 of the variance of the data. For wells C2 and D2, although PC1 did not explain the majority of the variance, it explained more than twice as much as any other PC, although at well C2 five PCs explained 0.10 or more of the variance in the data. For wells A1 and A3, the deeper of the three wells at site A, the variance was divided more evenly among the PCs than for the other wells.

The large amount of variance explained by $\mathrm{PC} 1$ at wells $\mathrm{C} 1$ and D1 indicates that a single process might be controlling most of the variability in the geochemistry of water at these wells. Further, loadings of the major ions on the first two PCs are very similar. At well C1, all major ions entered into the analysis are very strongly and negatively loaded on PC1, and only Si has any substantial loading on PC2 (fig. 6). The very heavy and similar loadings of all major ions on PC1 and the large fraction of variance explained by this PC implies that concentrations of the major ions covary at well $\mathrm{C} 1$. This 
Table 8. Correlations between specific conductance and trace element concentrations and between major ion and trace element concentrations, as indicated by Kendall's tau, for water (1986-2006) at seven wells transecting the freshwater/saline-water interface of the Edwards aquifer, San Antonio, Texas.

[Significant (at .05 level) correlation in bold; strong correlation (Kendall's tau greater than .5) in blue (positive) or red (negative); TZ, transition zone; FWZ freshwater zone]

\begin{tabular}{|c|c|c|c|c|c|c|c|c|c|c|c|c|c|}
\hline \multirow{2}{*}{$\begin{array}{c}\text { Well (fig. 2), } \\
\text { zone, and depth }\end{array}$} & \multirow[b]{2}{*}{ Constituent } & \multicolumn{12}{|c|}{ Kendall's tau } \\
\hline & & Arsenic & Barium & $\begin{array}{l}\text { Cad- } \\
\text { mium }\end{array}$ & $\begin{array}{l}\text { Chro- } \\
\text { mium }\end{array}$ & Copper & Iron & Lead & $\begin{array}{l}\text { Manga- } \\
\text { nese }\end{array}$ & $\begin{array}{l}\text { Mer- } \\
\text { cury }\end{array}$ & $\begin{array}{l}\text { Sele- } \\
\text { nium }\end{array}$ & Silver & Zinc \\
\hline \multirow{6}{*}{ A1 (TZ, deep) } & Calcium & -.19 & .11 & .04 & .04 & -.09 & -.30 & .15 & -.01 & .09 & -.03 & .12 & -.14 \\
\hline & Chloride & -.17 & -.20 & .09 & -.07 & -.11 & .06 & -.09 & .04 & .43 & -.06 & -.03 & -.15 \\
\hline & Potassium & -.29 & .06 & -.18 & -.09 & -.23 & -.09 & -.12 & .16 & -.04 & -.21 & -.21 & -.17 \\
\hline & Silica & -.08 & -.10 & .22 & -.21 & -.04 & .03 & -.05 & .05 & .23 & .06 & .07 & .03 \\
\hline & Sodium & -.12 & .69 & .08 & .62 & .04 & .60 & .28 & .51 & .20 & -.24 & .03 & .05 \\
\hline & Sulfate & -.04 & .05 & .46 & .12 & .18 & .30 & .37 & .12 & .17 & .03 & .14 & -.05 \\
\hline \multirow{7}{*}{ A2 (TZ, shallow) } & Chloride & -.49 & .56 & -.16 & .17 & -.30 & .39 & .27 & .70 & .41 & -.45 & -.28 & .02 \\
\hline & Fluoride & .01 & .07 & .26 & .19 & .09 & -.09 & .32 & -.12 & -.16 & .20 & .01 & .01 \\
\hline & Magnesium & -.42 & .76 & -.01 & .22 & -.28 & .48 & .22 & .62 & .38 & -.59 & -.12 & -.04 \\
\hline & Potassium & -.57 & .41 & -.17 & .07 & -.22 & .43 & .09 & .51 & .25 & -.44 & -.20 & -.20 \\
\hline & Silica & -.18 & -.06 & .16 & .04 & .03 & -.07 & .05 & .19 & .09 & -.04 & -.28 & .32 \\
\hline & Sodium & -.41 & .67 & -.08 & .29 & -.37 & .33 & .22 & .72 & .48 & -.47 & -.27 & .05 \\
\hline & Sulfate & -.47 & .62 & -.17 & .18 & -.30 & .43 & .18 & .62 & .51 & -.51 & -.26 & .01 \\
\hline \multirow[t]{3}{*}{ A3 (TZ, intermediate) } & $\mathrm{SC}$ & -.37 & .29 & -.24 & .21 & -.42 & .38 & .06 & .60 & .56 & -.61 & -.24 & .14 \\
\hline & Sodium & .03 & .48 & -.07 & .44 & -.14 & .25 & .20 & .45 & .31 & -.32 & -.14 & -.06 \\
\hline & Sulfate & .03 & .34 & .09 & .45 & -.03 & .45 & .31 & .39 & .22 & -.08 & -.25 & -.06 \\
\hline \multirow[t]{9}{*}{ C1 (FWZ, shallow) } & $\mathrm{SC}$ & .34 & -.34 & .02 & -.26 & -.33 & .30 & -.46 & .21 & .54 & -.23 & -.09 & -.11 \\
\hline & Calcium & .12 & -.22 & .02 & -.25 & -.29 & 0 & -.45 & -.08 & .33 & -.16 & .12 & -.19 \\
\hline & Chloride & .39 & -.42 & .05 & -.21 & -.38 & .34 & -.51 & .23 & .21 & -.22 & -.10 & -.03 \\
\hline & Fluoride & -.02 & -.62 & .18 & .18 & -.24 & .04 & -.42 & -.03 & -.26 & .16 & .32 & 0 \\
\hline & Magnesium & .19 & -.44 & .22 & -.04 & -.16 & .04 & -.38 & -.06 & .28 & .07 & .26 & -.24 \\
\hline & Potassium & .54 & -.20 & -.04 & -.38 & -.39 & .34 & -.49 & .16 & .16 & -.41 & -.09 & .01 \\
\hline & Silica & .27 & -.16 & .07 & -.07 & -.11 & .27 & -.37 & .27 & .49 & -.14 & -.17 & -.14 \\
\hline & Sodium & .31 & -.45 & .14 & -.12 & -.28 & .20 & -.51 & .22 & .18 & -.08 & -.01 & -.11 \\
\hline & Sulfate & .40 & -.41 & .11 & -.17 & -.34 & .38 & -.53 & .24 & .16 & -.17 & -.01 & -.09 \\
\hline
\end{tabular}


Table 8. Correlations between specific conductance and trace element concentrations and between major ion and trace element concentrations, as indicated by Kendall's tau, for water (1986-2006) at seven wells transecting the freshwater/saline-water interface of the Edwards aquifer, San Antonio, Texas-Continued.

\begin{tabular}{|c|c|c|c|c|c|c|c|c|c|c|c|c|c|}
\hline \multirow{2}{*}{$\begin{array}{c}\text { Well (fig. 2), } \\
\text { zone, and depth }\end{array}$} & \multirow[b]{2}{*}{ Constituent } & \multicolumn{12}{|c|}{ Kendall's tau } \\
\hline & & Arsenic & Barium & $\begin{array}{l}\text { Cad- } \\
\text { mium }\end{array}$ & $\begin{array}{l}\text { Chro- } \\
\text { mium }\end{array}$ & Copper & Iron & Lead & $\begin{array}{l}\text { Manga- } \\
\text { nese }\end{array}$ & $\begin{array}{l}\text { Mer- } \\
\text { cury }\end{array}$ & $\begin{array}{l}\text { Sele- } \\
\text { nium }\end{array}$ & Silver & Zinc \\
\hline \multirow[t]{9}{*}{ C2 (TZ, deep) } & $\mathrm{SC}$ & .06 & -.35 & -.11 & -.37 & -.08 & -.17 & -.23 & -.07 & .45 & -.15 & .15 & .03 \\
\hline & Calcium & .20 & -.27 & .24 & -.26 & .37 & -.47 & .03 & -.59 & -.38 & .39 & .40 & -.16 \\
\hline & Chloride & .48 & -.29 & .40 & -.02 & .47 & -.26 & .04 & -.36 & -.18 & .50 & .28 & -.15 \\
\hline & Fluoride & .08 & -.20 & .22 & -.16 & .19 & -.14 & .05 & -.26 & -.13 & .27 & .11 & .11 \\
\hline & Magnesium & .05 & -.19 & .10 & -.30 & .05 & -.57 & -.04 & -.34 & .13 & .11 & .40 & -.20 \\
\hline & Potassium & -.49 & .02 & -.29 & -.44 & -.17 & -.46 & -.01 & -.31 & -.11 & -.17 & .08 & .01 \\
\hline & Silica & -.23 & -.04 & -.10 & -.33 & -.23 & -.01 & -.13 & .14 & .15 & -.03 & .09 & .25 \\
\hline & Sodium & -.11 & -.06 & -.18 & -.11 & .02 & -.28 & -.18 & -.10 & .15 & .06 & .20 & -.27 \\
\hline & Sulfate & .36 & -.25 & .31 & .01 & .33 & -.10 & -.05 & -.15 & -.05 & .43 & -.05 & -.12 \\
\hline \multirow[t]{9}{*}{ D1 (FWZ, deep) } & $\mathrm{SC}$ & -.09 & .51 & .02 & .14 & .34 & .69 & .26 & .37 & .51 & -.17 & -.10 & -.10 \\
\hline & Calcium & -.36 & .42 & -.19 & -.08 & .02 & .31 & .28 & .05 & .25 & -.36 & -.13 & -.05 \\
\hline & Chloride & .08 & .62 & .19 & .28 & .39 & .70 & .28 & .49 & .33 & .01 & -.04 & -.19 \\
\hline & Fluoride & .21 & .06 & -.16 & .27 & -.14 & .13 & .13 & .02 & -.18 & .12 & -.06 & -.21 \\
\hline & Magnesium & .11 & .61 & .11 & .30 & .37 & .51 & .35 & .44 & .18 & .15 & .02 & -.32 \\
\hline & Potassium & -.03 & .59 & .11 & .22 & .41 & .63 & .28 & .53 & .32 & -.04 & -.07 & -.14 \\
\hline & Silica & -.11 & .22 & -.08 & .03 & .21 & .37 & .30 & .09 & .26 & -.22 & -.20 & .21 \\
\hline & Sodium & .01 & .57 & .07 & .23 & .39 & .66 & .32 & .44 & .43 & -.06 & -.04 & -.25 \\
\hline & Sulfate & -.03 & .56 & .13 & .19 & .33 & .69 & .23 & .44 & .41 & -.06 & -.04 & -.20 \\
\hline \multirow[t]{9}{*}{ D2 (FWZ, shallow) } & $\mathrm{SC}$ & -.30 & -.25 & -.29 & -.29 & -.17 & -.21 & -.02 & .19 & .43 & -.26 & -.14 & -.51 \\
\hline & Calcium & .12 & .05 & -.06 & .04 & -.03 & .20 & -.20 & .08 & -.09 & .24 & .20 & -.40 \\
\hline & Chloride & .31 & -.22 & .07 & .15 & .02 & .14 & -.23 & .23 & -.37 & .36 & .40 & -.33 \\
\hline & Fluorideluoride & .01 & -.08 & -.23 & .15 & -.23 & .09 & .02 & .29 & -.05 & .17 & .02 & -.20 \\
\hline & Magnesium & .47 & -.07 & .20 & .31 & .20 & -.01 & -.21 & .16 & -.13 & .59 & .39 & -.10 \\
\hline & Potassium & -.15 & -.13 & .09 & -.11 & .20 & .01 & .10 & .34 & .21 & -.10 & .15 & -.53 \\
\hline & Silica & .18 & .01 & .23 & -.06 & .29 & -.30 & .12 & -.02 & .22 & .04 & -.08 & .08 \\
\hline & Sodium & -.01 & -.36 & -.08 & -.06 & .15 & -.07 & -.14 & .37 & .40 & .06 & .02 & -.63 \\
\hline & Sulfate & .07 & -.40 & -.04 & -.04 & .14 & 0 & -.09 & .43 & .30 & .08 & .08 & -.64 \\
\hline
\end{tabular}

covariance indicates that dilution is a likely cause of most of the variability in the major ion concentrations at this well. Dilution results in decreases in ion concentrations that are proportional, and the ion concentrations therefore remain linearly correlated. As a result, all ions are strongly weighted with the same sign on a single PC. Well C1 intercepts a large karst cavern that provides most of the water at the well (Groschen, 1994), thus water at this well could be expected to be greatly affected by inputs of low-ionic-strength meteoric water. Loadings on the first two PCs at well D1 are very similar to those at C1 (fig. 6). This indicates that at well D1, dilution also might be causing most of the variability in major ion concentrations, even though the well does not penetrate a cavern. The well bore for well D1 does, however, penetrate a fault zone (fig. 3), which might facilitate inflows of meteoric water. The moderately strong loading of Si on PC2 at both wells indicates that at these two wells another process is occurring that affects concentrations of $\mathrm{Si}$, but that this process explains very little of the overall geochemical variability; PC2 explains only about 0.08 and 0.12 of the variance at wells $\mathrm{C} 1$ and D1, respectively.

At well D2, the third freshwater-zone well, the loadings of the variables on the first two PCs are similar to those at the other freshwater-zone wells, but with some differences. At this 


\section{A. Transition-zone wells}
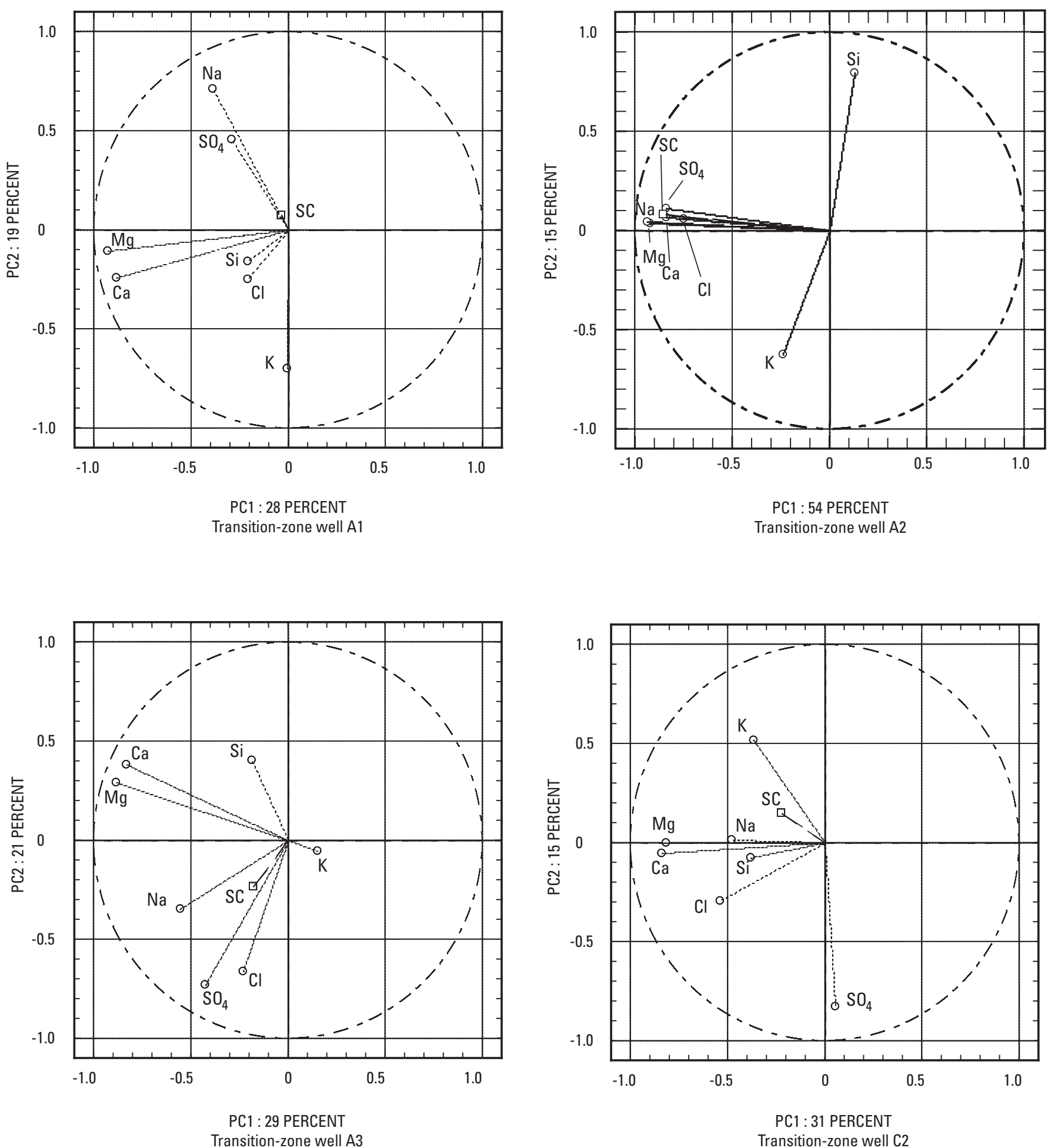

EXPLANATION

○ Active variable ( $\mathrm{Ca}$, calcium; $\mathrm{Cl}$, chloride; $\mathrm{Mg}$, magnesium; $\mathrm{K}$, potassium; $\mathrm{Si}$, silica; $\mathrm{Na}$, sodium; $\mathrm{SO}_{4}$, sulfate) $\square$ Supplemental variable (SC, specific conductance)

Figure 6. Loadings of geochemical variables on the first two principal components (PC) at (A) transition-zone wells $A 1, A 2, A 3$, and $C 2$, and (B) freshwater-zone wells C1, D1, and D2, San Antonio, Texas. 
B. Freshwater-zonewells

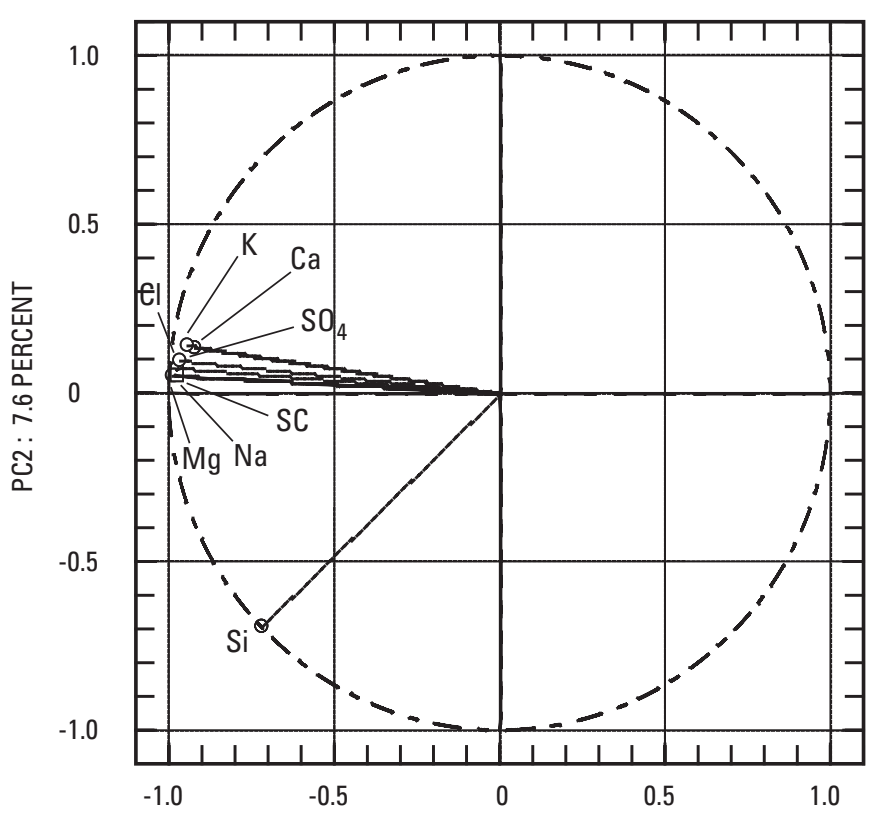

PC1 : 87 PERCENT

Freshwater-zone well C1

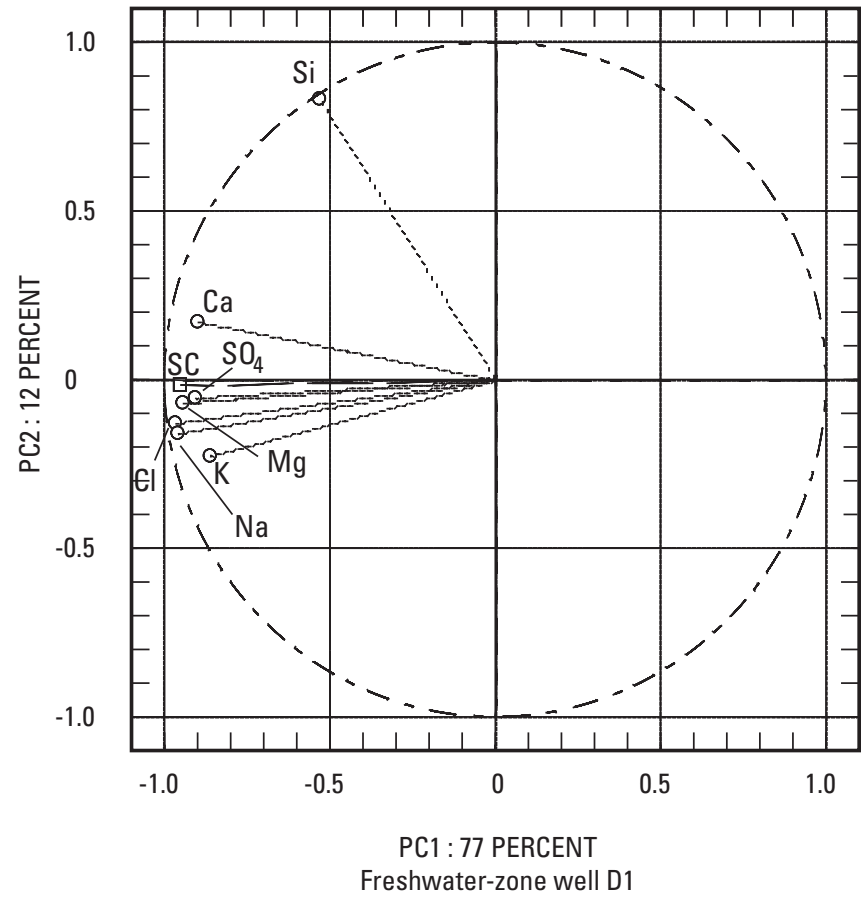

Freshwater-zone well D1

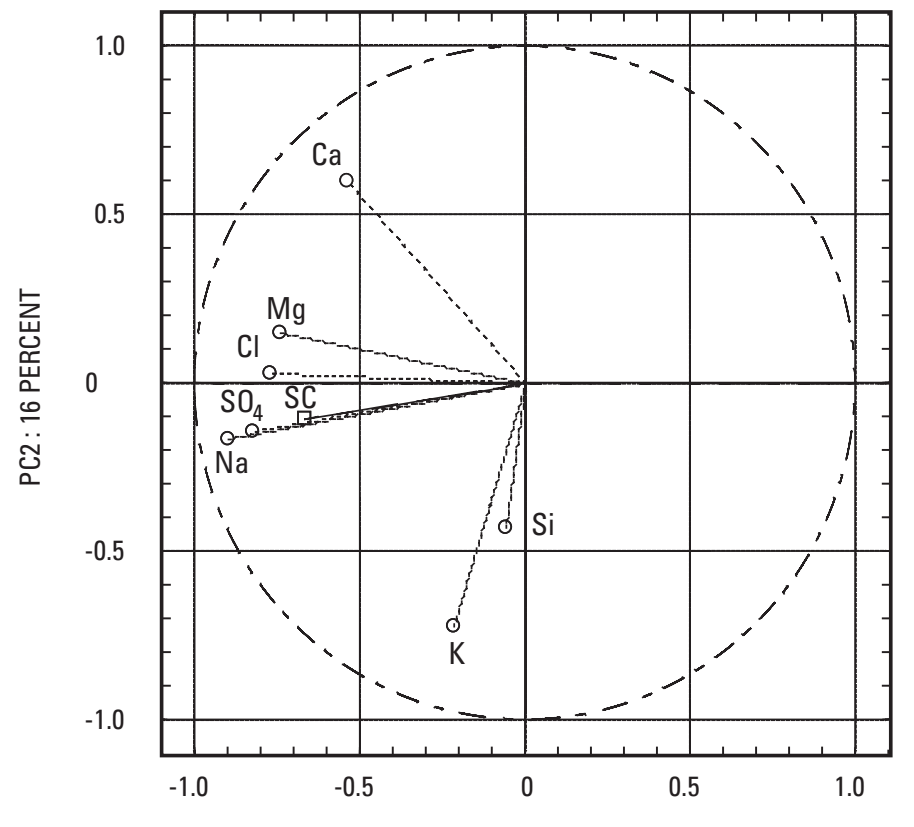

PC1 : 42 PERCENT

Freshwater-zone well D2

\section{EXPLANATION}

○ Active variable ( $\mathrm{Ca}$, calcium; $\mathrm{Cl}$, chloride; $\mathrm{M} \mathrm{g}$, magnesium; $\mathrm{K}$, potassium; $\mathrm{Si}$, silica; $\mathrm{Na}$, sodium; $\mathrm{SO}_{4}$, sulfate) $\square$ Supplemental variable (SC, specific conductance)

Figure 6.-Continued. 
Table 9. Fraction of variance explained by principal components analysis for water (1986-2006) at seven wells transecting the freshwater/saline-water interface of the Edwards aquifer, San Antonio, Texas.

[Principal component (PC) shown explains 0.10 or more of variance; --, fraction of variance explained by PC less than 0.10 of total variance for well]

\begin{tabular}{|c|c|c|c|c|c|c|c|}
\hline \multirow{2}{*}{$\begin{array}{c}\text { Principal } \\
\text { component }\end{array}$} & \multicolumn{7}{|c|}{$\begin{array}{c}\text { Well } \\
\text { (fig. 2) }\end{array}$} \\
\hline & A1 & $\mathbf{A} 2$ & A3 & C1 & $\mathrm{C} 2$ & D1 & D2 \\
\hline $\mathrm{PC} 2$ & .19 & .15 & .21 & -- & .15 & .12 & .16 \\
\hline PC3 & .17 & .13 & .14 & -- & .14 & -- & .14 \\
\hline PC5 & .11 & -- & .12 & -- & .12 & -- & -- \\
\hline Sum of variance & .89 & .81 & .91 & .87 & .85 & .89 & .86 \\
\hline
\end{tabular}

well, five major ions ( $\mathrm{Ca}, \mathrm{Mg}, \mathrm{Cl}, \mathrm{Na}$, and $\mathrm{SO}_{4}$ ) are moderately to heavily negatively loaded on PC1, but their loadings are slightly less than at wells C1 and D1. Furthermore, at this well, both $\mathrm{K}$ and Si have little loading on PC1, but have moderate loadings on PC2. At well D2, PC1 explains much less of the variance than at well $\mathrm{C} 1$ and $\mathrm{D} 1$, and PC2 explains more. The fairly similar loadings on PC1 at this well to those at wells $\mathrm{C} 1$ and D1 could indicate that dilution might still affect geochemical variability at this well, but that its influence is less strong. A second process, in which $\mathrm{Ca}$ is inversely related to $\mathrm{K}$ and $\mathrm{Si}$, also is occurring, but its influence is much less strong than that of dilution.

Well C2 is the northernmost of the transition-zone wells. It is completed below the RDM and does not intersect the cavern penetrated by well $\mathrm{C} 1$. The loadings of the major ions on the first two PCs have some similarities to those for the water from the freshwater-zone wells, but some differences as well. For water at well C2, PC1 explains only 0.31 of the total variance, and the next four PCs each explain more than 0.10 , indicating that PCA is not useful to reduce the number of variables needed to explain the variance. This lack of one or two predominant PCs indicates that there is no single process occurring at this well that affects the geochemical variability, but this lack also might result from less geochemical variability at this well than at the freshwaterzone wells. Three major ions $(\mathrm{Ca}, \mathrm{Mg}$, and $\mathrm{Cl})$ are moderately to heavily loaded on PC1, and none are positively loaded, indicating the possible influence of dilution here as well. However, the small fraction (0.31) of variance explained by PC1 indicates that dilution is relatively minor in controlling variations in the aqueous geochemistry. It might also result from a relatively minor amount of geochemical variability at this well.

Of the three transition-zone wells at site A, A2 is shallowest (fig. 3). The PC loadings for well A2 are very similar to those for freshwater-zone wells $\mathrm{C} 1$ and D1, except that $\mathrm{K}$ and Si have little loading on PC1 but are heavily loaded on PC2 (although inversely) (fig. 6). PC1 explains more than one-half the variance at well A2. The loadings on this PC and the relatively large fraction of variance that this PC explains indicate that, at this well, dilution also might be affecting variations in the major ion geochemistry.

Of the two deeper wells at site A, A3 is intermediate in depth and completed in the RDM, and A1 is the deepest and completed below the RDM (fig. 3). PCA of the geochemical data for wells A1 and A3 indicates little systematic variation in major ion concentrations. Similar to the PCA for well C2 data, PCA for well A1 and A3 data indicates that each of the first five PCs explains more than one-tenth of the total variance in the data, and the first PC explains less than one-third, thus PCA is not very effective in reducing the number of variables required to explain the variance (table 9). The lack of a small number of PCs that explain most of the variance indicates that there is no large-scale systematic variation in the major ion concentrations at these wells. Unlike for the shallow well at site A, well A2, a plot of the first two PCs for water from wells A1 and A3 are more scattered (fig. 6), with few major ions covarying together. At wells A1 and A3, $\mathrm{Ca}$ and $\mathrm{Mg}$ covary and are heavily loaded on PC1. The lack of correlation between SC and any major ions is seen clearly here.

In summary, PCA indicates that variations in geochemical concentrations covary at freshwater-zone wells C1, D1, and to a lesser extent D2, and at transition-zone well A2. This covariance likely results from a similar process, probably dilution. SC was heavily loaded along with four or more major ions on PC1. In contrast, at the deeper transition-zone wells A1 and A3, PCA was not effective at reducing the number of variables needed to explain the variance in the geochemical data. This indicates that there is no systematic variation in major ion concentrations, such as might be attributable to dilution, mixing of two or more geochemically distinct waters, or geochemical reactions that would alter major ion proportions. For transition-zone wells A1 and A3, there were no strong covariances among any major ions except for $\mathrm{Ca}$ and $\mathrm{Mg}$ on PC1, and SC did not covary with any major ions. The PCA for well C2, a transition-zone well, indicated geochemical variability intermediate between that of the freshwaterzone wells and well A2 and that of the transition-zone wells A1 and A3. 


\section{Temporal Trends}

SC, concentrations of major ions, four molar ratios of major ions, and concentrations of trace elements in water from each of the seven wells were tested for temporal trends. For all wells except $\mathrm{C} 1$, if the datasets of $\mathrm{SC}$, major ion concentrations, and major ion ratios were normally distributed, linear regression was used; and for the datasets that were nonnormally distributed, Kendall's tau test was used, as described in the "Statistical Methods" section. There was a lapse in data collection during October 1993-July 1995, and a sample was not collected in December 1995. Each dataset therefore was tested for trends during March or July 1986 through September 1993 (period 1), from January 1996 through December 2006 (period 2), and for the total period of sampling from March or July 1986 through December 2006 (period T). For freshwater-zone well $\mathrm{C} 1$, where the residuals were serially correlated, temporal trends were analyzed from a summary dataset, as described in the Statistical Methods section.

\section{Specific Conductance}

It is illustrative to look at how the results of the trend tests (table 10) are reflected in a graphical representation of SC over time (fig. 7). SC is taken as the example, as it often is used as a surrogate for dissolved solids (Singh and Kalra, 1975); dissolved solids, in turn, is used to define the potability of a water and, in the Edwards aquifer, distinguish between freshwater and saline water. SC had a significant trend in 14 of 21 possible cases (three periods for each of seven wells).

At well A1, the deepest site A transition-zone well, SC had no significant trend at the .05 level for period 1 and weak (tau or $\mathrm{r}^{2}$ less than .30) downward trends for period 2 and period T (fig. 7; table 10). SC at well A3, the next deepest well at this site, also had no trend for period 1 but had strong (tau or $\mathrm{r}^{2}$ greater than or equal to .30) downward trends for period 2 and period T. At well A2, the shallowest at this site, SC had strong downward trends for periods 1,2 , and $\mathrm{T}$. Thus the trend in SC at all three site A wells was either no trend, weakly downward, or strongly downward. At C2, the fourth transitionzone well, SC had a strong upward trend for period 1 and no trend for period 2; the trend for period T was weakly upward. Thus the trends for this well indicate a lessening of factors causing salinity to increase. At the four transition-zone wells, it therefore appears that over time there is a trend toward less salinity or a cessation in increasing salinity.

For the freshwater-zone wells, SC has a notable temporal pattern at well $\mathrm{C} 1$ : SC shows several increases and decreases over time, with the most marked changes during period 1 (fig. 7). The temporal pattern in $\mathrm{SC}$ at $\mathrm{C} 1$ is very different from those at the other wells, which are monotonic. The cyclic pattern observed in the SC data was not observed at any other wells, and likely reflects a high degree of surface-water/ ground-water interaction resulting from the cavern penetrated by well $\mathrm{C} 1$. It is highly dissimilar from the $\mathrm{SC}$ trends observed at transition-zone well $\mathrm{C} 2$, which is screened below the RDM at the same site. The overall trend at $\mathrm{C} 1$ is strongly upward for period $\mathrm{T}$, with no trend for periods 1 or 2, although the lack of trend for the shorter periods might result from the relatively small number of data points within the time-grouped datasets.

At the two site D wells, both freshwater-zone wells, the temporal trends in SC are different from each other. At well D1, completed below the RDM, there is a weak downward trend for period 1 , no trend for period 2, and a weak downward trend for period T. This is similar to the pattern of trends in the transition-zone wells. At well D2, completed above the $\mathrm{RDM}$, there is a weak upward trend for period 1 , no trend for period 2, and a weak upward trend for period T. The RDM might act as a semiconfining unit, with different geochemical processes occurring above and below it.

The general trend in SC at the southern site along the transect (A wells; saline water) is downward, with the strongest downward trend at the shallowest well (A2). However, that pattern reverses at the middle site along the transect $(\mathrm{C}$ wells), with the deeper of the two wells (C2 screened below the RDM and containing saline water) having a general upward trend. At the northern site along the transect (D wells; freshwater), the deeper well (D1) has a downward trend and the shallower well (D2) has an upward trend. There is no systematic change in the direction of trend in SC by water type (saline or fresh), between sites, or with depth.

\section{Major Ions and Major Ion Ratios}

In general, trends in major ions correspond, as might be expected, with those in SC. The major ions with the greatest number of temporal trends were $\mathrm{Ca}, \mathrm{Cl}, \mathrm{Na}$, and $\mathrm{SO}_{4}$ (table 10). For example, at well A2 there were numerous strong downward trends, particularly for period $\mathrm{T}$, and at well $\mathrm{C} 1$ there were numerous strong upward trends for period $\mathrm{T}$. Two or more strong trends occurred at all wells except the site D wells, at which there were no strong trends. In most instances the trend at a well was consistent for all three periods, with either the same direction of trend for all three periods or a mix of no trend and the same type of trend for all three periods. The only reversals of trend occurred at well $\mathrm{C} 2$ for $\mathrm{Si}$, for which the trend was downward for period 1 and upward for period 2, and at well D1 for $\mathrm{Mg}$, for which the trend was downward for period 1 and upward for period 2. At any well, the direction of the trend was consistent for SC, $\mathrm{Cl}, \mathrm{K}, \mathrm{Na}$, and $\mathrm{SO}_{4}$, but trends for $\mathrm{HCO}_{3}, \mathrm{Ca}, \mathrm{F}, \mathrm{Mg}$, and $\mathrm{Si}$ sometimes were opposite of those of the other major ions. This might indicate a common source for $\mathrm{Cl}, \mathrm{K}, \mathrm{Na}$, and $\mathrm{SO}_{4}$, likely the saline zone. In contrast, the source of $\mathrm{HCO}_{3}$ and $\mathrm{Ca}$ (and $\mathrm{Mg}$, to a lesser extent) is dissolution of calcium carbonate, and the concentrations are controlled by calcite equilibrium and dissolution kinetics.

Temporal trends in molar ratios of major ions $\mathrm{Mg}: \mathrm{Ca}$, $\mathrm{SO}_{4}: \mathrm{Cl}, \mathrm{Mg}: \mathrm{Na}$, and $\mathrm{Na}: \mathrm{Cl}$ were tested. In only three cases were the trends strong (table 10). The greatest number of trends was for $\mathrm{SO}_{4}: \mathrm{Cl}$ (eight); $\mathrm{SO}_{4}: \mathrm{Cl}$ had a strong downward trend in two cases, and $\mathrm{Mg}$ :Ca had a strong upward trend in 
A.

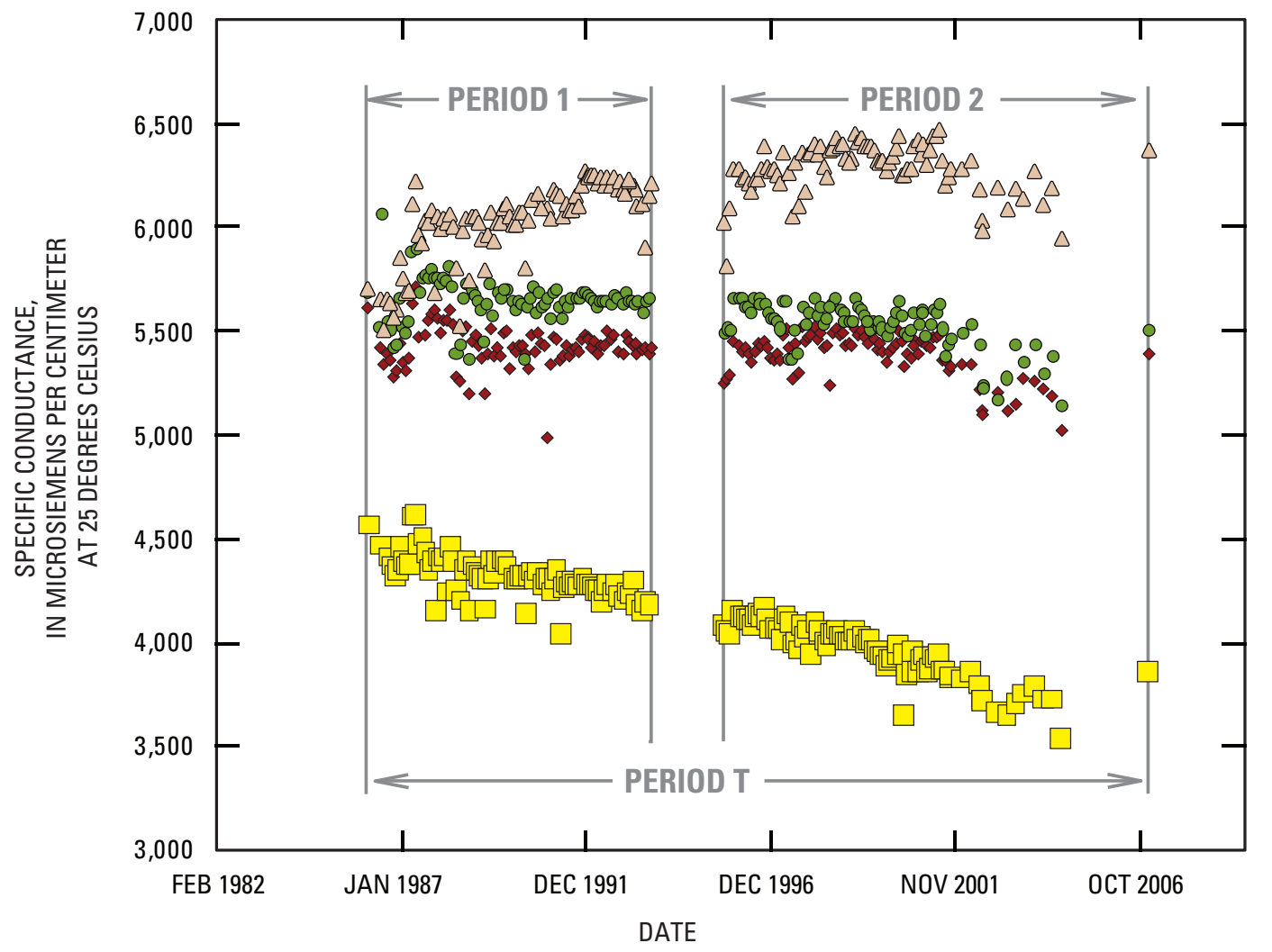

\section{EXPLANATION}

Transition-zone wells

$\diamond \mathrm{A} 1$

$\square \quad A 2$

- A 3

$\triangle \quad C 2$

Period 1 (M arch or J uly 1986September 1993) Period 2 (January 1996-

December 2006)

Period T (M arch or July 1986December 2006)
B.

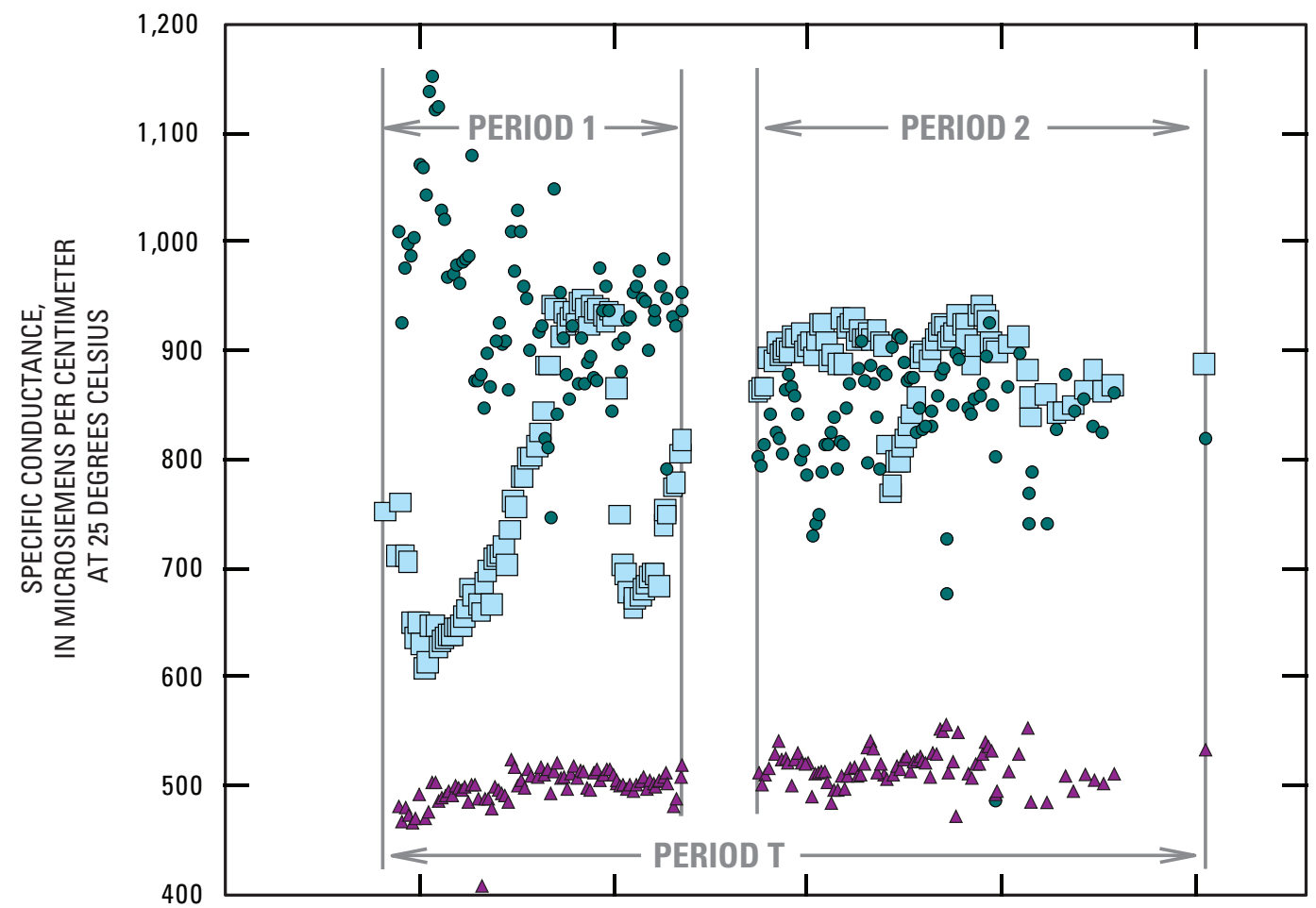

EXPLANATION

Freshwater-zonewells

$\square \mathrm{Cl}$

- D1

$\Delta$ D2

Period 1 (M arch or J uly 1986September 1993)

Period 2 (January 1996-

December 2006)

Period T (M arch or July 1986December 2006)

Figure 7. Specific conductance datasets, $(A)$ transition zone and (B) freshwater zone, for seven monitoring wells transecting the freshwater/saline-water interface, San Antonio, Texas. 
Table 10. Summary of temporal trends in major ion concentrations and major ion molar ratios for water (1986-2006) at seven wells transecting the freshwater/saline-water interface of the Edwards aquifer, San Antonio, Texas.

[Strong trend (coefficient of determination or Kendall's tau greater than or equal to .30) in blue; statistics computed using Kendall's tau shaded gray; SC, specific conductance; -, no significant (at .05 level) trend; D, significant (at .05 level) downward trend; U, significant (at .05 level) upward trend]

\begin{tabular}{|c|c|c|c|c|c|c|c|c|c|c|c|c|c|c|c|}
\hline \multirow[b]{2}{*}{$\begin{array}{l}\text { Well } \\
\text { (fig. 2) }\end{array}$} & \multirow[b]{2}{*}{$\begin{array}{c}\text { Time } \\
\text { period }^{1}\end{array}$} & \multicolumn{14}{|c|}{ Constituent } \\
\hline & & SC & $\begin{array}{l}\text { Bicar- } \\
\text { bonate }\end{array}$ & $\begin{array}{l}\text { Cal- } \\
\text { cium }\end{array}$ & $\begin{array}{l}\text { Chlo- } \\
\text { ride }\end{array}$ & $\begin{array}{l}\text { Fluo- } \\
\text { ride }\end{array}$ & $\begin{array}{l}\text { Magne- } \\
\text { sium }\end{array}$ & $\begin{array}{l}\text { Potas- } \\
\text { sium }\end{array}$ & Silica & Sodium & $\begin{array}{l}\text { Sul- } \\
\text { fate }\end{array}$ & $\begin{array}{l}\text { Mag- } \\
\text { nesium: } \\
\text { calcium }\end{array}$ & $\begin{array}{l}\text { Sulfate: } \\
\text { chloride }\end{array}$ & $\begin{array}{c}\text { Mag- } \\
\text { nesium: } \\
\text { sodium }\end{array}$ & $\begin{array}{l}\text { Sodium: } \\
\text { chloride }\end{array}$ \\
\hline \multirow[t]{3}{*}{ A1 } & 1986-1993 & - & - & - & D & - & - & - & D & D & D & - & - & - & - \\
\hline & 1996-2006 & D & - & - & - & $\mathrm{U}$ & - & - & - & - & - & - & - & - & - \\
\hline & 1986-2006 & D & D & $\mathrm{U}$ & D & - & - & - & - & D & D & - & D & $\mathrm{U}$ & - \\
\hline \multirow[t]{3}{*}{$\mathrm{A} 2$} & 1986-1993 & D & D & D & D & D & D & - & - & D & D & U & - & - & U \\
\hline & 1996-2006 & D & - & D & D & - & D & D & - & D & D & - & - & U & - \\
\hline & 1986-2006 & D & D & D & D & U & D & - & - & D & D & - & - & U & - \\
\hline \multirow[t]{3}{*}{ A3 } & 1986-1993 & - & - & - & D & - & - & - & - & D & D & - & - & - & U \\
\hline & 1996-2006 & D & - & - & D & U & - & D & U & D & D & - & D & - & - \\
\hline & 1986-2006 & D & D & - & D & $\mathrm{U}$ & - & - & - & D & D & D & D & - & - \\
\hline \multirow[t]{3}{*}{$\mathrm{C} 1$} & 1986-1993 & - & - & - & - & - & - & - & - & - & - & - & - & - & - \\
\hline & 1996-2006 & - & - & - & - & - & - & - & - & - & - & - & D & - & - \\
\hline & 1986-2006 & $\mathbf{U}$ & - & $\mathbf{U}$ & $\mathbf{U}$ & $\mathbf{U}$ & $\mathbf{U}$ & U & $\mathrm{U}$ & U & $\mathbf{U}$ & $\mathbf{U}$ & - & D & - \\
\hline \multirow[t]{3}{*}{$\mathrm{C} 2$} & 1986-1993 & $\mathbf{U}$ & - & U & - & - & U & U & $\mathrm{D}$ & - & - & - & - & - & - \\
\hline & 1996-2006 & - & - & - & U & U & - & - & $\mathrm{U}$ & - & - & - & D & - & - \\
\hline & 1986-2006 & $\mathrm{U}$ & U & $\mathbf{U}$ & $\mathbf{U}$ & U & $\mathbf{U}$ & U & $\mathrm{U}$ & $\mathrm{U}$ & - & D & D & - & - \\
\hline \multirow[t]{3}{*}{ D1 } & 1986-1993 & D & - & U & $\mathrm{D}$ & - & D & - & D & - & D & - & - & U & - \\
\hline & 1996-2006 & - & - & - & - & $\mathrm{U}$ & $\mathrm{U}$ & - & - & - & - & $\mathrm{U}$ & D & - & - \\
\hline & 1986-2006 & D & D & D & D & U & D & D & D & D & D & - & - & $\mathrm{U}$ & $\mathrm{D}$ \\
\hline \multirow[t]{3}{*}{ D2 } & 1986-1993 & U & - & U & U & - & U & - & D & $\mathrm{U}$ & U & - & - & D & $\mathrm{D}$ \\
\hline & 1996-2006 & - & - & U & U & - & U & - & - & U & U & - & - & - & - \\
\hline & 1986-2006 & U & D & U & $\mathrm{U}$ & U & - & - & - & U & U & - & D & D & D \\
\hline
\end{tabular}

${ }^{1}$ 1986-1993, period 1 (March or July 1986-September 1993); 1996-2006, period 2 (January 1996-December 2006); 1986-2006, period T (March or July 1986-December 2006).

one case. The small number of strong trends indicates that the geochemical composition of the water at the wells varies less than the major ion concentrations, consistent with the hypothesis that dilution is the dominant process affecting the geochemistry.

\section{Trace Elements}

Temporal trends in trace elements were tested with the Kendall tau test for those datasets in which the number of detections was 50 percent or more. Because data were collected on an annual basis, all data for a trace element at a well were tested together without dividing them into two periods. In all cases, either there was no trend or the trend was downward (table 11). Fe was the trace element with the most downward trends; concentrations decreased over time in three of the four transition-zone wells (A1, A3, and C2) and in the deeper freshwater-zone well at the D site (well D1). A decrease in Fe might result from an increase in the oxidation condition in these wells: Under reducing conditions, Fe generally occurs as $\mathrm{Fe}^{+2}$, which is soluble; under oxidizing conditions, Fe generally occurs as $\mathrm{Fe}^{+3}$, which is much less soluble. Thus as water becomes more oxidizing, the concentration of Fe in solution will tend to decrease. 
Table 11. Summary of temporal trends in trace element concentrations for water (1986-2006) at seven wells transecting the freshwater/saline-water interface of the Edwards aquifer, San Antonio, Texas.

[Data tested for datasets with 50 percent or more detections; strong trend (Kendall's tau greater than or equal to .30) in bold; na, not available; -, no significant (at .05 level) trend; D, significant (at .05 level) downward trend]

\begin{tabular}{|c|c|c|c|c|c|c|c|c|c|c|c|c|}
\hline $\begin{array}{c}\text { Well } \\
\text { (fig. 2) }\end{array}$ & \multicolumn{12}{|c|}{ Trace element } \\
\hline $\mathrm{A} 2$ & na & - & na & na & na & - & na & na & na & na & na & na \\
\hline $\mathrm{A} 3$ & na & - & na & na & na & D & na & na & na & na & na & na \\
\hline $\mathrm{C} 2$ & na & - & na & na & na & D & na & na & na & na & na & na \\
\hline D1 & na & - & na & na & na & D & na & - & na & na & na & - \\
\hline D2 & na & - & na & na & na & - & na & - & na & na & na & D \\
\hline
\end{tabular}

\section{Relations between Geochemistry and Hydrologic Indicator Variables}

To determine if hydrologic conditions were affecting the geochemical composition of the ground water at six of the seven wells, the relations between geochemical variables (SC, major ion concentrations, and major ion molar ratios) and two hydrologic indicators (water level and $\mathrm{P}_{\text {eff }}$, defined and described in the "Indicators of Hydrologic Condition" section) were investigated for concurrent correlation and time-lagged correlation, as described in the "Statistical Methods" section. For those relations where conditions for use of linear correlation were met, the linear correlation between the geochemical variables and a variety of measures of the hydrologic indicators was computed. For the given sampling date, the correlation was computed between the geochemical variable and concurrent or prior time-averaged water level-specifically the maximum water level (J-17 index well) on the day of sample collection, and between the geochemical variable and moving average of maximum daily water level for 7, 30, 60, and 90 days, 6 months, and 1 year prior to sample collection (fig. 8). The correlation also was computed between the geochemical variable and concurrent or prior time-averaged $\mathrm{P}_{\text {eff }}$ - specifically the $\mathrm{P}_{\text {eff }}$ on the day of sampling, and between the geochemical variable and mean daily $\mathrm{P}_{\text {eff }}$ for $7,15,30$, and 90 days prior to sampling.

To better investigate the effect of prior hydrologic conditions on the aqueous geochemistry at the seven wells, multilag correlation (as described in the "Statistical Methods" section) with a lag from 0 to 15 was used to investigate relations between the geochemical variable and water level at the J-17 well. Because data were collected monthly, a lag of 0 to 15 corresponds to a time lag of 0 (instantaneous) to 15 months at 1-month intervals. Data for period 1 and period 2 were tested separately.

\section{Correlations between Specific Conductance, Major lons, and Major Ion Ratios and Water Level}

Conditions for use of linear correlation were met for relations between $\mathrm{SC}$, major ion concentrations, and major ion ratios and water level at all wells except $\mathrm{C} 1$ and $\mathrm{C} 2$, for which alternative analyses of data are described in the "Statistical Methods" section. Relations between SC and major ion concentrations at well $\mathrm{C} 1$ and water level are discussed at the end of this section. Significant correlations between concentrations of major ions and multiple temporal measures of water level in the $\mathrm{J}-17$ well, and between four major ion molar ratios and the same measures of water level are summarized in table 12. Correlations between geochemical variables and measures of water level in the freshwater-zone wells were much more frequent than correlations between geochemical variables and measures of water level in the transition-zone wells.

There were correlations between SC and all measures of water level at the two freshwater-zone wells tested with linear correlation (D1, D2), but there were no correlations between SC and any measures of water level at any of the transition-zone wells (A1, A2, A3, and C2). At well D2, the correlation was negative, meaning that as water level in the well increased (water level is assumed to represent a regional increase in head in the aquifer), the SC at the well tended to decrease. This negative correlation was strongest for the water level on the same day the SC measurement was made, indicating that the geochemistry of water in well D2 reacts rapidly to changes in water level in the J-17 index well. In contrast, the correlation between SC and water level for well D1 was positive, indicating that as water level in the aquifer increases, the water in well D1 becomes more mineralized. Although this relation is counterintuitive, as rising water level in the freshwater part of the aquifer might be expected to dilute 


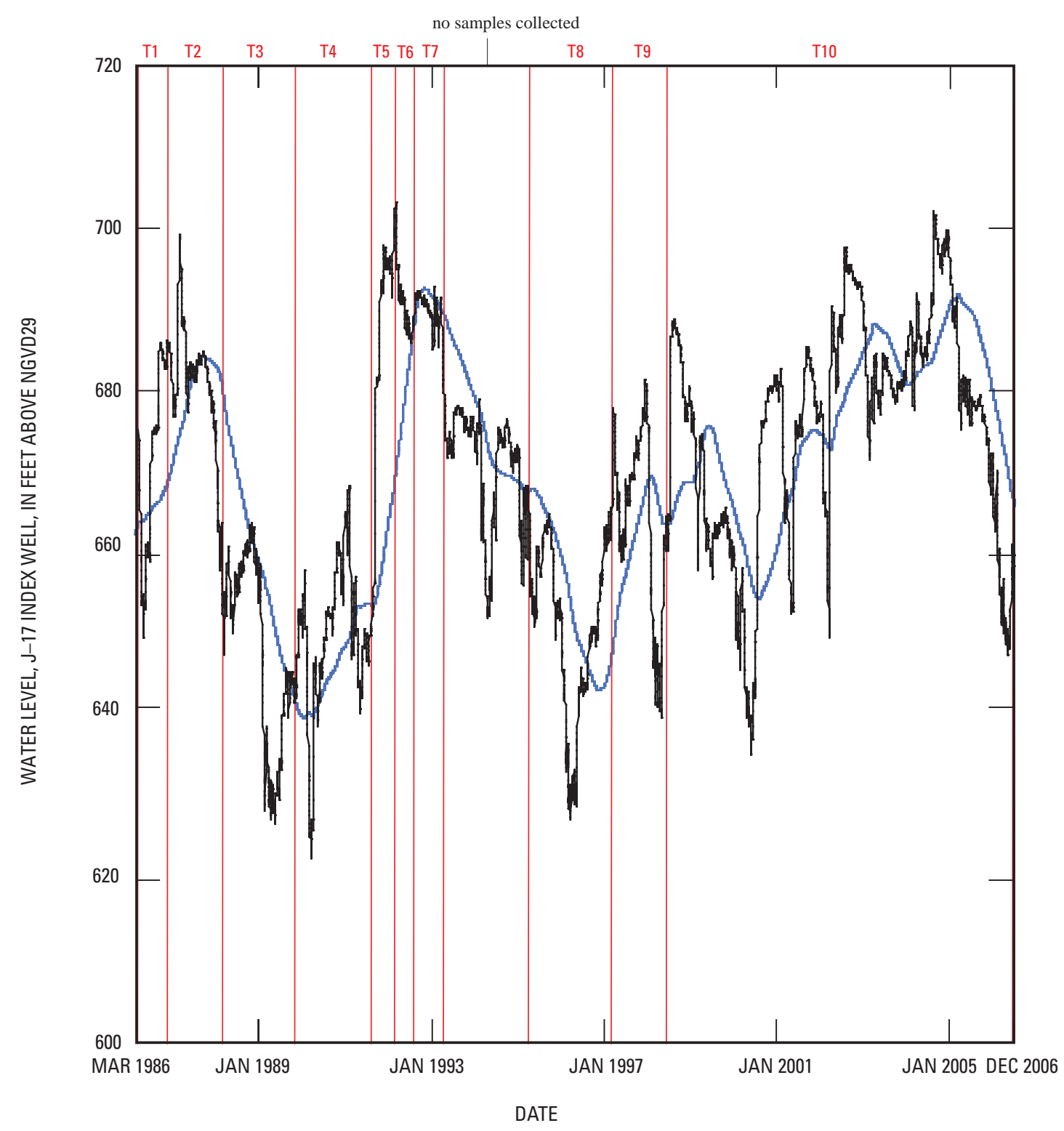

EXPLANATION

Daily maximum water level, well J - 17

1-year moving annual average of daily maximum water level, well J - 17

T5 Time interval (table 13) for computation of daily mean water level

Figure 8. Daily maximum water level and 1-year moving average of daily maximum water level in the J-17 index well, San Antonio, Texas, 1986-2006, and time intervals (T1-T10) used for piecewise analysis of the relation between geochemical variables at freshwaterzone well $\mathrm{C} 1$ and water level in the $\mathrm{J}-17$ index well. 
Table 12. Correlations, as indicated by Pearson's r, between specific conductance, major ion concentrations, and major ion molar ratios in water (1986-2006) and water level in the J-17 index well, Edwards aquifer, San Antonio, Texas.

[Although all correlations tested, Pearson's $r$ shown only for statistically significant (at .05 level) correlations; strongest correlation for each variable at each well (largest Pearson's $r$ for each variable at each well) in bold; TZ, transition zone; --, no statistically significant correlation; FWZ, freshwater zone; SC, specific conductance]

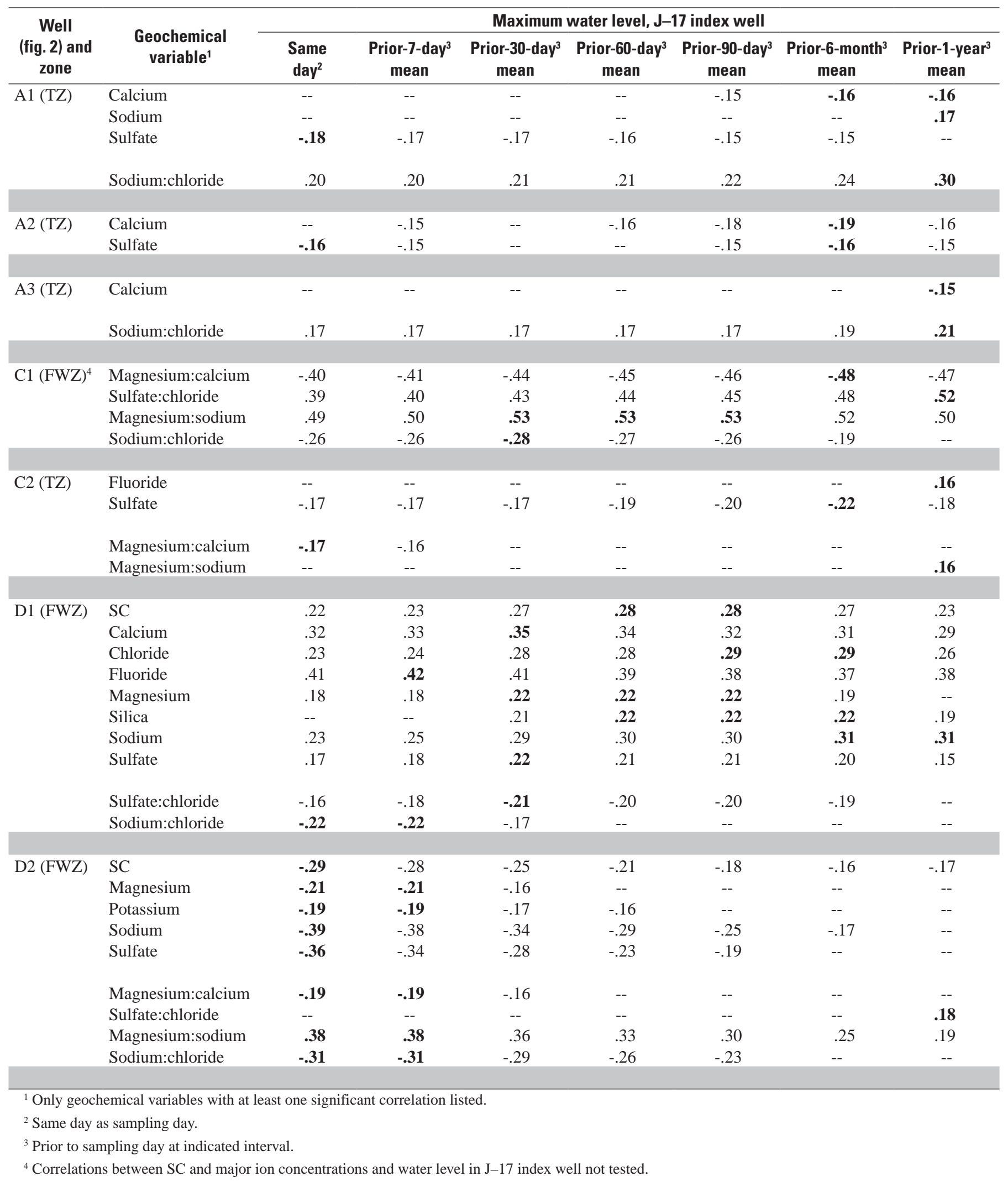


more saline water and result in a decrease in $\mathrm{SC}$, a positive correlation between SC and water level has been observed at other freshwater-zone wells in the San Antonio segment of the Edwards aquifer (Harden, 1968, p. 12) and at freshwater-zone wells in the Barton Springs segment of the Edwards aquifer (Garner and Mahler, 2006). The correlation at well D1 was strongest for the 60- and 90-day mean water levels prior to SC measurement, indicating a reaction time slower than that at well D2.

There were few correlations between major ion concentrations and water level at the transition-zone wells (table 12), and they were relatively weak (absolute value of Pearson's $r$ from .15 to .22). Most correlations were between $\mathrm{Ca}$ and water level (wells A1, A2, and A3) and between $\mathrm{SO}_{4}$ and water level (wells A1, A2, and C2). These correlations in all cases were negative, indicating that as water level in the aquifer increases, concentrations of these major ions tend to decrease. The correlations between $\mathrm{Ca}$ and water level were strongest for mean water levels representing the longer time periods (6 months to 1 year); in contrast, the correlations between $\mathrm{SO}_{4}$ and water level were strongest at wells A1 and A2 for water levels recorded the same day as samples were collected, but correlations were strongest at well $\mathrm{C} 2$ for the prior-6-month mean water level.

There were multiple correlations between major ion concentrations and water level at freshwater-zone wells D1 and D2 (table 12). There were significant correlations between $\mathrm{Mg}, \mathrm{Na}$, and $\mathrm{SO}_{4}$ and water level at both wells, but as with $\mathrm{SC}$, the correlation was negative at well D2 and positive at well D1. At well D2, the strongest correlations were for water levels measured on the same day that the samples were collected. The strongest correlations at well D1 mostly were for mean water levels representing intermediate prior periods of time (30 days to 6 months).

Except at wells C1 and D2, major ion molar ratios were only weakly correlated with water level (absolute value of Pearson's $r$ of .30 or less). The major ion ratio with the most correlations was $\mathrm{Na}: \mathrm{Cl}$. In the two transition-zone wells (A1 and $\mathrm{A} 3$ ) at which $\mathrm{Na}: \mathrm{Cl}$ was correlated with water level, the correlation was positive. In all three freshwater-zone wells the correlation was negative. At wells C1 and D2, all four major ion molar ratios were correlated with water level. The correlations were strongest at well $\mathrm{C} 1$, and tended to be strongest for mean water level for an intermediate to long period preceding sample collection. At well D2, the correlations for all ratios except $\mathrm{SO}_{4}: \mathrm{Cl}$ were strongest between the major ion ratio and the water level measured on the same day the sample was collected and between the major ion ratio and the prior-7-day mean water level.

The piecewise relations between $\mathrm{SC}$ and major ion concentrations in well $\mathrm{C} 1$ and water level in the J-17 index well were investigated by dividing the sampling period into 10 time intervals, T1 through T10 (fig. 9; table 13); during each interval the relation was relatively consistent. SC and major ion concentrations for each interval were tested for linear correlation with each of the temporal measures of water level (table 14). SC is correlated with at least one of the temporal measures of water level for eight of the 10 time intervals; for six of those time intervals the strongest of the correlations between SC and one of the temporal measures of water level is very strong ( $r$ greater than .9). Numerous very strong relations also exist between at least one of the measures of water level and concentrations of $\mathrm{Na}, \mathrm{Cl}$, and $\mathrm{SO}_{4}$, which are those major ions associated with transition-zone (saline) water. $\mathrm{HCO}_{3}$ has the fewest correlations with water level. In most cases, when there is a correlation between a constituent concentration and water level, the correlation is negative, meaning that the concentration of the constituent decreases as the water level in the index well increases. The most numerous and strongest linear relations for a given temporal measure of water level occurred during T3, T5, T7, and T9; and these are either for the prior60-day mean well level or for the prior-1-year mean well level.

Relations between SC and major ion concentrations at well $\mathrm{C} 1$ and water level in the J-17 index well were statistically related, but not monotonic (fig. 9). Rather, at some times there is a strong linear relation between water level and the different geochemical variables, but in a piecewise fashion: The strong linear relation lasts for time intervals as short as 8 months to as long as 7 years. The linear relation is not the same from one time interval to the next, and a given water level might correspond to a different SC or constituent concentration at different times. The same type of relation occurs for some major ions, including $\mathrm{Cl}, \mathrm{Na}$, and $\mathrm{SO}_{4}$.

If taken piecewise, the relations between $\mathrm{SC}$ and major ions and water level are much stronger at well $\mathrm{C} 1$ than at any of the other wells. Although the relations between the geochemical variables and water level are different for each time interval, on the basis of SC the water in the well appears to be becoming more mineralized and less sensitive to changes in water level with time (fig. 9): For a given water level, SC tends to be lower during the earlier time intervals, and for the most recent and longest time interval (T10, 1999-2006), SC has varied relatively little even though water level has continued to fluctuate.

\section{Correlations between Specific Conductance, Major lons, and Major Ion Ratios and Effective Rainfall}

Correlations between geochemical variables (SC, major ion concentrations, and four major ion molar ratios) and several temporal measures of $\mathrm{P}_{\text {eff }}$ as defined and described in the "Indicators of Hydrologic Condition" section are summarized in table 15. There were fewer correlations between geochemical variables and $\mathrm{P}_{\text {eff }}$ than between geochemical variables and water level.

$\mathrm{SC}$ was correlated with $\mathrm{P}_{\text {eff }}$ at all freshwater-zone wells and at one transition-zone well (A3). All SC correlations with $\mathrm{P}_{\text {eff }}$ were negative except at well D1. Correlations were not as strong as they were between geochemical variables and water level. 
A.

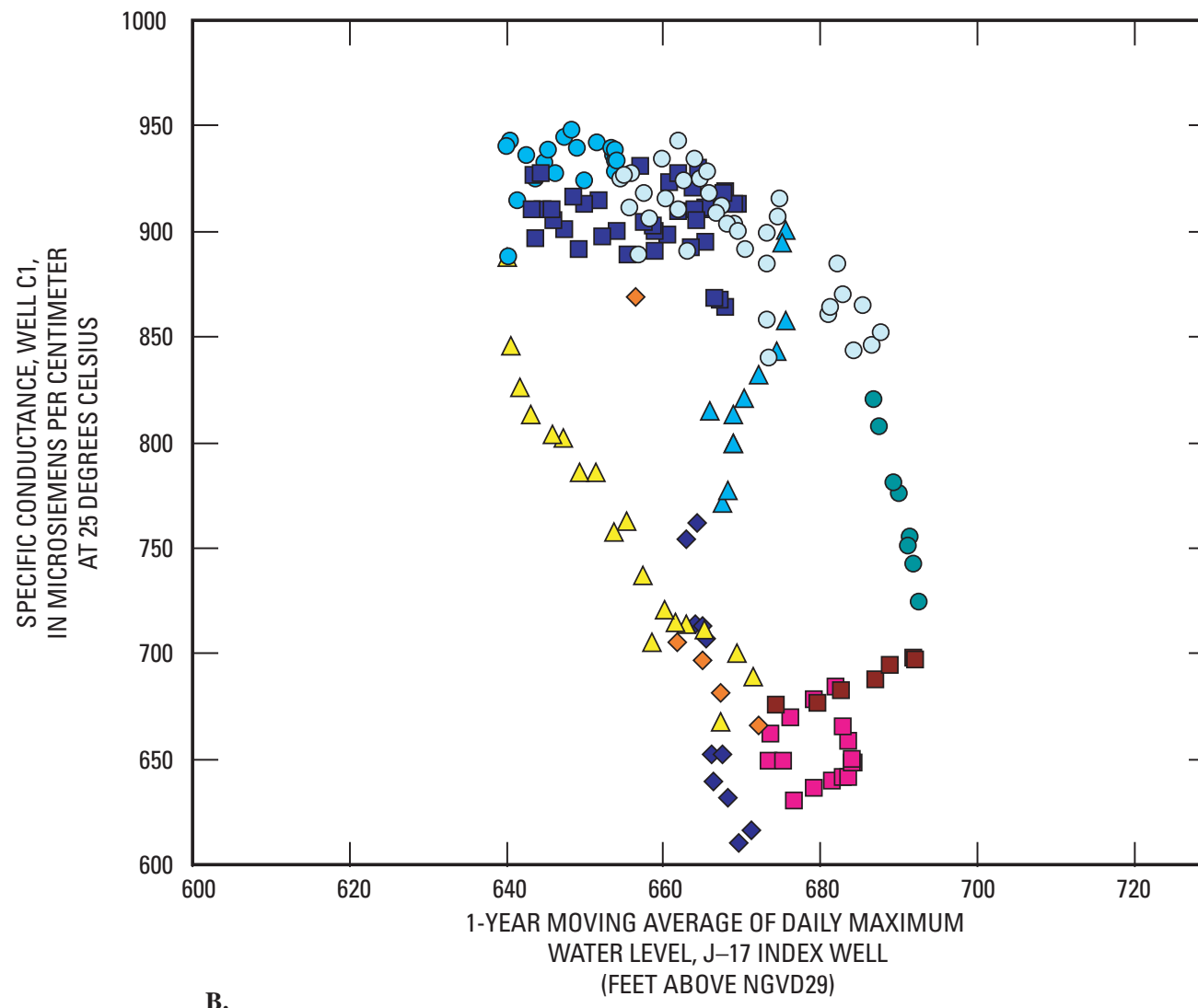

B.

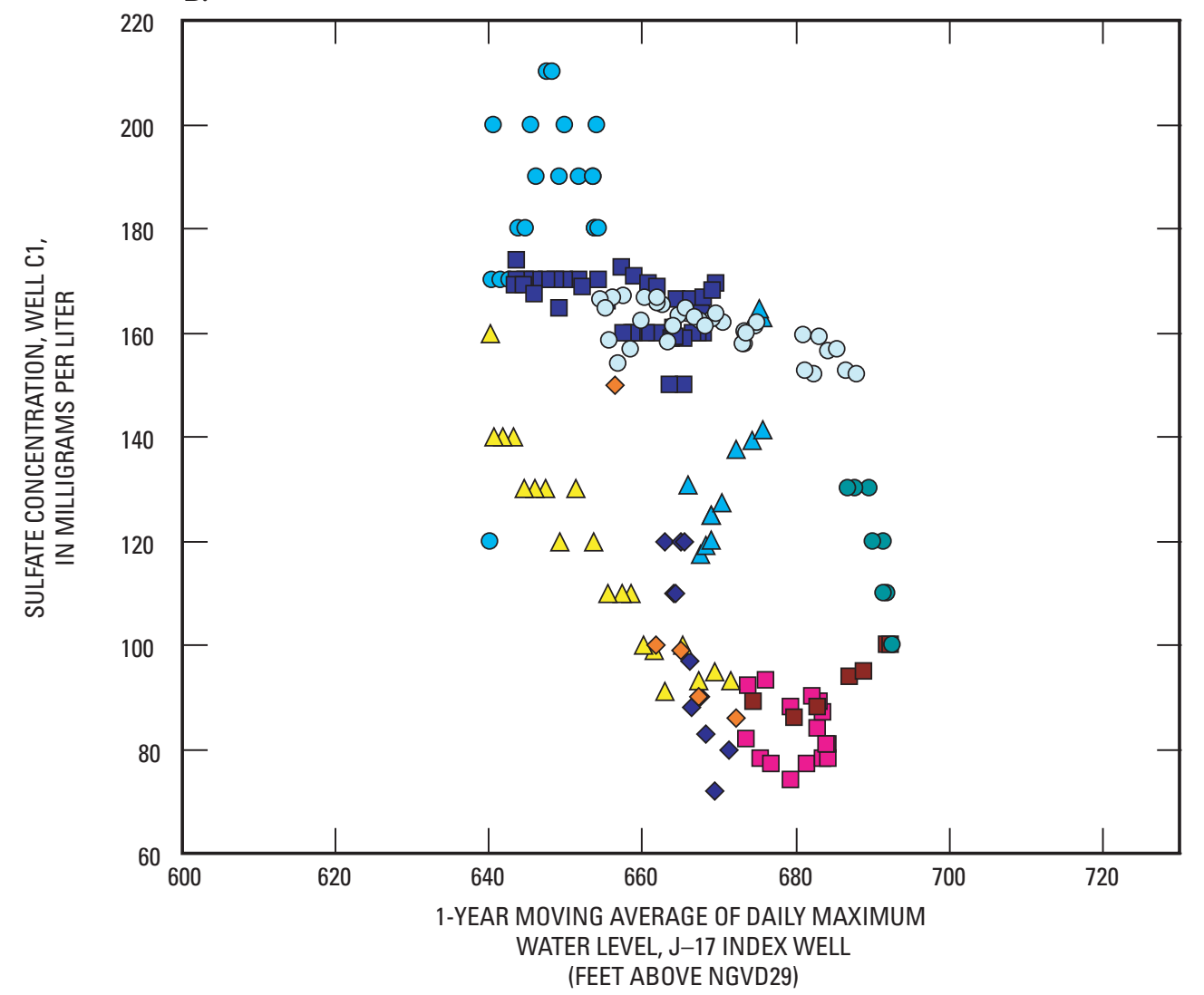

\section{EXPLANATION}

Time intervals (table 13)

$\diamond \mathrm{T} 1$

$\square \mathrm{T} 2$

$\triangle \mathrm{T} 3$

○ $\mathrm{T4}$

$\diamond \mathrm{T} 5$

口 T6

- T7

口 T8

$\triangle \mathrm{T} 9$

○ T10

Figure 9. Relations between (A) specific conductance and (B) sulfate concentration at freshwater-zone well C1 and 1-year moving average of daily maximum water level in the J-17 index well, San Antonio, Texas, for 10 time intervals, March 1986-November 2006. 
Table 13. Summary of time periods and intervals analyzed for concurrent and multilag correlation between specific conductance and major ion concentrations in water (1986-2006) at well $\mathrm{C} 1$ and water level in the $\mathrm{J}-17$ index well, Edwards aquifer, San Antonio area, Texas.

\begin{tabular}{ccc}
\hline Time period & $\begin{array}{c}\text { Time } \\
\text { interval }\end{array}$ & $\begin{array}{c}\text { Interval begin and end } \\
\text { dates }\end{array}$ \\
\hline $\begin{array}{ccc}\text { Period 1 (March or July 1986- } \\
\text { September 1993) }\end{array}$ & T1 & $3 / 13 / 1986-4 / 17 / 1987$ \\
T2 & $5 / 21 / 1987-8 / 24 / 1988$ \\
T3 & $9 / 21 / 1988-4 / 23 / 1990$ \\
T4 & $5 / 21 / 1990-12 / 23 / 1991$ \\
T5 & $1 / 21 / 1992-6 / 29 / 1992$ \\
T6 & $7 / 20 / 1992-1 / 12 / 1993$ \\
Deriod 2 (January 1996- & T7 & $2 / 19 / 1993-9 / 27 / 1993$ \\
& T8 & $1 / 1 / 1996-10 / 28 / 1998$ \\
& T9 & $11 / 23 / 1998-10 / 19 / 1999$ \\
& T10 & $11 / 16 / 1999-11 / 19 / 2006$ \\
\hline
\end{tabular}

Similar to the relations between geochemical variables and water level, there were more correlations between a major ion concentration and $\mathrm{P}_{\text {eff }}$ at the freshwater-zone wells than at the transition-zone wells. However, there were few consistencies among wells regarding which major ions were correlated with $\mathrm{P}_{\text {eff }}$, with only $\mathrm{SO}_{4}$ correlated with $\mathrm{P}_{\text {eff }}$ at all freshwaterzone wells. Of the transition-zone wells, correlations between major ion concentrations and $\mathrm{P}_{\text {eff }}$ at well $\mathrm{A} 1$ were positive, the single correlation at well $\mathrm{C} 2$ was negative, and correlations at well A3 were positive and negative. Of the freshwater-zone wells, most of the correlations at well $\mathrm{C} 1$ and all but one of the correlations at well D2 were negative, and most of the correlations at well D1 were positive. At all freshwater-zone wells, the strongest correlations between concentrations of major ions and $\mathrm{P}_{\text {eff }}$ were for the mean of the longest time period tested, 90 days. This might reflect the lag between rainfall and its arrival at the water table following infiltration. The strongest relations between concentrations of major ions and $\mathrm{P}_{\text {eff }}$ were at well D2. This might indicate that well D2 receives more diffuse infiltration from rainfall than do wells $\mathrm{C} 1$ and D1.

There was a more consistent relation between at least one of the major ion ratios and $\mathrm{P}_{\text {eff }}$ at the wells (table 15) than there was between major ion ratios and water level (table 12). The $\mathrm{Mg}$ :Ca ratio was negatively correlated with $\mathrm{P}_{\text {eff }}$ at every well, although at different lag times. This might be caused by meteoric water, which is acidic and dissolves calcium carbonate relatively rapidly as it infiltrates. The dissolution of high magnesium calcite rocks proceeds more slowly, therefore the $\mathrm{Mg}$ :Ca ratio might be expected to decrease in response to infiltration of meteoric water. There were no other consistent relations at the transition-zone wells, but $\mathrm{Na}: \mathrm{Cl}$ was correlated with $\mathrm{P}_{\text {eff }}$ at all of the freshwater-zone wells; the correlation was positive at well $\mathrm{C} 1$ and negative at wells D1 and D2.

\section{Multilag Correlations Between Specific Conductance and Selected Major Ions and Water Level}

It is reasonable to expect that there might be a lag between a hydrologic event, as measured by hydrologic indicators such as water level and $\mathrm{P}_{\text {eff }}$, and a geochemical response because of the time required for water to move through an aquifer. In fact, Harden (1968) hypothesized that because a positive correlation between SC and water level at some wells was counterintuitive, perhaps the correlation was actually negative, but that the response lagged behind the input signal sufficiently that the correlation appeared to be positive when SC was compared to the concurrent water level. (This is likely to occur only if there are regularly spaced increases and decreases in the input signal.) To investigate whether there was a delay between an increase in water level and a geochemical response at the wells, a multilag cross-correlation model was used to compare relations between geochemical variables ( $\mathrm{SC}$; major ion concentrations $\mathrm{Ca}, \mathrm{Cl}, \mathrm{Mg}, \mathrm{Na}$, and $\mathrm{SO}_{4}$; and major ion ratios $\mathrm{Mg}: \mathrm{Ca}, \mathrm{SO}_{4}: \mathrm{Cl}, \mathrm{Mg}: \mathrm{Na}$, and $\mathrm{Na}: \mathrm{Cl}$ ) in six of the seven wells (all but $\mathrm{C} 1$ ) and water level in the $\mathrm{J}-17$ index well from 1 to 15 months prior to collection of each sample. The relations for period 1 and period 2 were tested separately. Results for a lag of 0 will differ from those determined by linear correlation for the complete dataset (table 12) because the cross-correlation coefficient was computed for two different periods, as required because of the need for a continuous dataset with no gaps. Well C1 was not included in the analysis because of its highly nonlinear response to changes in water level, as discussed in the "Correlations Between Specific Conductance, Major Ions, and Major Ion Ratios and Water Level" section.

The results of the cross-correlation analysis are shown in table 16. Although the correlations mostly were consistent in sign for period 1 and period 2 for each relation tested, the lag with the strongest correlation was not. For about 55 percent of the significant correlations for each well and period, the strongest correlation was at a lag of 1 or more months between water level and the maximum major ion concentration response, and for about 45 percent of the relations, the strongest correlations were at a lag of 0 .

For the transition-zone wells, SC at wells A1 and C2 was positively correlated with water level in the J-17 index well, and SC at well A2 was negatively correlated with water level, with the strongest correlation for a lag of 2 months at well C2. For the freshwater-zone wells, SC at well D2 was negatively correlated with water level, and SC at well D1 was positively correlated with water level. At both wells D1 and D2, the strongest correlation was for a lag of 4 or 5 months, although for well D1 this occurred for period 1 and for well D2 for 
Table 14. Correlations, as indicated by Pearson's $r$, between specific conductance and major ion concentrations in water (1986-2006) at well C1, and concurrent and time-averaged prior water levels in the J-17 index well, Edwards aquifer, San Antonio, Texas.

[Although all correlations tested, Pearson's r shown only for statistically significant (at .05 level) correlations; strongest correlation for each variable for each time interval (largest Pearson's r for each variable for each time interval) in bold; SC, specific conductance; -, no statistically significant correlation]

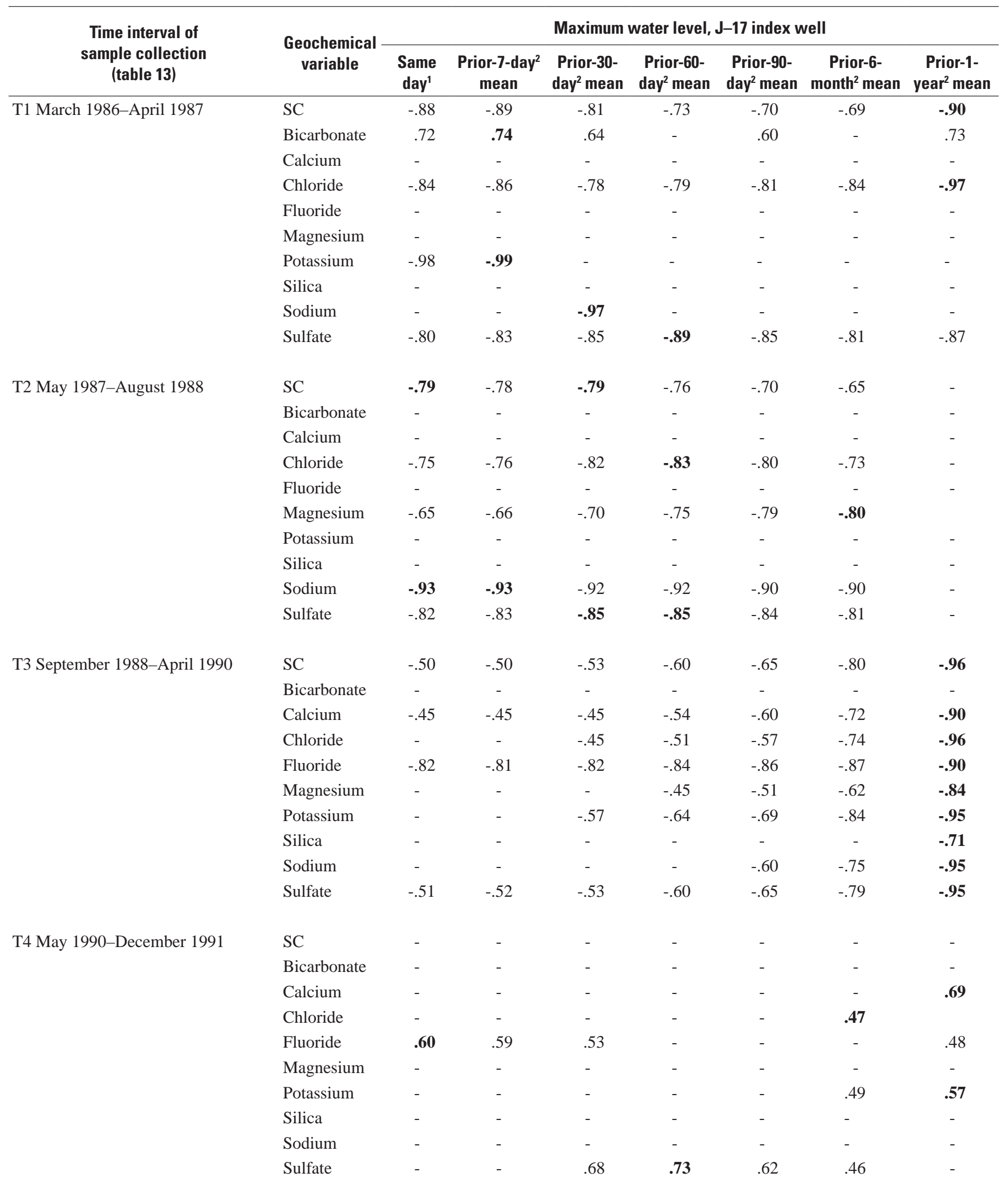


Table 14. Correlations, as indicated by Pearson's r, between specific conductance and major ion concentrations in water (1986-2006) at well C1, and concurrent and time-averaged prior water levels in the J-17 index well, Edwards aquifer, San Antonio, TexasContinued.

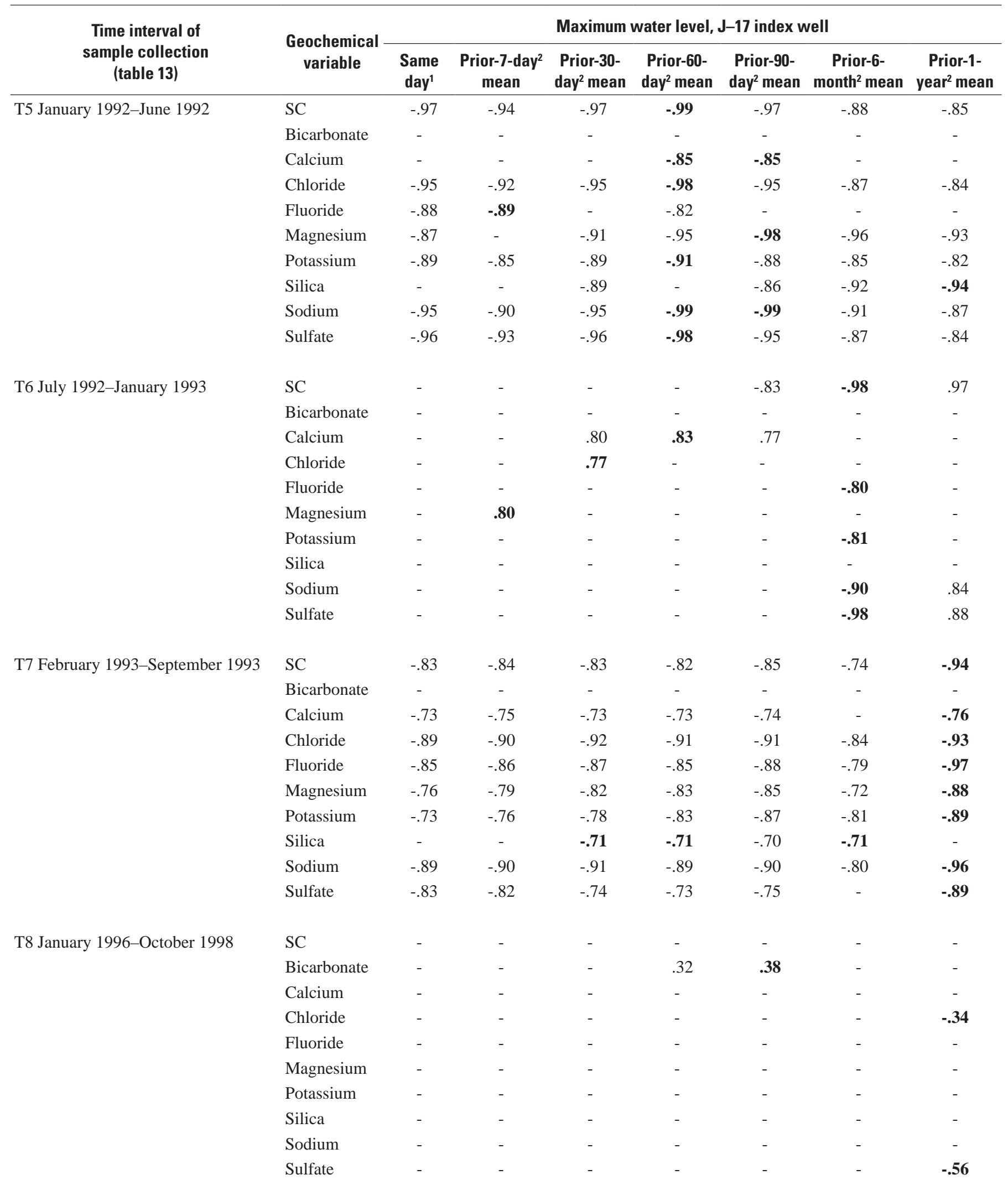


Table 14. Correlations, as indicated by Pearson's $r$, between specific conductance and major ion concentrations in water (1986-2006) at well $\mathrm{C} 1$, and concurrent and time-averaged prior water levels in the J-17 index well, Edwards aquifer, San Antonio, TexasContinued.

\begin{tabular}{|c|c|c|c|c|c|c|c|c|}
\hline $\begin{array}{l}\text { Time interval of } \\
\text { sample collection } \\
\text { (table 13) }\end{array}$ & $\begin{array}{l}\text { Geochemical } \\
\text { variable }\end{array}$ & \multicolumn{7}{|c|}{ Maximum water level, J-17 index well } \\
\hline \multirow{6}{*}{ T9 November 1998-October 1999} & Bicarbonate & - & - & - & - & - & - & - \\
\hline & Calcium & -.64 & -.68 & -.75 & -.87 & -.84 & - & .65 \\
\hline & Magnesium & -.81 & -.84 & -.83 & -.89 & -.87 & - & .74 \\
\hline & Potassium & -.72 & -.74 & -.74 & -.83 & -.88 & - & .64 \\
\hline & Silica & - & - & - & - & - & - & - \\
\hline & Sodium & -.87 & -.89 & -.89 & -.94 & -.91 & - & .81 \\
\hline \multirow{9}{*}{ T10 November 1999-November 2006} & Bicarbonate & - & - & - & - & - & - & - \\
\hline & Calcium & .34 & - & .34 & .34 & .35 & .36 & .40 \\
\hline & Chloride & -.49 & -.51 & -.58 & -.60 & -.58 & -.51 & -.61 \\
\hline & Fluoride & - & - & - & - & - & - & - \\
\hline & Magnesium & - & - & - & - & - & - & - \\
\hline & Potassium & - & - & - & - & - & - & - \\
\hline & Silica & -.46 & -.48 & -.46 & -.51 & -.54 & -.50 & - \\
\hline & Sodium & - & - & - & - & - & - & -.33 \\
\hline & Sulfate & -.61 & -.62 & -.65 & -.66 & -.64 & -.57 & -.67 \\
\hline
\end{tabular}

${ }^{1}$ Same day as sampling day.

${ }^{2}$ Prior to sampling day at indicated interval.

period 2. At well D1 there was an equally strong correlation for a lag of 0 for period 2 .

Among the four transition-zone wells, there were some consistencies regarding the correlations between major ion concentrations and water level. $\mathrm{Mg}$ was positively correlated with water level at three of the four wells (A1, A3, and C2), with the strongest correlation at $\mathrm{A} 1$ and $\mathrm{C} 2$ for a lag of 0 , and at $\mathrm{A} 3$ for a lag of 2 months. $\mathrm{SO}_{4}$ and water level were negatively correlated at all four wells, with the strongest correlations at lags of either 0 or 1 month. Between the two freshwater-zone wells, little consistency in correlations between major ion concentrations and water level is apparent.

There were relatively few correlations between major ion ratios and water level at the transition-zone wells at any lags. There was no correlation between $\mathrm{Mg}$ :Ca and water level at any of the four wells, and a correlation between $\mathrm{Na}: \mathrm{Cl}$ and water level only at wells A1 and A3. There was, however, a correlation between $\mathrm{Mg}: \mathrm{Na}$ and $\mathrm{SO}_{4}: \mathrm{Cl}$ and water level at three wells. The strongest correlations between $\mathrm{Mg}: \mathrm{Na}$ and water level occurred at a lag of 2 or 3 months, and between $\mathrm{SO}_{4}: \mathrm{Cl}$ and water level at a lag of 0 to 1 month.

In contrast, there were a number of correlations between major ion ratios and regional water level at the freshwater- zone wells. $\mathrm{Mg}$ :Ca was negatively correlated with water level at wells D1 and D2, with the strongest correlation at a lag of 0 , which might indicate an influx of chemically aggressive meteoric water that dissolves calcium carbonate. $\mathrm{SO}_{4}: \mathrm{Cl}$ also was correlated with water level at both wells; the correlation was positive at well D2 and negative at well D1. Again, the strongest correlations were for a lag of 0 , indicating that the geochemistry of these wells responds rapidly to a change in water level. In contrast, although there was a relatively strong correlation between $\mathrm{Na}: \mathrm{Cl}$ and water level in period 1 (crosscorrelation coefficients of -0.41 and -0.55 for D1 and D2, respectively), it occurred for relatively long lags ( 9 and 11 months, respectively), indicating that this geochemical relation might be responding to a different process than the others.

\section{Synthesis of Results of the Statistical Analysis}

A number of inferences regarding the geochemical variability at the seven monitoring wells along the transect can be drawn from the results of the statistical analyses. These include differences in the geochemical variability and trends between the transition-zone wells and the freshwater-zone 
Table 15. Correlations, as indicated by Pearson's $r$, between specific conductance, major ion concentrations, and major ion molar ratios in water (1986-2006) and effective rainfall, Edwards aquifer, San Antonio, Texas.

[Although all correlations tested, Pearson's $r$ shown only for statistically significant (at .05 level) correlations; strongest correlation for each variable for each well (largest Pearson's $r$ for each variable for each well) in bold; TZ, transition zone; --, no statistically significant correlation; FWZ, freshwater zone; SC, specific conductance]

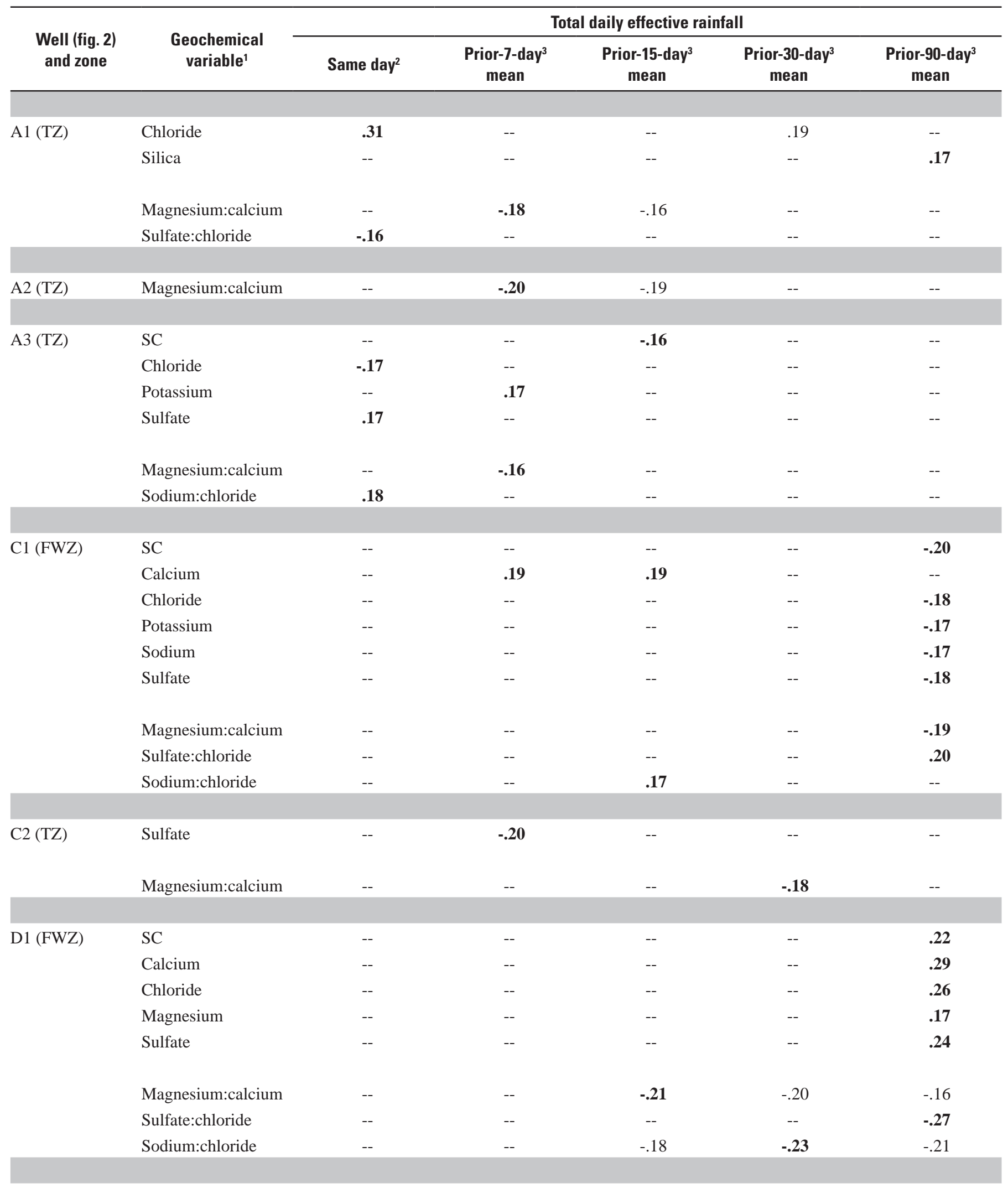


Table 15. Correlations, as indicated by Pearson's r, between specific conductance, major ion concentrations, and major ion molar ratios in water (1986-2006) and effective rainfall, Edwards aquifer, San Antonio, Texas-Continued.

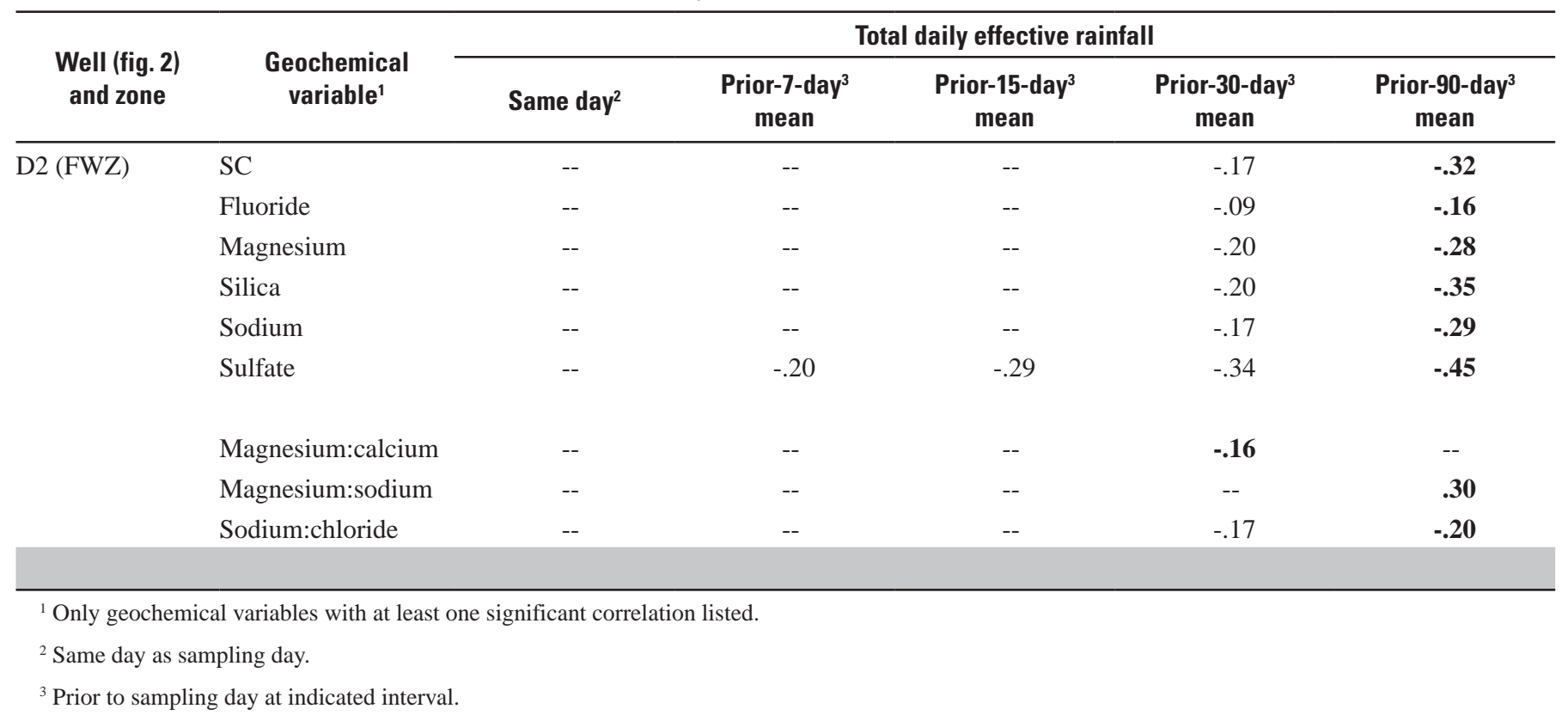

wells, the process or processes most likely affecting variability, the relations to aquifer water level, and the lack of a general trend in response either with depth or with position across the transect.

In general, the geochemistry at the freshwater-zone wells is more variable than that at the transition-zone wells, and much of the variability in three of the four transition-zone wells might result from the use of different laboratory analytical methods or reporting procedures during the period of sampling (U.S. Geological Survey, 2008). The greater variability at the freshwater-zone wells relative to the transitionzone wells is reflected in the larger coefficient of variation for several major ions (table 4). At the freshwater-zone wells, $\mathrm{SC}$ is strongly and positively correlated to concentrations of several major ions, but at the transition-zone wells SC is not correlated with concentrations of major ions. Because SC is a "master" variable reflecting the combined influence of the major ion concentrations, a lack of correlation indicates that the variability is largely random and likely attributable to analytical variability.

Two lines of evidence indicate that the principal process, other than analytical artifact, causing the variability in the geochemistry at the freshwater-zone wells and at one transitionzone well (well A2) is dilution by meteoric water. First, all correlations between major ion concentrations and all correlations between trace element concentrations are positive, which would be unlikely to result from any process other than dilution. Second, the PCA results indicate dilution as the principal process affecting the geochemical variability. For freshwaterzone wells C1 and D1, the major ions are strongly loaded on a single PC, and this PC explains most of the variance in the data. This result indicates that a single process controls the variability and that this same single process causes all major ion concentrations to increase or decrease simultaneously. Wells C1 and D1 are drilled through a cavern and a fault zone, respectively, which provide potential pathways for inflow of meteoric water. For freshwater-zone well D2 and transitionzone wells A2 and C2, a similar loading on the first PC is seen, but less variability is explained by that PC. Thus dilution nonetheless appears to be a major factor controlling variability in the aqueous geochemistry at wells that do not obviously penetrate highly transmissive zones such as caves or faults. In a karst area such as that of the transect, wells might penetrate zones that have undergone dedolomitization (Groschen, 1994), zones with small fractures, or zones with other features that might enhance transmissivity. For transition-zone wells A1 and $\mathrm{A} 3$, the variability is explained in relatively equal amounts by five PCs, indicating that there is no dominant process or processes affecting the variability.

There are significant temporal trends in SC and major ion concentrations for 1986-2006, but the trends are not consistent among the transition-zone wells or among the freshwater-zone wells (table 10). All three wells at transition-zone site A have an overall downward trend in SC, and for those major ion concentrations that show a trend, the trend is mostly downward. The most and strongest trends were at well A2, which is the shallowest site A well. Additionally, at wells A1 and A3 there is a downward trend in Fe concentrations (table 11), which would result from a decrease in salinity and an increase in oxidizing conditions. However, at transition-zone well C2, temporal trends in SC and most major ions are mostly upward. Direction of trend also is not consistent among the freshwaterzone wells-at wells C1 and D2, the overall trends in SC and most major ions generally are upward. At well C1, short-term 


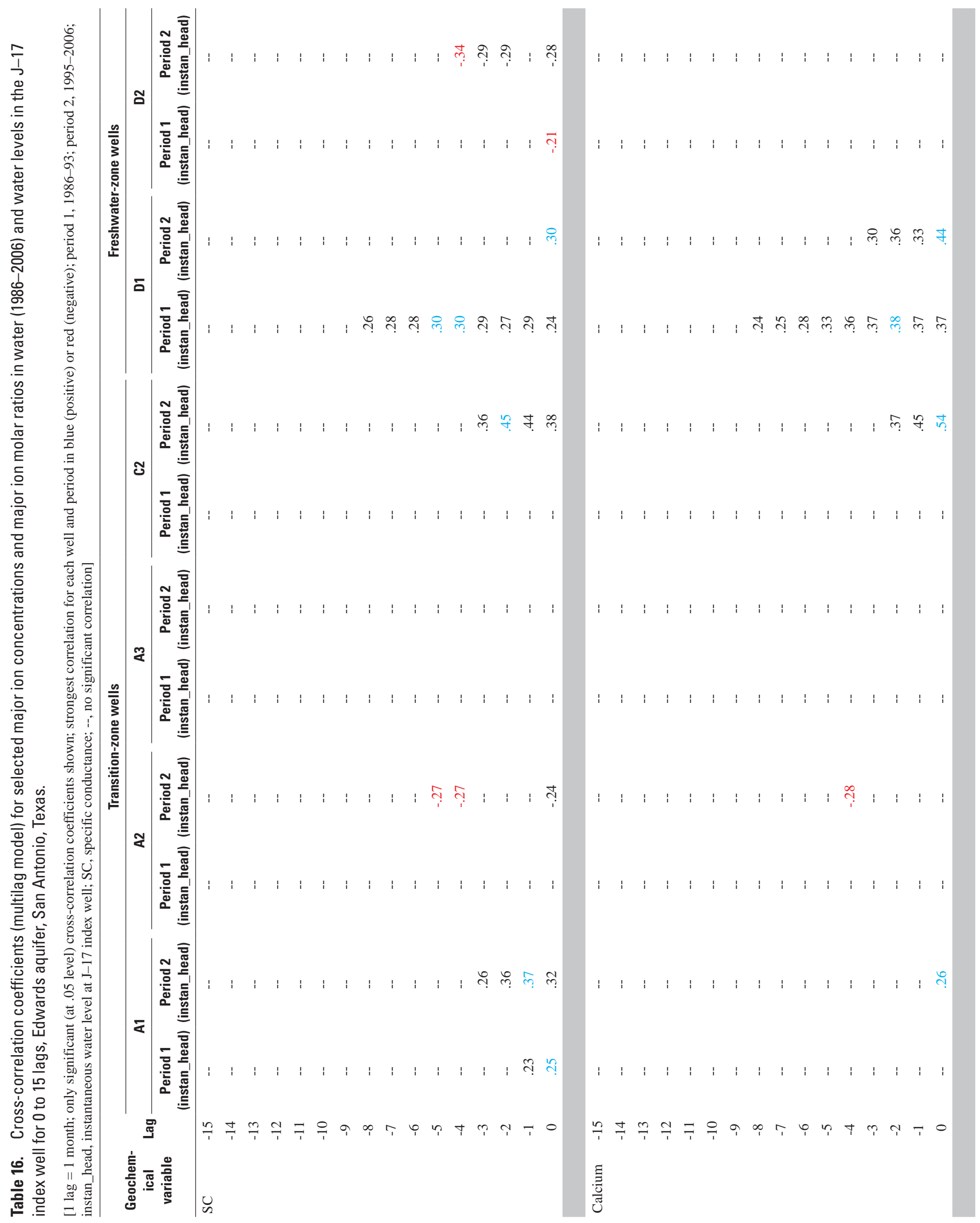




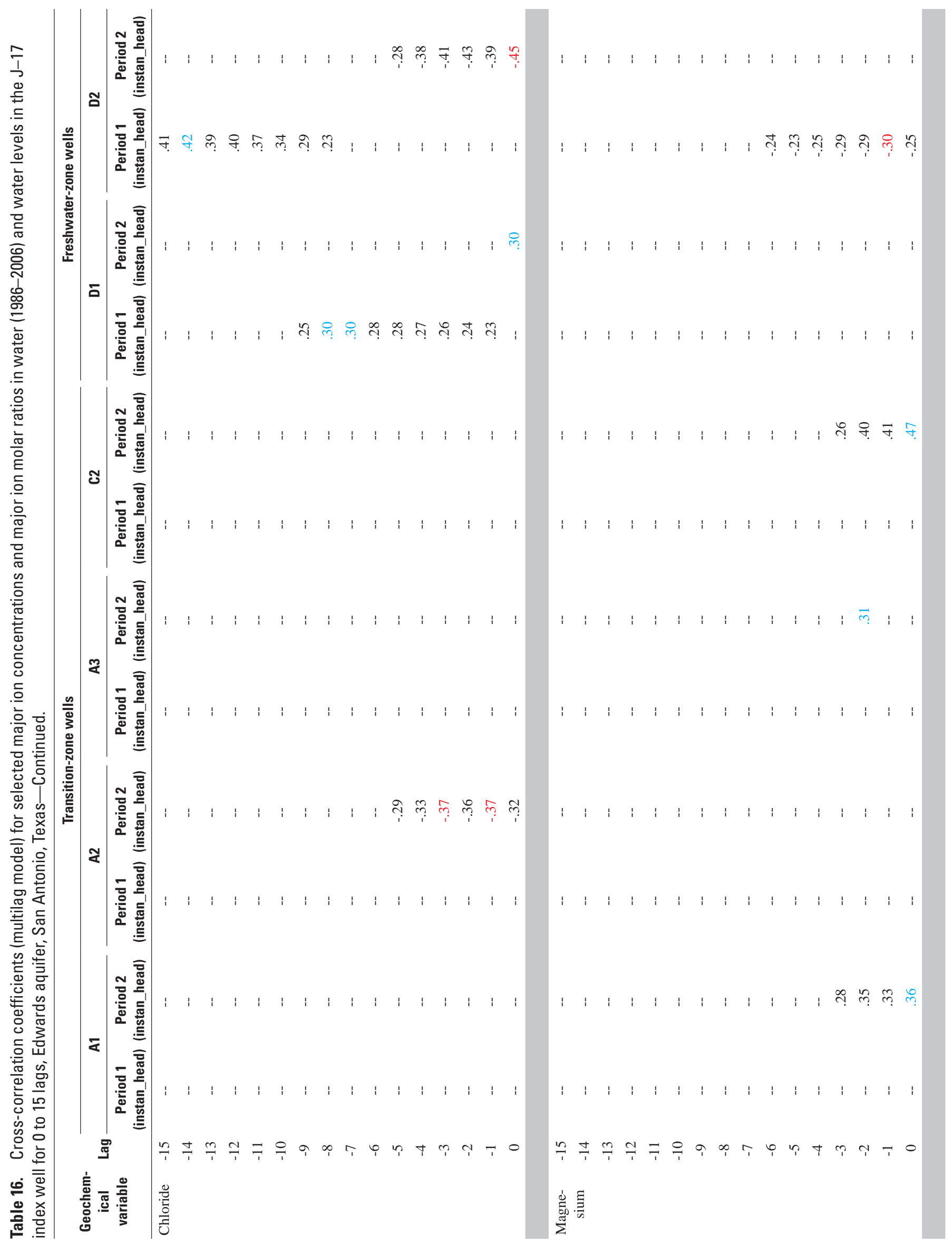




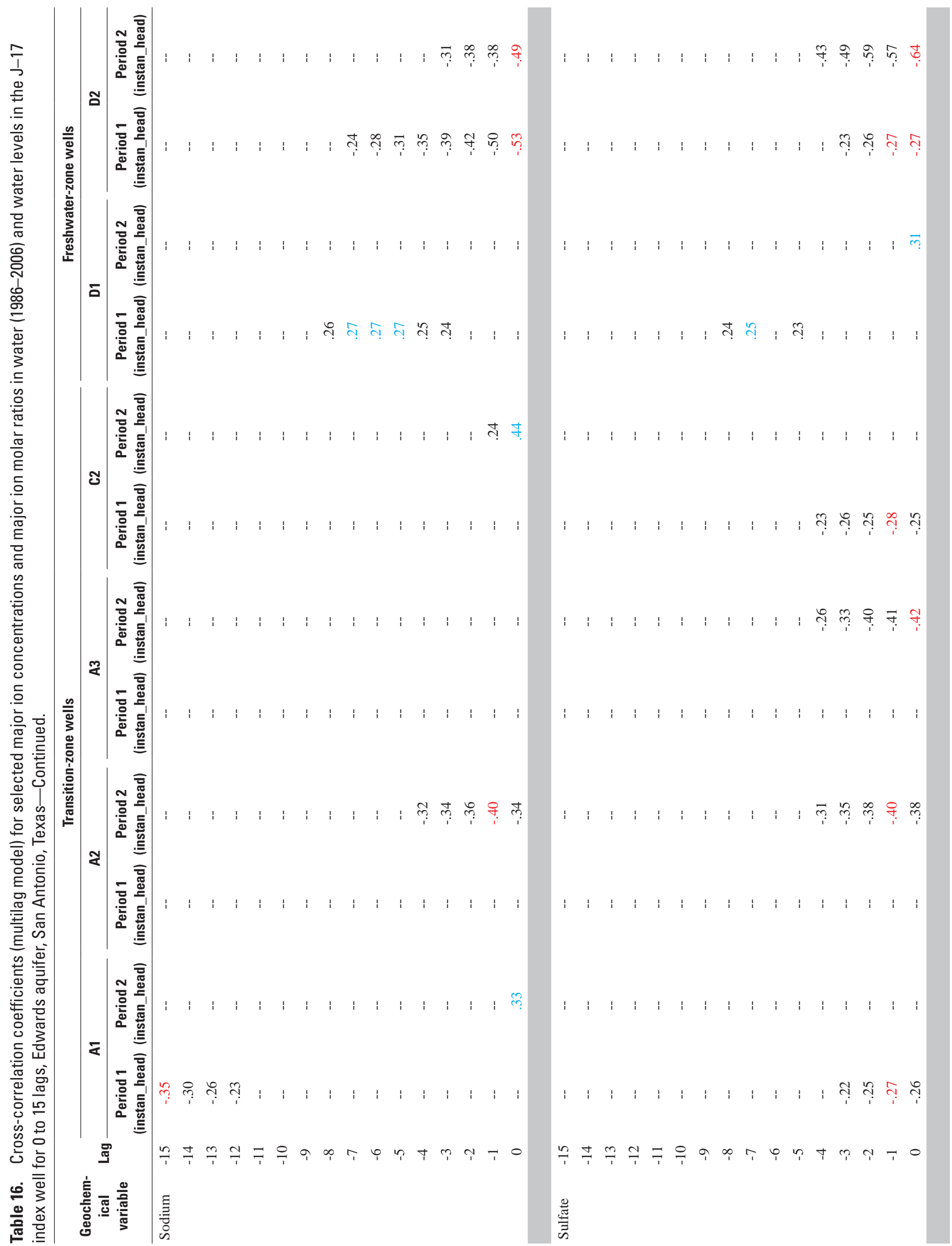




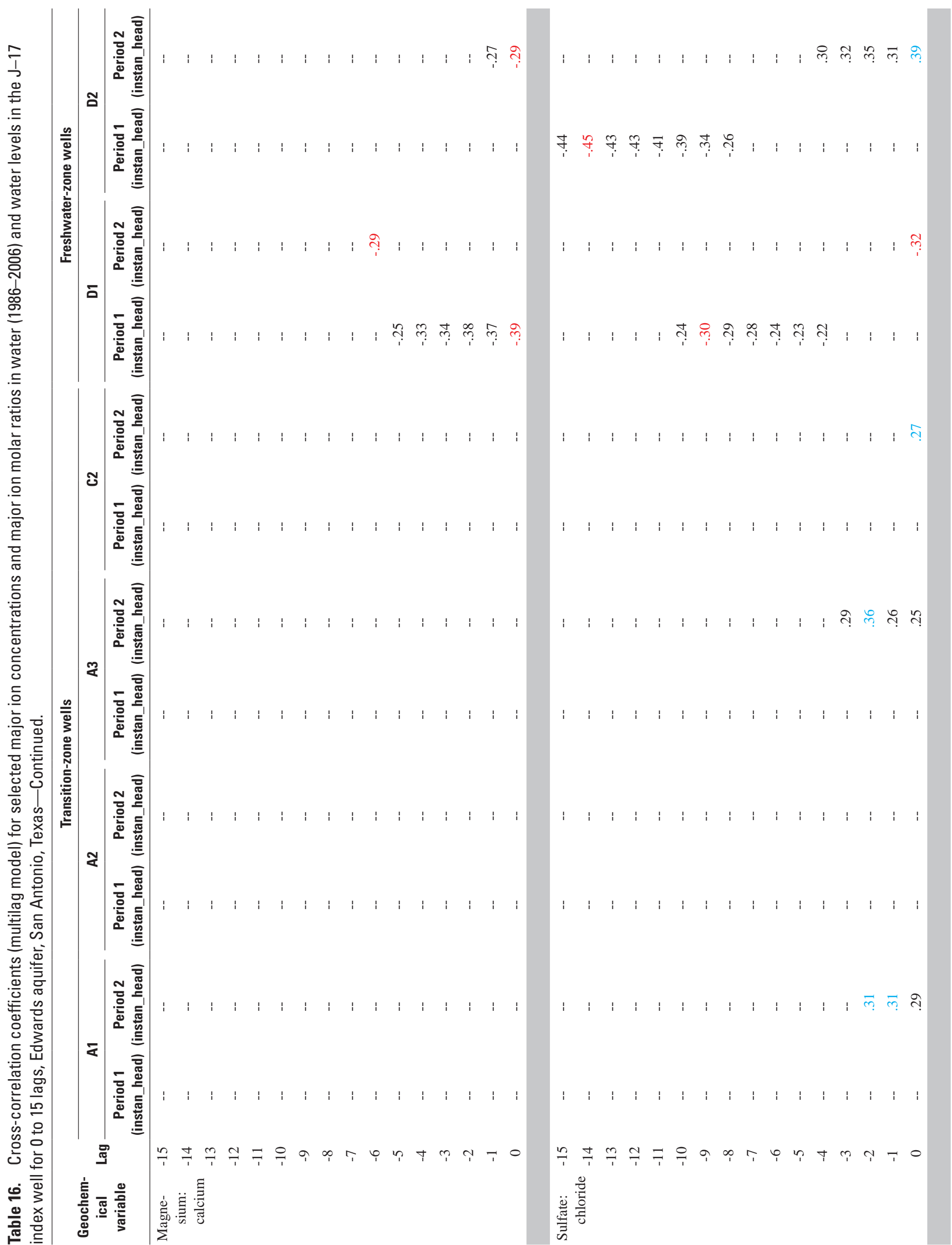




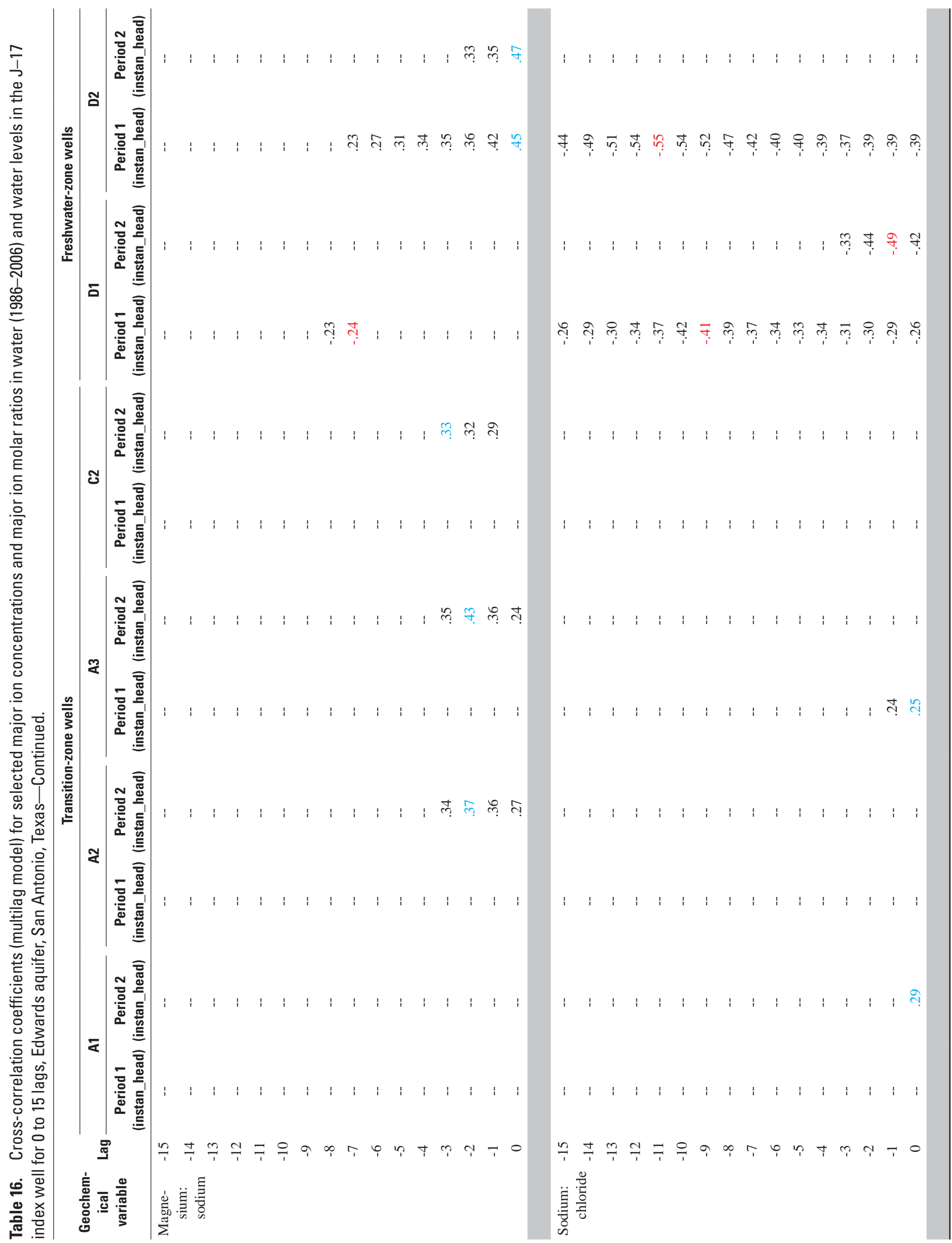


trends correlate strongly with changes in water level, but this relation is not linear through time. At well D1, trends in SC and major ions concentrations generally are downward.

Of the two hydrologic indicators tested for correlation with SC, major ion concentrations, and major ion molar ratios, maximum daily water level (concurrent or prior timeaveraged) at the $\mathrm{J}-17$ index well correlated more frequently with the geochemical variables than did $\mathrm{P}_{\text {eff }}$ (concurrent or prior time-averaged). The pattern of correlation at the transition-zone wells was different from that at the freshwater-zone wells. At the transition-zone wells there were few correlations between the geochemical variables and the hydrologic indicators measured concurrently with the samples. However, when the relations were tested using cross correlation, which involves relations with a lag in the response, there were some stronger correlations, as discussed in the next paragraph. At transition-zone well A2, the correlations between the geochemical variables and prior time-averaged values of the two hydrologic indicators (tables 12,15) were negative, consistent with the hypothesis of dilution indicated by the PCA; but at wells A1, A3, and C2 there were both negative and positive correlations. At freshwater-zone wells C1 (table 15) and D2 (tables 12, 15), SC and major ion concentrations tended to be negatively correlated with the hydrologic indicators, again consistent with dilution of the ground water by meteoric water as interpreted from the PCA. In contrast, although the PCA indicated dilution as the controlling geochemical process at well D1, SC and major ion concentrations at this well were positively correlated with the hydrologic indicators. The positive correlations indicate that dilution is occurring when water levels and rainfall rates are low rather than high. Although this response is counterintuitive, it is consistent with the geochemical response at other wells in the San Antonio segment of the Edwards aquifer (Harden, 1968), as well as with the geochemical response at some wells in the Barton Springs segment of the Edwards aquifer (Garner and Mahler, 2006), and does not appear to result from a lag between the hydrologic signal and the geochemical response. Ground-water geochemistry near the freshwater/saline-water interface also might be correlated with other hydrologic indicators not tested here, such as pumping rate and streamflow in creeks flowing over, and losing water to the aquifer, in the recharge zone. In the Barton Springs segment of the Edwards aquifer, for example, concentrations of several major ions and nitrate are more strongly correlated with estimated total recharge through creek beds than they are with aquifer water level as represented by spring discharge (Mahler and others, 2006).

The lag times corresponding to the strongest correlations were different at the transition-zone wells compared with those at the freshwater-zone wells. The strongest correlations between geochemical variables and water level that occurred at the transition-zone wells in many cases were for lag times of 3 to 5 months. In contrast, the strongest correlations at the freshwater-zone wells tended to be at a lag of 0 - that is, coincident with the time of sample collection. This result indicates that the freshwater-zone wells tend to respond rapidly to changes in hydrologic conditions, and the transition-zone wells respond more slowly. It also demonstrates that, for the transition-zone wells, some correlations might not be identified if a multilag correlation model is not used.

The statistical analyses indicate that, although the transition-zone wells are less well connected to surficial hydrologic conditions than the freshwater-zone wells, there is some connection but the response time is longer. The geochemistry at the transition-zone wells is less variable than that at the freshwater-zone wells, as indicated by the coefficient of variation. However, at lags of 1 to 5 months, in several instances variability in SC, major ion concentrations, and major ion ratios is relatively well correlated with water level in the J-17 index well. Of the four transition-zone wells, well A2, which is the shallowest, shows the most connection to the freshwater zone of the aquifer: It has more geochemical variability, it appears to be affected by dilution as indicated by the PCA, and there are more and stronger cross-correlations between major ions and water level in the index well relative to the other transition-zone wells.

The analyses indicate that the freshwater-zone wells are closely connected to surficial hydrologic conditions, but that the three of them have very different responses. Well C1, which penetrates a karst cavern, has geochemistry that varies cyclically; at times SC and concentrations of major ions are strongly and negatively correlated with water level in the aquifer, but the relation is not linear over the long term. At well D2, SC and major ion concentrations also are negatively correlated with water level in the aquifer, but that correlation is strongest with water level on the day that the sample is collected. In contrast, at well D1, SC and major ion concentrations are positively correlated with water level in the aquifer, but the cause of the phenomenon remains to be explained.

\section{Summary}

This report by the U.S. Geological Survey, in cooperation with the San Antonio Water System, describes the results of a statistical analysis of major ion and trace element geochemistry of water at seven wells transecting the freshwater/salinewater interface (the 1,000-mg/L dissolved solids concentration threshold) of the Edwards aquifer in San Antonio, Texas, either over time or in response to variations in hydrologic conditions. The data used in this report were collected during 1986-2006. The seven monitoring wells are screened at different depths in the aquifer at three sites that form a generally north-to-south transect. The three wells of the southern site and the deeper of the two middle-site wells are open to the transition zone, which commonly is defined as the zone in which dissolved solids concentration varies between 1,000 and 10,000 milligrams per liter, thus the transition zone contains saline water. The shallower well of the middle site and the two wells of the northern site are open to the freshwater zone. Freshwater overlies saline water along the transect. In some sections of the aquifer the overlying freshwater is separated 
from the underlying saline water by the regional dense member (RDM), the lowermost member of the Person Formation. At each site, the deepest well is screened below the RDM, and the other wells, with one exception, are screened above the RDM; one well is completed in the RDM.

Parametric and nonparametric statistical methods were used to analyze the resulting geochemical data. Standard statistical methods were used to compute descriptive statistics. Principal components analysis (PCA) was used to gain more insight into the relations between the major ions in water at each of the seven wells. Temporal trends were evaluated by linear regression or by the Kendall's tau test. Relations between the aqueous geochemistry at each well and the two hydrologic indicators were investigated using simple correlation (Pearson's r) and a multilag model.

Mean specific conductance (SC) values were greater at transition-zone wells than at freshwater-zone wells, but SC did not vary systematically with depth. Concentrations of all major ions except bicarbonate were greater at transition-zone wells than at freshwater-zone wells, but concentrations tended to be more variable at freshwater-zone wells. Mean molar ratios of magnesium:calcium, sulfate:chloride, and sodium:chloride were similar at transition-zone wells and freshwater-zone wells; magnesium:sodium was elevated at freshwater-zone wells relative to transition-zone wells.

Concentrations of trace elements at the seven monitoring wells for many water samples were below the laboratory reporting level. Detections of trace elements were more frequent at transition-zone wells, and mean concentrations of cadmium, chromium, copper, lead, and silver were elevated at transition-zone wells relative to freshwater-zone wells. Mean concentrations of barium at freshwater-zone wells were elevated relative to transition-zone wells, and concentrations of iron at two freshwater-zone wells were 10 to 40 times higher than those at the other five wells.

All strong correlations between SC and major ions were positive, and in general there were more and stronger correlations between SC and major ions in the water from the freshwater-zone wells than from the transition-zone wells. Except for the shallowest transition-zone well, the transitionzone wells had relatively few strong correlations overall. The lack of a strong correlation indicates that the variability in the major ion concentrations at these wells might be a result of analytical variability caused by the multiple analytical methods used.

In most cases, strong correlations between concentrations of trace elements were positive, and transition-zone wells and freshwater-zone wells had water with a similar number of significant correlations. In water from the transition-zone wells, there were four consistent correlations: arsenic and copper, cadmium and lead, arsenic and selenium, and copper and selenium. In the water from the three freshwater-zone wells, concentrations of chromium and selenium were strongly correlated. Concentrations of all trace elements were correlated with concentrations of one or more other trace element except zinc. There were about twice as many correla- tions that were positive and strong between major ions and trace elements as there were correlations that were negative and strong.

PCA indicates that variations in geochemical concentrations covary at the three freshwater-zone wells and at the shallowest transition-zone well. This covariance likely results from dilution of ground water by low-ionic-strength meteoric water. At the two deeper transition-zone wells at the southern site, PCA was not effective at reducing the number of variables needed to explain the variance in the geochemical data. This indicates that there is no systematic variation in major ion concentrations, such as might be attributable to dilution, mixing of two or more geochemically distinct waters, or geochemical reactions that would alter major ion proportions. The PCA for the deeper, transition-zone well at the middle site (C2) indicated geochemical variability intermediate between that of the freshwater-zone wells and shallowest transitionzone well (A2) and that of the two deeper transition-zone wells.

Trends were tested for SC, major ion concentrations, and molar ratios of major ions for the first part of the sampling period, for the second part of the sampling period, and for the entire sampling period, and results indicate marked differences between wells in strength and direction of trends. At three transition-zone wells, there was a general trend toward less salinity over the 21-year period of sampling, as indicated by comparison between the first and second parts of the sampling period. At the three transition-zone wells at the southern site, SC trends either changed from no trend to a weak or strong downward trend or were strong and downward for both parts of the sampling period; at the transition-zone (deeper) well at the middle site, the SC trend changed from strongly upward to no trend. Trends in SC at the freshwater-zone wells were less consistent. At the freshwater-zone (shallower) well at the middle site, the trend changed from fluctuating strongly upward and downward to less fluctuation, but there was an overall increase in salinity during the entire sampling period. The freshwater-zone well that is screened below the RDM had an overall downward trend for SC, and the freshwater-zone well that is screened above the RDM, had an overall upward trend for SC. There is no systematic change in the direction of trend in SC by water type (fresh or saline), between sites, or with depth.

In general, trends in major ion concentrations corresponded to those in SC. The major ions with the greatest number of temporal trends were calcium, chloride, sodium, and sulfate. At any well, the direction of the trend was consistent for SC, chloride, potassium, sodium, and sulfate, but trends for bicarbonate, calcium, fluoride, magnesium, and silica sometimes were opposite of those of the other major ions. This might indicate a common source for chloride, potassium, sodium, and sulfate, likely the saline zone. In contrast, the source of bicarbonate and calcium (and magnesium, to a lesser extent) is dissolution of calcium carbonate, and the concentrations are controlled by calcite equilibrium and dissolution kinetics. 
There were fewer temporal trends in major ion molar ratios than in the concentrations of the major ions themselves, and there were fewer strong trends. The small number of strong trends indicates that the geochemical composition of the water at the wells varies less than the major ion concentrations, consistent with the hypothesis that dilution is the dominant process affecting the geochemistry.

Trends in concentrations of trace elements, samples for which were collected annually, were tested for the entire sampling period. In all cases, either there was no trend or the trend was downward. Iron was the trace element with the most downward trends; concentrations decreased over time in three of the four transition-zone wells and in the deeper of the two freshwater-zone wells.

Relations between geochemical variables (SC, major ions, and major ion molar ratios) and hydrologic indicators (concurrent or prior time-averaged measures of water level and effective rainfall $\left[\mathrm{P}_{\text {eff }}\right]$ ) were investigated first with linear correlation and then with a multilag correlation model. Correlations between geochemical variables and measures of water level in the freshwater-zone wells were much more frequent than correlations between geochemical variables and measures of water level in the transition-zone wells. There were correlations between SC and all measures of water level at the two freshwater-zone wells tested with linear correlation (northern site wells), but there were no correlations between SC and any measures of water level at any transition-zone wells. There were few correlations between major ions and water level at the transition-zone wells, and they were relatively weak. There were multiple correlations between major ions and water level at the freshwater-zone wells at the northern site. Except at two freshwater wells (one middle site and one northern site), major ion molar ratios were only weakly correlated with water level.

$\mathrm{SC}$ was correlated with $\mathrm{P}_{\text {eff }}$ at all freshwater-zone wells and at one transition-zone well. All SC correlations with $\mathrm{P}_{\text {eff }}$ were negative except for that at one freshwater-zone well. Correlations were not as strong as they were between geochemical variables and water level. There were more correlations between a major ion concentration and $\mathrm{P}_{\text {eff }}$ at the freshwaterzone wells than at the transition-zone wells. There was a more consistent relation between at least one of the major ion ratios and $\mathrm{P}_{\text {eff }}$ at the wells than there was between major ion ratios and water level.

A multilag correlation model was used to determine if there were some relations that the simple correlation was missing because of a lag in response time between the hydrologic indicator and the geochemical response. The results of the multilag correlation model indicate that in some cases the strongest correlation between a geochemical variable and water level was for a lag time of 1 or more months. However, in many cases the strongest correlation was for a lag of 0 , indicating that the geochemistry responds relatively rapidly to changes in regional water level.

The statistical analyses taken together indicate that the geochemistry at the freshwater-zone wells is more variable than that at the transition-zone wells. The geochemical variability at the freshwater-zone wells might result from dilution of ground water by meteoric water. This is indicated by relatively constant major ion molar ratios, a preponderance of positive correlations between SC, major ions, and trace elements, and a PCA in which the major ions are strongly loaded on the first principal component. Much of the variability in three of the four transition-zone wells might result from the use of different laboratory analytical methods or reporting procedures during the period of sampling. This is reflected in a lack of correlation between SC and major ion concentrations in the transition-zone wells and a PCA in which the variability is fairly evenly distributed across several principal components. The statistical analyses further indicate that, although the transition-zone wells are less well connected to surficial hydrologic conditions than the freshwater-zone wells, there is some connection but the response time is longer. The freshwater-zone wells are closely connected to surficial hydrologic conditions, but the three of them have very different responses.

\section{References Cited}

Ashworth, J.B., and Hopkins, Janie, 1995, Aquifers of Texas: Texas Water Development Board Report 345, 69 p.

Davis, J.C., 1986, Statistics and data analysis in geology (2d ed.): New York, Wiley, 646 p.

Garner, B.D., and Mahler, B.J., 2006, Relation of specific conductance in ground water to intersection of flow paths by wells, and associated major ion and nitrate geochemistry, Barton Springs segment of the Edwards aquifer, Austin, Texas, 1978-2003: U.S. Geological Survey Scientific Investigations Report 2007-5002, 39 p.

Groschen, G.E., 1994, Analysis of data from test-well sites along the downdip limit of freshwater in the Edwards aquifer, San Antonio, Texas, 1985-87: U.S. Geological Survey Water-Resources Investigations Report 93-4100, 92 p.

Haan, C.T., 1977, Statistical methods in hydrology: Ames, Iowa, Iowa State University Press, 378 p.

Harden, R.W., 1968, Review of water quality changes in Edwards reservoir-Especially near the bad water line: Austin, R.W. Harden and Associates, Inc., 23 p. [file memorandum]

Helsel, D.R. and Hirsch, R.M., 2002, Statistical methods in water resources: U.S. Geological Survey Techniques of Water-Resources Investigations, book 4, chap. A3, accessed May 19, 2008, at http://water.usgs.gov/pubs/twri/twri4a3/.

Laaksoharju, M., Skarman, C., and Skarman, E., 1999, Multivariate mixing and mass balance (M3) calculations, a new tool for decoding hydrogeochemical information: Applied Geochemistry, v. 14 , no. 7 , p. $861-871$. 
Lindgren, R.J., 2006, Diffuse-flow conceptualization and simulation of the Edwards aquifer, San Antonio region, Texas: U.S. Geological Survey Scientific Investigations Report 2006-5319, 48 p.

Lindgren, R.J., Dutton, A.R., Hovorka, S.D., Worthington, S.R.H., and Painter, Scott, 2004, Conceptualization and simulation of the Edwards aquifer, San Antonio region, Texas: U.S. Geological Survey Scientific Investigations Report 2004-5277, 143 p., 7 pl.

Maclay, R.W., 1995, Geology and hydrology of the Edwards aquifer in the San Antonio area, Texas: U.S. Geological Survey Water-Resources Investigations Report 95-4186, $64 \mathrm{p}$.

Maclay, R.W., and Land, L.F., 1988, Simulation of flow in the Edwards aquifer, San Antonio region, Texas, and refinement of storage and flow concepts: U.S. Geological Survey Water-Supply Paper 2336-A, 48 p.

Mahler, B.J., Garner, B.D., Musgrove, M., Guilfoyle, A., and Rao, M.V., 2006, Recent (2003-05) water quality of Barton Springs, Austin, Texas, with emphasis on factors affecting variability: U.S. Geological Survey Scientific Investigations Report 2006-5299, 83 p.

Miller, L.D., and Long, A.J., 2006, Statistical analyses of hydrologic system components and simulation of Edwards aquifer water-level response to rainfall using transferfunction models, San Antonio region, Texas: U.S. Geological Survey Scientific Investigations Report 2006-5131, 20 p.
Schultz, A.L., 1992, Using geophysical logs in the Edwards aquifer to estimate water quality along the freshwater/ saline-water interface (Uvalde to San Antonio, Texas): San Antonio, Edwards Underground Water District Report 92-03, 47 p.

Schultz, A.L., 1994, Review and update of the position of the Edwards aquifer freshwater/saline-water interface from Uvalde to Kyle, Texas: San Antonio, Edwards Underground Water District Report 94-05, 31 p.

Singh, T., and Kalra, Y.P., 1975, Specific conductance method for in situ estimation of total dissolved solids: Journal of the American Water Works Association, v. 67, no. 2, p. 99-100.

U.S. Geological Survey, 2007, National Water Information System (NWISWeb) data available on the World Wide Web, accessed September 2007-December 2007 at http://waterdata.usgs.gov/nwis/.

U.S. Geological Survey, 2008, National Water Information System (NWISWeb) NWIS water quality method codes, accessed November 28, 2008, at http://waterdata.usgs.gov/ nwis/help/?read_file $=q w \_m e t h \&$ format $=$ table

William F. Guyton Associates, Inc., 1986, Drilling, construction, and testing of monitor wells for the Edwards aquifer bad water line experiment: William F. Guyton Associates, Inc., $56 \mathrm{p}$.

Publishing support provided by

Lafayette Publishing Service Center

Information regarding water resources in Texas is available at

http://tx.usgs.gov/ 